LBNL-51448

\title{
Characterizing the Fabric of the Urban Environment: A Case Study of Greater Houston, Texas ${ }^{*}$
}

\author{
Leanna Shea Rose, Hashem Akbari, and Haider Taha \\ Heat Island Group \\ Environmental Energy Technologies Division \\ Lawrence Berkeley National Laboratory \\ University of California
}

Berkeley, California 94720

January 2003

\footnotetext{
* This work was supported by the U. S. Environmental Protection Agency under the Urban Heat Island Pilot Project (UHIPP) through the U. S. Department of Energy under contract DE-AC03$76 \mathrm{SF} 00098$.
} 


\section{DISCLAIMER}

This document was prepared as an account of work sponsored by the United States Government. While this document is believed to contain correct information, neither the United States Government nor any agency thereof, nor the Regents of the University of California, nor any of their employees, makes any warranty, express or implied, or assumes any legal responsibility for the accuracy, completeness, or usefulness of any information, apparatus, product, or process disclosed, or represents that its use would not infringe privately owned rights. Reference herein to any specific commercial product, process, or service by its trade name, trademark, manufacturer, or otherwise, does not necessarily constitute or imply its endorsement, recommendation, or favoring by the United States Government or any agency thereof, or The Regents of the University of California. The views and opinions of authors expressed herein do not necessarily state or reflect those of the United States Government or any agency thereof or The Regents of the University of California. 


\title{
Characterizing the Fabric of the Urban Environment: A Case Study of Houston, Texas*
}

\author{
Leanna Shea Rose, Hashem Akbari and Haider Taha \\ Heat Island Group \\ Lawrence Berkeley National Laboratory \\ Berkeley, California 94720
}

\begin{abstract}
In this report, the materials and various surface types that comprise a city are referred to as the "urban fabric". Urban fabric data are needed in order to estimate the impact of light-colored surfaces (roofs and pavements) and urban vegetation (trees, grass, shrubs) on the meteorology and air quality of a city, and to design effective urban-environmental implementation programs. We discuss the results of a semi-automatic Monte-Carlo statistical approach used to develop data on surface-type distribution and city-fabric makeup (percentage of various surface-types) using aerial color orthophotography. The digital aerial photographs for Houston covered a total of about $52 \mathrm{~km}^{2}(20$ $\mathrm{mi}^{2}$ ). At $0.30-\mathrm{m}$ resolution, there were approximately $5.8 \times 10^{8}$ pixels of data.

Four major land-use types were examined: (1) commercial, (2) industrial, (3) educational, and (4) residential. On average, for the regions studied, vegetation covers about $39 \%$ of the area, roofs cover about $21 \%$, and paved surfaces cover about $29 \%$. For the most part, trees shade streets, parking lots, grass, and sidewalks. At ground level, i.e., view from below the vegetation canopies, paved surfaces cover about $32 \%$ of the study area.

GLOBEIS model data from University of Texas and land-use/land-cover (LULC) information from the United States Geological Survey (USGS) were used to extrapolate these results from neighborhood scales to Greater Houston. It was found that in an area of roughly $3,430 \mathrm{~km}^{2}$, defining most of Greater Houston, over $56 \%$ is residential. The total roof area is about $740 \mathrm{~km}^{2}$, and the total paved surface area (roads, parking areas, sidewalks) covers about $1000 \mathrm{~km}^{2}$. Vegetation covers about $1,320 \mathrm{~km}^{2}$.
\end{abstract}

${ }^{*}$ This work was supported by the U. S. Environmental Protection Agency through the U. S. Department of Energy under contract DE-AC03-76SF00098. 



\section{Acknowledgements}

This work was supported by the U. S. Environmental Protection Agency under the Urban Heat Island Pilot Project (UHIPP) through the U. S. Department of Energy under contract DE-AC03-76SF00098.

We acknowledge the support and guidance from Eva Wong, Edgar Mercado and Jeanne Briskin of the EPA. 



\section{Executive Summary}

The Heat Island Reduction Initiative (HIRI) is a joint program sponsored by the U. S. Environmental Protection Agency (EPA) and the Department of Energy (DOE) to encourage the use of strategies designed to reduce demand for cooling energy and slow smog formation. As part of the initiative, the Urban Heat Island Pilot Project (UHIPP) was launched to quantify the potential energy savings, economic benefits, and air-quality improvements of heat-island reduction strategies. EPA selected five metropolitan areas (Sacramento, CA; Salt Lake City, UT; Chicago, IL; Houston, TX; and Baton Rouge, LA) for the UHIPP study. Since the inception of the project, LBNL has conducted detailed studies to investigate the effects of mitigation technologies on heating- and cooling-energy use in these pilot cities. In addition, LBNL has collected urban surface characteristics data and conducted meteorological and air quality simulations for the pilot cities.

One of the components of UHIPP research activities is the analysis of the fabric of the pilot cities by accurately characterizing various surface components. This is important because the fabric of a city is directly relevant to the design and implementation of realistic heat-island reduction strategies. Of particular importance is the characterization of the area fractions of vegetative cover and various surface-types. Accurate characterization of the urban fabric would allow the design of implementation programs with a better assessment of the costs and benefits of program components. In addition, the results of such a detailed analysis will be used in simulating the effects of heat-island reduction strategies on local meteorology and air quality.

This report discusses a method for developing high-quality data on surface-type distribution and city-fabric makeup (percentage of various surface-types) using aerial color orthophotography. This method was previously applied to Sacramento, Salt Lake City, and Chicago. Here the method is applied to analyze the fabric of Houston.

The imagery of Houston obtained for this analysis covered a total of about $52 \mathrm{~km}^{2}\left(20 \mathrm{mi}^{2}\right)$. Picture EX.1 depicts a sample orthophoto of downtown Houston. At 0.3-m resolution, there were a total of approximately $5.8 \times 10^{8}$ pixels of data. We devised a semi-automatic method to sample the data and visually identify the surface-type for each pixel. The method involves four steps:

- visually inspecting aerial orthophotos and preparing a list of various surface types that are identifiable in the photos;

- grouping of surface types (categories) into major types;

- randomly sampling a subset of data for each region via a Monte-Carlo sampling approach, and visually inspecting each sample and assigning a surface classification to it (these surface classifications are summarized in Table EX.1); and

- extrapolating the results to Greater Houston, using the United States Geological Survey (USGS) land-use/land-cover (LULC) data as a basis for extrapolation.

The classification scheme in Table EX.1 may include more detail than is necessary (but on the other hand, more details can be seen in the photos, for example mailboxes, small benches, etc., that are, of course, irrelevant to this task). A distinction was made between Category 1, "Unidentified," and Category 30, "Other Feature." Those surfaces classified as "Unidentified" could not be accurately defined, while those in the "Other Feature" category could be, but were not relevant to this study. This distinction was necessary to avoid incorrectly assigning these known features. 
Table EX.1. Visually identifiable features of interest in the Houston region (based on aerial orthophotos).

\begin{tabular}{|ll||ll|}
\hline Category & Description & Category & Description \\
\hline 1 & Unidentified & 16 & Swimming Pool \\
2 & Tree Covering Roof & 17 & Auto Covering Road \\
3 & Tree Covering Road & 18 & Private Paved Surfaces \\
4 & Tree Covering Sidewalk & 19 & Parking Deck \\
5 & Tree Covering Parking & 20 & Alley \\
6 & Tree Covering Grass & 21 & Water \\
7 & Tree Covering Dry/Barren Land & 22 & Grass on Roof \\
8 & Tree Covering Other & 23 & Train Tracks \\
9 & Tree Covering Alley & 24 & Auto Covering Parking \\
10 & Roof & 25 & Recreational Surface \\
11 & Road & 26 & Residential Driveway \\
12 & Sidewalk & 27 & Awning \\
13 & Parking Area & 28 & N/A \\
14 & Grass & 29 & N/A \\
15 & Dry/Barren Land & 30 & Other Feature (not of interest) \\
\hline
\end{tabular}

The various tree categories (Categories 2-9) were later grouped under one category (designated only as "Trees"). For meteorological modeling purposes, one tree category is usually sufficient to determine the fraction of vegetation in the urban area. However, for planning and implementation purposes, one would like to "see" what lies beneath the canopy of trees. Thus in this case the areas beneath the trees are simply totaled and the tree canopy ignored, assuming that tree trunk area is negligible. As shown in Table EX.2, categories of related and similar surface-types were grouped in representative types for an "above-the-canopy" perspective. The grouping was done in order to aggregate similar surfaces that may also have similar albedos. For instance, the "Sidewalk" surfacetype is the total of the "Residential Driveway" and "Sidewalk" categories since in the areas analyzed, these categories both appeared to be similar, i.e., light-colored concrete. "Parking Area" is the total of parking lots and decks, "Grass" is the total of ground-level grass and roof grass, and the category "Miscellaneous" is the total of sporadic surface-types such as swimming pools, small water bodies, alleys, autos, privately-owned surfaces, and railroad tracks. For characterization of the surfaces "under the canopy," the primary criterion for grouping was the function or use of the surface-type. For instance, the under-the-canopy "Roof" category includes "Tree Covering Roof" (Cat. 2), "Roof" (Cat. 10), "Parking Deck" (Cat. 19), "Grass on Roof" (Cat. 22), and "Awning" (Cat. 27). Table EX.2 also shows the assignment of various categories (identified in Table EX.1) to surface-types under the canopy. Under-the-canopy characterization also includes a new general category, "Private-ownership Paved Surfaces," to distinguish between public surfaces and those surfaces owned privately. The "Tree Cover" category was eliminated, since at the ground level there is no tree canopy.

\footnotetext{
* When sunlight hits a surface, some of the incident solar radiation is reflected (this fraction is called albedo $=\hat{a}$ ) and the rest is either absorbed or transmitted. Low-â surfaces of course become much hotter than high-â surfaces.
} 
Table EX.2. Major surface-types.

\begin{tabular}{|c|c|c|c|}
\hline Surface-Type & Categories included* & Surface-Type & Categories included \\
\hline \multicolumn{4}{|c|}{ Above-the-canopy view } \\
\hline Roof & 10,27 & Tree Cover & $2-9$ \\
\hline Road & 11 & Grass & 6,14 \\
\hline Parking Area & 13,19 & Barren Land & 15 \\
\hline Sidewalk \& Driveway & 12,26 & Miscellaneous & $16-18,20,21,23-25,30$ \\
\hline \multicolumn{4}{|c|}{ Under-the-canopy view } \\
\hline Roof & $2,10,19,22,27$ & $\begin{array}{l}\text { Privately-owned } \\
\text { Paved Surfaces }\end{array}$ & 18,26 \\
\hline Road & $3,9,11,17,20$ & Grass & 6,14 \\
\hline Parking Area & $5,13,24$ & Barren Land & 7,15 \\
\hline Sidewalk & 4,12 & Miscellaneous & $8,16,21,23,25,30$ \\
\hline
\end{tabular}

* Surface-type categories are defined in Table EX.1.

Results from this analysis suggest several possible ways to classify land use and surface types in the Greater Houston area. In this study, the major land-use types examined were commercial, industrial, transportation/communication, and residential. Sixteen different areas within the Houston region were selected for this analysis. For each of these areas, up to 28 different surface-types were identified and their fractional areas computed. The results are shown in Figure EX.1 (above-thecanopy view of the city) and Figure EX.2 (under the tree canopy). In the heavily developed downtown Houston area, a top-down view (above the canopy) shows that vegetation (trees, grass, and shrubs) covers $5 \%$ of the area, whereas roofs cover $28 \%$ and paved surfaces (roads, parking areas, and sidewalks) cover $58 \%$ of the total area. The under-the-canopy fabric consists of $58 \%$ paved surfaces, $34 \%$ roofs, and $4 \%$ grass.

Above-the-canopy surface-type percentages in a university campus area were $41 \%$ vegetation, $12 \%$ roofs, and $39 \%$ paved surfaces. In commercial areas, vegetation covers an average of $18 \%$, roofs $29 \%$, and paved surfaces $45 \%$. In industrial areas, $32 \%, 15 \%$, and $25 \%$ are covered by vegetation, roofs, and paved surfaces, respectively. Residential areas exhibit a wide range of surfacetype distributions. On average, vegetation covers about $49 \%$ of the area (ranging from $23 \%$ to $69 \%$ ), roofs cover about $21 \%$ (ranging from $8 \%$ to $29 \%$ ), and paved surfaces cover about $25 \%$ (ranging from $14 \%$ to $41 \%$ ). This variability in many similar land-use categories demonstrates their sitespecific nature. Thus this suggests that it may be especially difficult to account for the variation between similar land-uses in different areas in most traditional land-use/land-cover classification systems.

The analysis suggests that in Houston, trees mostly shade the streets, parking lots, grass, and sidewalks. Under the canopy, the percentage of paved surfaces is higher than above the canopy (see Figure EX.2). On the average, paved surfaces cover $37 \%$ of non-residential areas, but only $28 \%$ of 
the residential areas. This smaller percentage is primarily due to smaller (generally two-lane) roads in residential areas and the absence of large parking lots.

In order to extrapolate these results from neighborhood to regional scales, e.g., Greater Houston, GLOBEIS model data from University of Texas and Environ Corp., and land-use/land-cover (LULC) data from the United States Geological Survey (USGS) were used as the basis for mapping the area distributions. In this method, the Houston LULCs were mapped onto those of the USGS and the total areas of various surface-types were calculated for the entire region of interest. For an area of roughly $3430 \mathrm{~km}^{2}$, including most of Greater Houston, about $65 \%$ is residential (see Figure EX.3a). The total roof area, as seen from above the canopy, comprises about $21 \%$ of the urban area (about $740 \mathrm{~km}^{2}$ ), total paved surfaces (roads, parking areas, sidewalks) $29 \%$ (about $1000 \mathrm{~km}^{2}$ ), and total vegetated area about 39\% (1320 $\mathrm{km}^{2}$ ) (see Figure EX.3b). The actual total roof and paved surface area, as seen from under the canopy, are about the same as above the canopy. But the total vegetated area (only grass and bushes) is about $37 \%\left(1270 \mathrm{~km}^{2}\right)$ (see Figure EX.3c).

Houston is a fairly green city, but the potential for urban reforestation remains large. If we assume that trees can potentially shade $20 \%$ of the roof area, $20 \%$ of roads, $50 \%$ of sidewalks, and $30 \%$ of parking areas, this would add up to about an additional $12 \%$ tree cover for the entire city. An additional tree cover of $12 \%$ is about $410 \mathrm{~km}^{2}$ of the urban area. Assuming that an average mature tree has a horizontal cross-section of about $50 \mathrm{~m}^{2}$, these calculations suggest a potential for adding 8 million trees in Houston. Planting 8 million additional trees can have a significant effect on cooling Houston and on ozone air quality.

The potential for increasing the albedo of urban Houston is also significant. Impermeable surfaces (roofs and pavements, as seen from above the canopy) amount to $50 \%$ of the total area of Houston. For illustration purposes, if we assume that the albedo of residential roofs can be increased by 0.1 , commercial roofs by 0.2 , roads and parking areas by 0.15 , and sidewalks by 0.1 , the albedo of the urban areas in Houston can then be increased by about 0.06 . Like urban vegetation, a higher urban albedo would reduce ambient temperatures and in turn can reduce ozone formation in the region.

In Houston there is a significant variation in the fabric of the neighborhoods selected for this analysis. Although an attempt was made to select neighborhoods that represent the city's varied landuse/land-cover, the results should not be extrapolated to other cities and regions. Many cities are unique in terms of land-use patterns and construction (e.g., most urban homes in the West Coast are single-story as opposed to two-story houses in the east). It is recommended that a similar analysis for several other cities in different regions of the country be performed in order to expand our understanding of their fabric. 


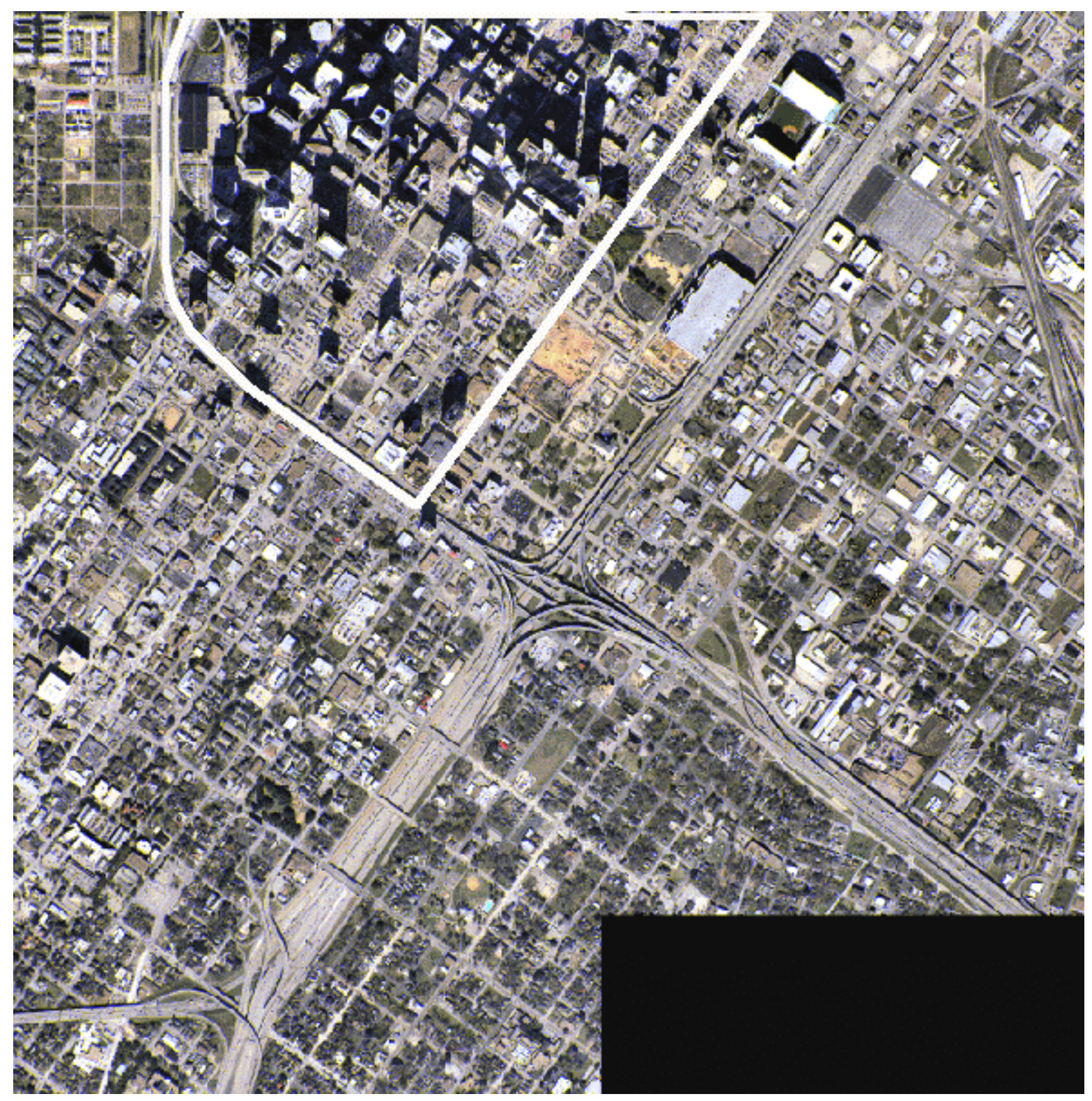

Picture EX.1. Aerial orthophoto of downtown Houston, TX. 


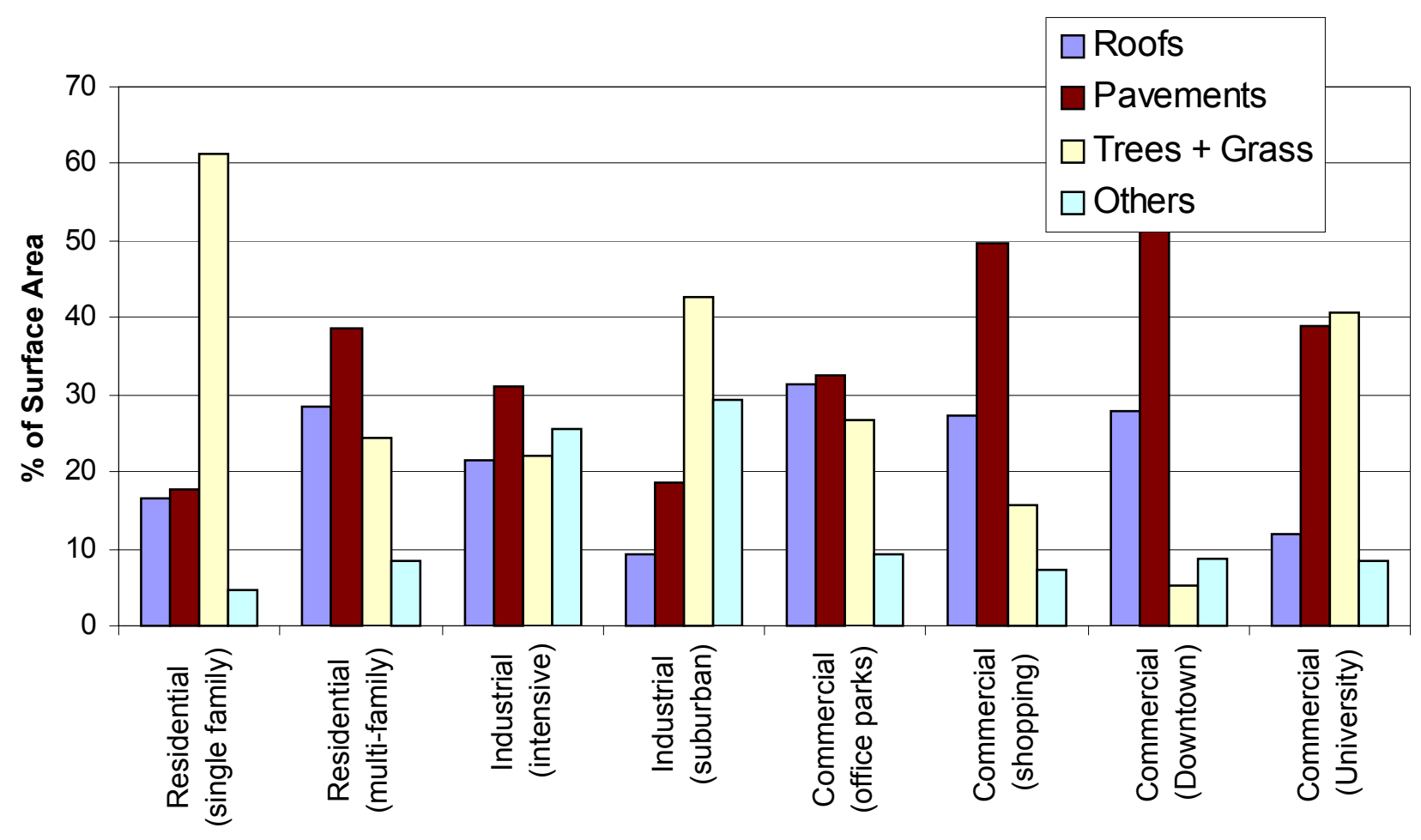

Figure EX.1. Above-the-canopy fabric of Greater Houston, TX; grouped by land-use type.

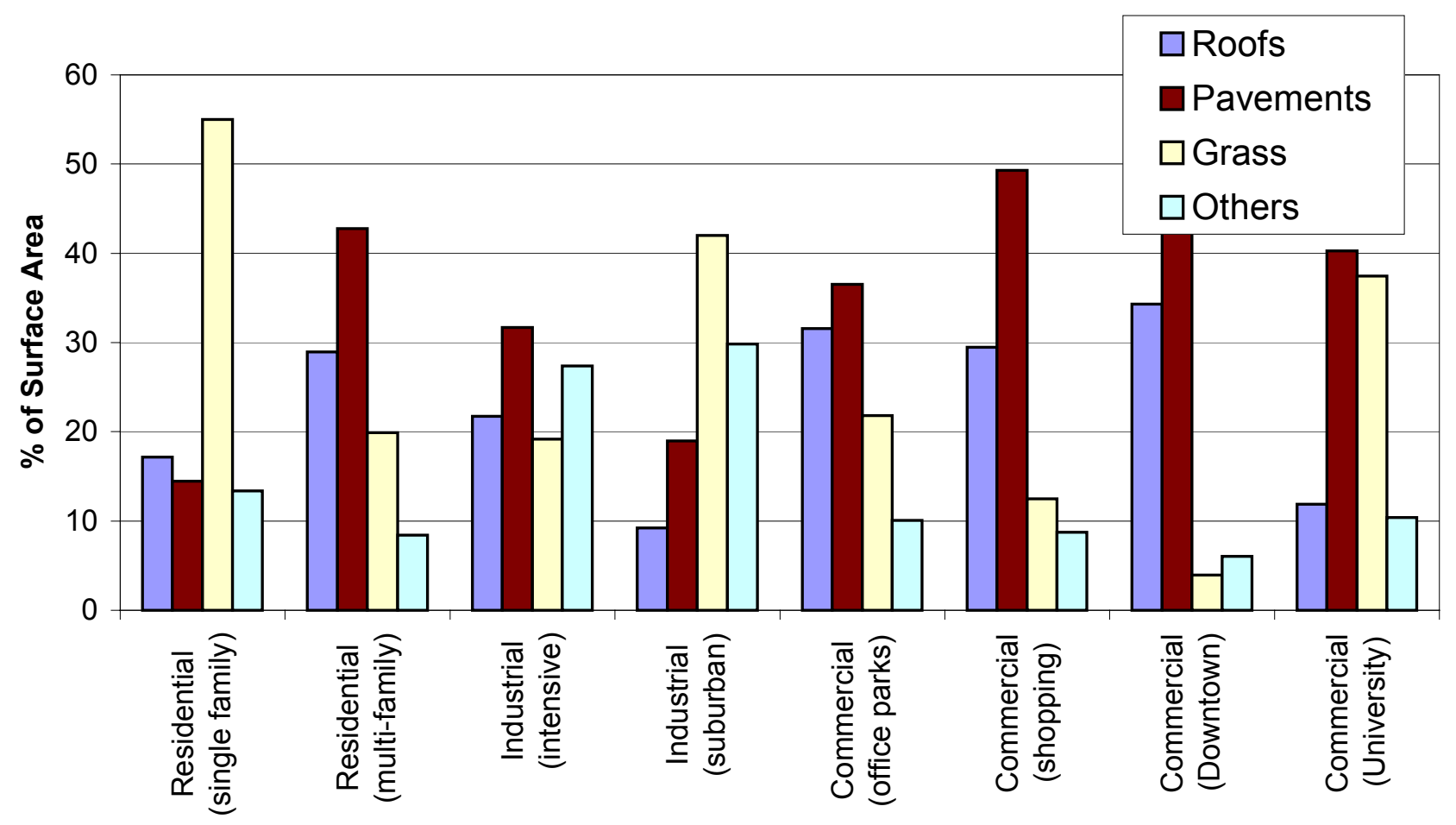

Figure EX.2. Under-the-canopy fabric of Greater Houston, TX; grouped by land-use type. 


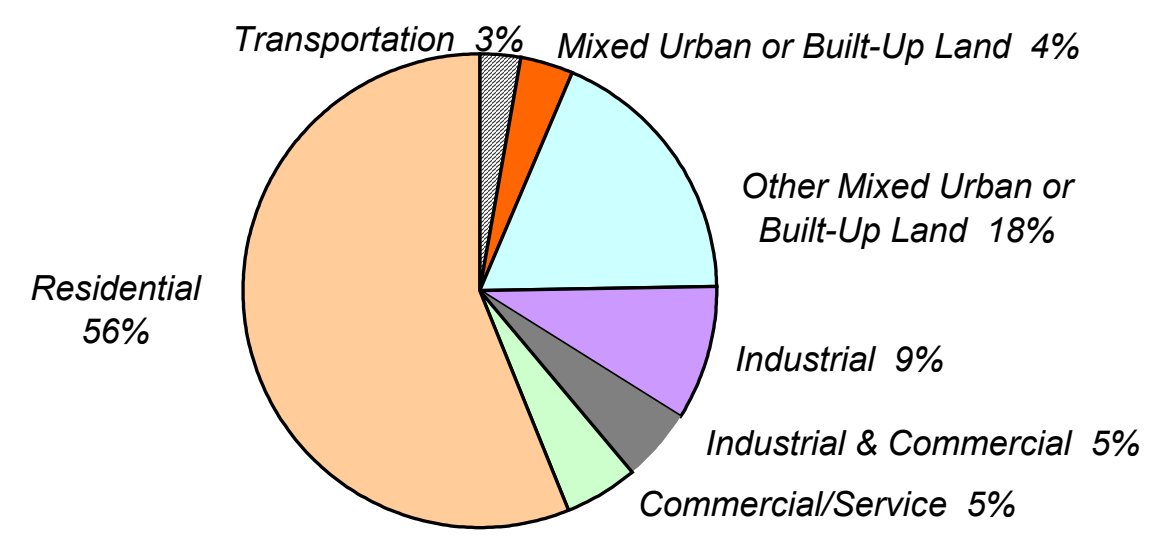

a) Area by USGS LULC Categories

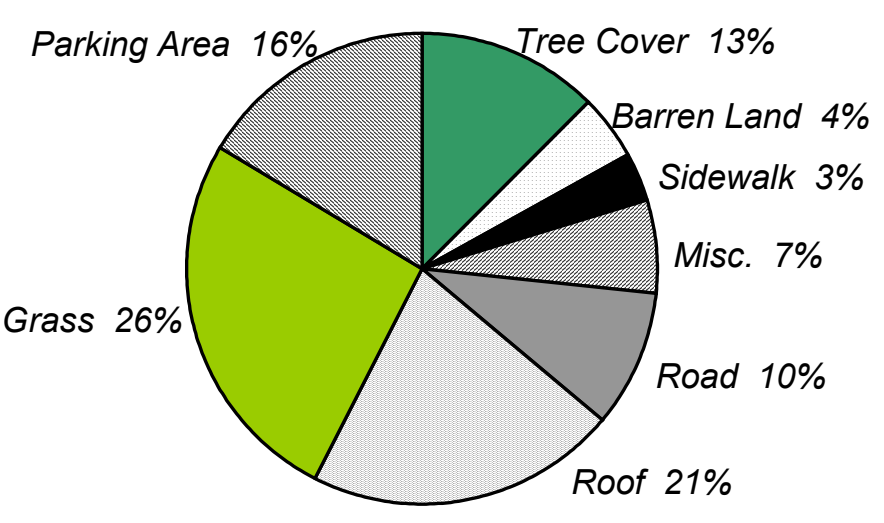

b) Area by Land-Cover Category Above the Canopy

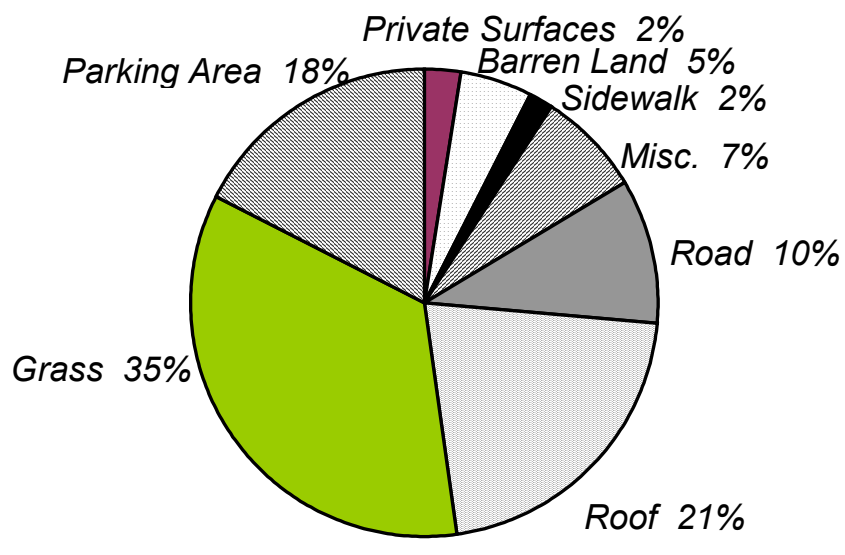

c) Area by Land-Cover Category Under the Canopy

Figure EX.3. Land-use/land-cover of the entire developed area of Greater Houston, TX. 



\section{Table of Contents}

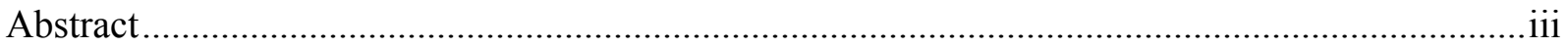

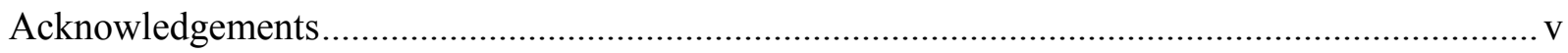

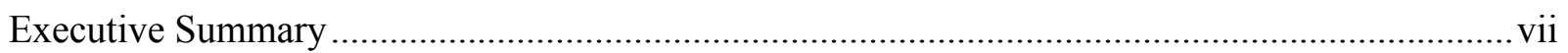

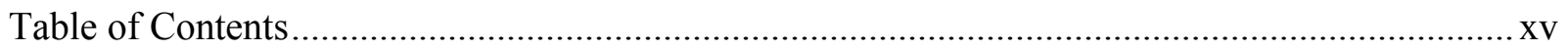

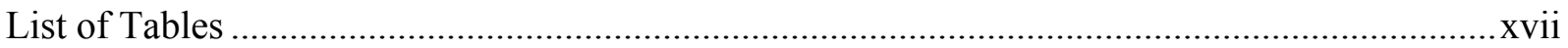

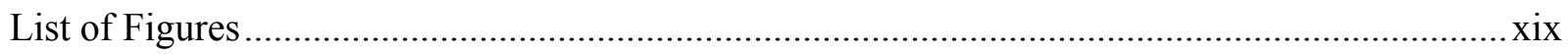

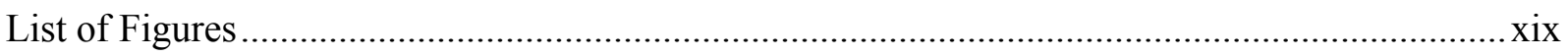

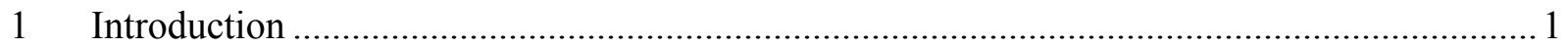

2 Custom Remotely-Sensed Data for Houston................................................................. 2

3 Method of Analysis for Custom Color Digital Orthophotos .............................................. 4

3.1 Identification of Surface-Types ...................................................................... 4

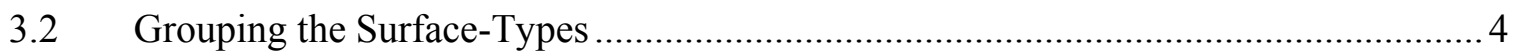

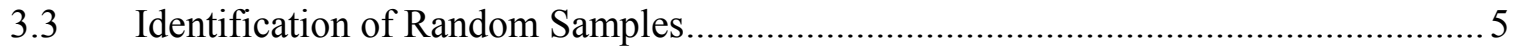

3.4 Extrapolation of Data for Climate Simulation ........................................................ 6

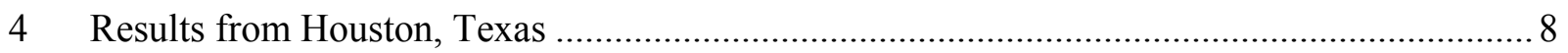

4.1 Educational Area: University of Houston .............................................................. 8

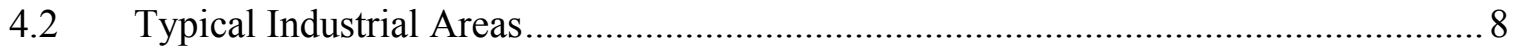

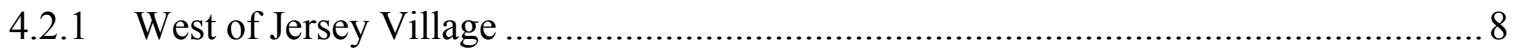

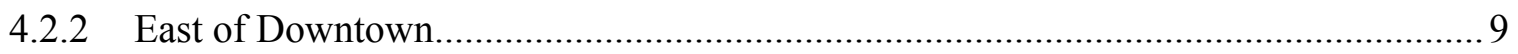

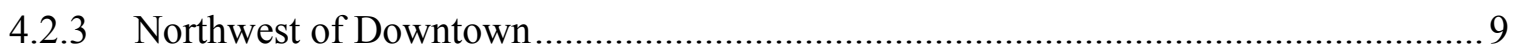

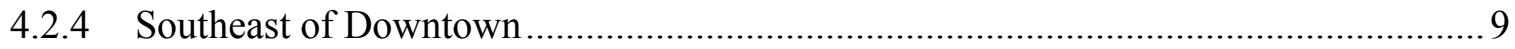

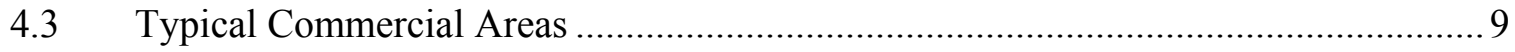

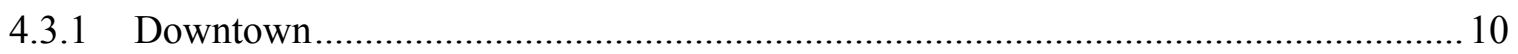

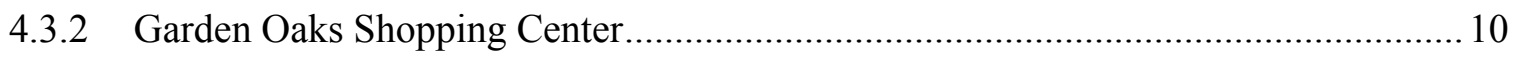

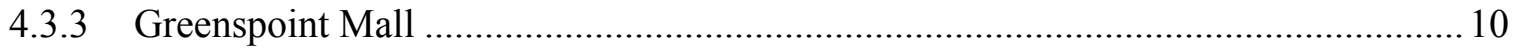

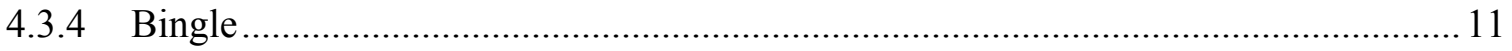

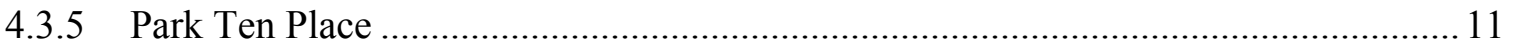

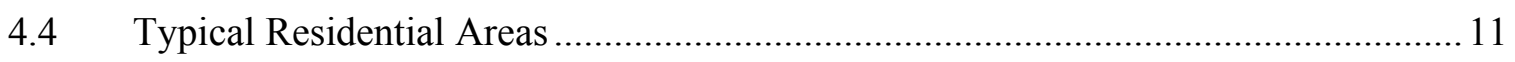

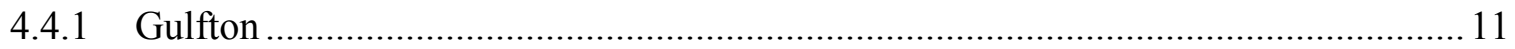

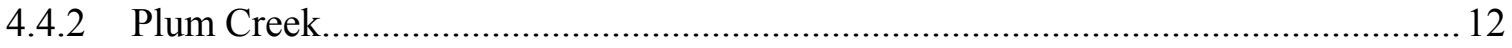

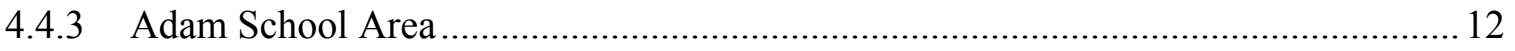

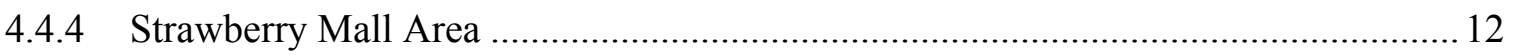

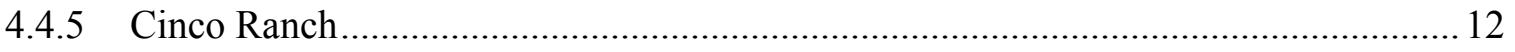

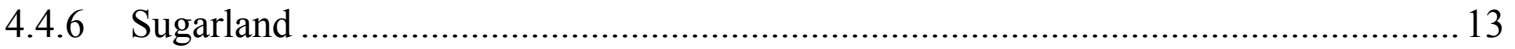




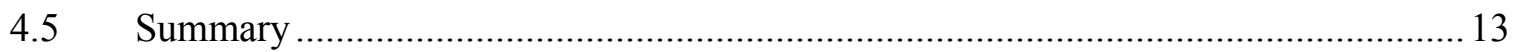

5 Extrapolation to Regional Scale .................................................................................... 16

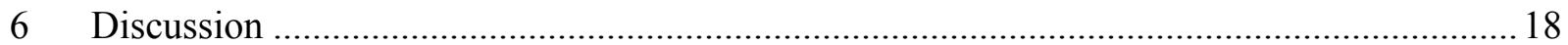

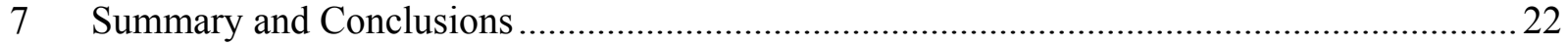

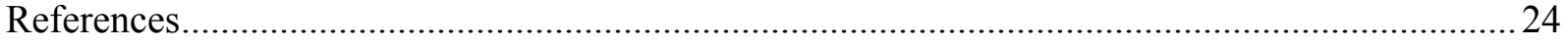




\section{List of Tables}

Table EX.1. Visually identifiable features of interest in the Houston region (based on aerial orthophotos) viii

Table EX.2. Major surface-types. ix

Table 1. USGS land use/land cover (LULC) percentages for three cities: Sacramento, CA; Salt Lake

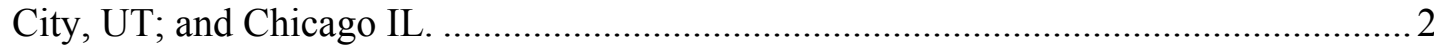

Table 2. Comparison of the fabric of Salt Lake City, Sacramento, and Chicago. ............................. 3

Table 3. Visually identifiable features of interest in the Houston region (based on aerial

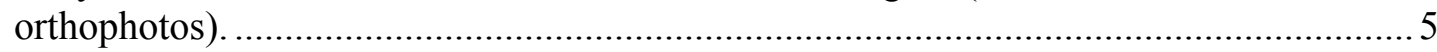

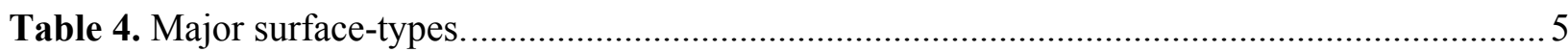

Table 5. The impact of sample size on estimates of area percentages of land-use categories for Downtown Houston. The entries show the "sample mean" in percentage of areas; the numbers in parenthesis are standard deviations of the means. Note that the above-thecanopy percentages show the "bird's-eye" view of the surfaces; under-the-canopy percentages are the actual land-use types.

Table 6. Above-the-canopy view of Greater Houston, TX. Entries are rounded to nearest $0.1 \%$. Numbers in parenthesis show the standard deviations of the last 100 samples.

Table 7. Under-the-canopy view of Greater Houston, TX. Entries are rounded to nearest $0.1 \%$. Numbers in parenthesis show the standard deviations of the last 100 samples.............. 15

Table 8. GLOBEIS LULC in the Houston-Galveston area............................................................ 16

Table 9. Recast of Houston-Galveston GLOBEIS LULC into USGS LULC classification............... 16

Table 10. USGS LULC description for urban area and related observed land-use categories (OLUC).19

Table 11. Calculated surface area percentages by USGS LULC categories.................................. 19

Table 12. Total surface areas $\left(\mathrm{km}^{2}\right)$ in Greater Houston (by Category)..........................................20

Table 13. USGS land use/land cover (LULC) percentages for three cities: Sacramento, CA, Salt Lake City, UT, Chicago, IL, and Houston, TX........................................................... 20

Table 14. Comparison of the fabric of Salt Lake City, UT, Sacramento, CA, Chicago, IL, and

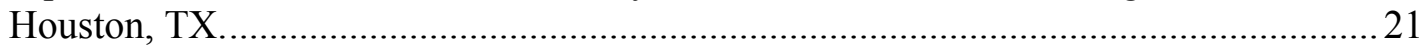

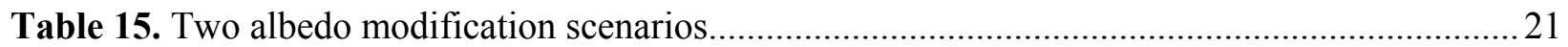

Table 16. Net change in the albedo of Houston for high- and low-albedo scenarios........................ 22 
xviii 


\section{List of Figures}

Picture EX.1 Aerial orthophoto of downtown Houston, TX........................................................

Figure EX.1 Above-the-canopy fabric of Greater Houston, TX; grouped by land-use type..............xii

Figure EX.2 Under-the-canopy fabric of Greater Houston, TX; grouped by land-use type...............xii

Figure EX.3. Land-use/land-cover of the entire developed area of Greater Houston, TX...............xiii

Figure 1. Geographical locations of the digital aerial orthophotos taken for analysis in the

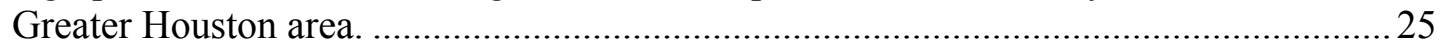

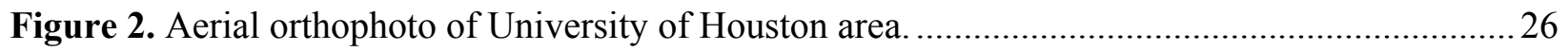

Figure 3. Aerial orthophoto of the West of Jersey Village area...................................................2 27

Figure 4. Aerial orthophoto of the East of Downtown Houston area. .............................................28

Figure 5. Aerial orthophoto of the Northwest of Downtown Houston area.....................................29

Figure 6. Aerial orthophoto of the Southeast of Downtown Houston area....................................... 30

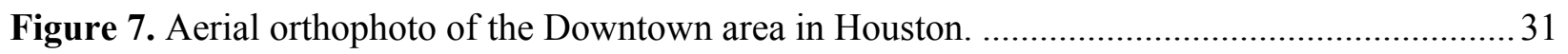

Figure 8. Aerial orthophoto of the Garden Oaks Shopping Center area......................................... 32

Figure 9. Aerial orthophoto of the Greenspoint Mall area.......................................................... 33

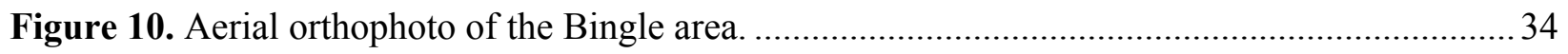

Figure 11. Aerial orthophoto of the Park Ten Place area............................................................... 35

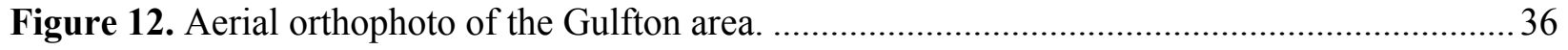

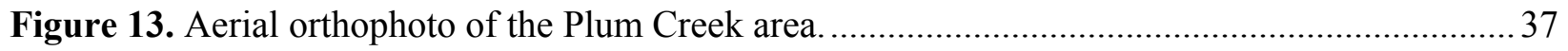

Figure 14. Aerial orthophoto of the Adam School area............................................................ 38

Figure 15. Aerial orthophoto of the Strawberry Mall area.............................................................. 39

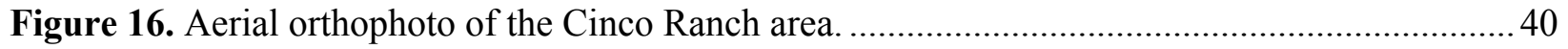

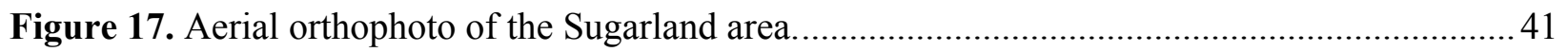

Figure 18. Above-the-canopy fabric of Greater Houston, TX.................................................. 42

Figure 19. Under-the-canopy fabric of Greater Houston, TX................................................. 42

Figure 20. Above-the-canopy fabric of Greater Houston, TX grouped by land-use type.................. 43

Figure 21. Under-the-canopy fabric of Greater Houston, TX, grouped by land-use type. ................43

Figure 22. Average characteristics of above-the-canopy fabric of Greater Houston, TX................ 44

Figure 23. Average characteristics of under-the-canopy fabric of Greater Houston, TX..................44

Figure 24. Land use/land cover of the entire developed area of Greater Houston, TX.................... 45 


\section{$1 \quad$ Introduction}

In a joint effort to curb the demand for cooling energy and to slow smog formation in U.S. cities, the U. S. Environmental Protection Agency (EPA) and the Department of Energy (DOE) formed the Heat Island Reduction Initiative (HIRI). Through this initiative the Urban Heat Island Pilot Project (UHIPP) was launched to quantify the potential energy savings, economic benefits, and air-quality improvements attainable by implementation of heat-island reduction strategies. Five metropolitan areas (Sacramento, CA; Salt Lake City, UT; Chicago, IL; Houston, TX; and Baton Rouge, LA) were selected by the EPA for detailed analysis. LBNL's role in the project has been to conduct detailed studies of the effects of mitigation technologies on heating- and cooling-energy use in the selected pilot cities and to collect urban surface characteristics data in accordance with requirements of meteorological and air-quality simulations for the pilot cities.

One of the components of UHIPP research activities is to analyze the fabric of the pilot cities by accurately characterizing various surface components. This is important because the fabric of a city is directly relevant to the design and implementation of realistic heat-island reduction strategies. Of particular importance is the characterization of the area fraction of various surface-types. These data are required to model and analyze the impact of heat-island mitigation measures in reducing energy consumption and improving air quality. Thus, it is important to characterize the surface as accurately as possible, particularly in terms of surface-type distribution and vegetative fraction. An accurate characterization of the surface will also allow a better estimate of the potential for increasing surface albedo (roofs, pavements) and urban vegetation. This would in turn provide more accurate modeling of the impact of heat-island reduction measures on ambient cooling and urban ozone air quality.

In three earlier studies, we characterized the fabric of Sacramento, Salt Lake City, and Chicago, using high-resolution aerial digital orthophotos covering selected areas in each city (Akbari et al., 1999 and Akbari and Rose, 2001a,b). Four major land-use types were examined: commercial, industrial, transportation, and residential. Although there were differences between the fabrics of these three metropolitan areas, some significant similarities were found. Table 1 shows the land use/land cover (LULC) for the three metropolitan areas based on USGS data. Of approximately $800 \mathrm{~km}^{2}$ of urban area in Sacramento about 49\% was residential; about $59 \%$ of the $620 \mathrm{~km}^{2}$ urban area in Salt Lake City was residential; and about $53 \%$ of $2,520 \mathrm{~km}^{2}$ urban area in Chicago was residential. The fraction of Industrial, Transportation, and Mixed Urban land-uses in these three cities varied only by a few percentages.

For the entire metropolitan area, the percentage of the total roof areas, as seen from above the canopy, in the Sacramento and Salt Lake City metropolitan areas was about $19 \%$ and in Chicago metropolitan area was about $25 \%$ (see Table 2). The percentage of paved areas ranged from $30 \%$ to $39 \%$, vegetated areas $29 \%$ to $41 \%$, and other areas $10 \%-40 \%$. Under the canopy, the roof area ranged from $20 \%$ to $25 \%$, paved surfaces $36 \%$ to $45 \%$, vegetated areas $20 \%$ to $30 \%$, and other areas $9 \%$ to $15 \%$.

In residential areas, the percentage of the total roof areas, as seen from above the canopy, ranged from $19 \%$ to $26 \%$, paved surfaces $25 \%-26 \%$, vegetated areas $39 \%-47 \%$, and others $4 \%-16 \%$. Under the canopy, roof area ranged from $20 \%$ to $27 \%$, paved surfaces $29 \%$ to $32 \%$, vegetated areas $33 \%$ to $39 \%$, and other areas $6 \%$ to $17 \%$.

\footnotetext{
* When sunlight hits a surface, some of the incident solar radiation is reflected (this fraction is called albedo $=\hat{a}$ ) and the rest is either absorbed or transmitted. Low-â surfaces of course become much hotter than high-â surfaces.
} 
Other researchers involved in the analysis of urban climate have tried to quantitatively characterize the surface-type composition of various urban areas. One such work was the analysis of the urban fabric in Sacramento by Myrup and Morgan (1972). They applied the strategy of examining the land-use data in progressively smaller segments of macro-scale (representative areas of Sacramento), meso-scale (individual communities), micro-scale (land-use ordinance zones), and basic-scale (city blocks). The data they used included USGS photos, parks and recreation plans, city engineering roadways, and detailed aerial photos. Their analysis covered $195 \mathrm{~km}^{2}\left(76 \mathrm{mi}^{2}\right)$ of urban areas. The percentages of the land-use areas were calculated as follows: residential $35.5 \%$, commercial $7.2 \%$, industrial $13.5 \%$, streets and freeways $17.0 \%$, institutional $3.2 \%$, and open space and recreational $23.6 \%$. They found the average residential area to be composed of about $22 \%$ streets, $23 \%$ roofs, $22 \%$ other impervious surfaces, and 33\% green areas. Overall, they found a composition of $14 \%$ streets, $22 \%$ roofs, $22 \%$ other impervious surfaces, $36 \%$ green areas, and $3 \%$ water surfaces. They defined "other impervious surfaces" to include highway shoulder strips, airport runways, and parking lots. Streets included curbs and sidewalks.

In this report, we apply the urban fabric analysis to Houston, Texas. We discuss our effort in data collection and analysis of digital aerial photography and present results of the analysis for several representative areas in Houston. Results from the analysis of representative areas are used to estimate the fabric of Greater Houston (for use in meteorological and air-quality modeling).

Table 1. USGS land use/land cover (LULC) percentages for three cities: Sacramento, CA; Salt Lake City, UT; and Chicago IL.

\begin{tabular}{|lccc|}
\hline & Sacramento & Salt Lake City & Chicago \\
\hline Total Metropolitan Area $\left(\mathbf{k m}^{\mathbf{2}}\right) \rightarrow$ & 809 & 624 & 2521 \\
LULC (\%) $\downarrow$ & & & \\
Residential & 49.3 & 59.1 & 53.5 \\
Commercial/Service & 17.1 & 15.0 & 19.2 \\
Industrial & 7.2 & 4.9 & 11.5 \\
Transportation/Communication & 11.4 & 9.8 & 7.7 \\
Industrial and Commercial & 0.3 & 0.0 & 0.1 \\
Mixed Urban or Built-up Land & 5.2 & 1.9 & 0.4 \\
Other Mixed Urban or Built-up Land & 9.5 & 9.4 & 7.6 \\
\hline
\end{tabular}

\section{Custom Remotely-Sensed Data for Houston}

In the studies for Sacramento, Salt Lake City, and Chicago, a variety of available data sources were considered for analyzing the fabric. Some of these data were obtained from NASA remote sensing platforms, others from satellite or high-altitude aircraft, and a third group from high-resolution cameras flown at low altitudes. A full discussion of the various data sources considered for this application can be found in Akbari et al. (1999) and Akbari and Rose, (2001a).

Of all approaches tested, high-resolution aerial orthophotography has the highest potential for accurately producing estimates of surface areas for various land-covers and land-uses in a region. To obtain this custom high-resolution data, a color digital camera is flown at low altitude aboard an aircraft equipped with a GPS (Global Positioning System) and a computer for acquiring and storing 
data from both the camera and the GPS. The data collected by the GPS along with topographical data are used in the process of orthorectification. This minimizes errors that are created by the terrain and angle between the camera and surface.

Table 2. Comparison of the fabric of Salt Lake City, Sacramento, and Chicago.

\begin{tabular}{|lcccr|}
\hline City & Vegetation & Roofs & Pavements & Other \\
\hline Above-the-canopy & & & & \\
Metropolitan Salt Lake City & 40.9 & 19.0 & 30.3 & 9.7 \\
Metropolitan Sacramento & 28.6 & 18.7 & 38.5 & 14.3 \\
Metropolitan Chicago & 30.5 & 24.8 & 33.7 & 11.0 \\
Residential Salt Lake City & 46.6 & 19.7 & 25.3 & 8.5 \\
Residential Sacramento & 39.2 & 19.4 & 25.6 & 15.8 \\
Residential Chicago & 44.3 & 25.9 & 25.7 & 4.1 \\
Under-the-canopy & & & & \\
Metropolitan Salt Lake City & 33.3 & 21.9 & 36.4 & 8.5 \\
Metropolitan Sacramento & 20.3 & 19.7 & 44.5 & 15.4 \\
Metropolitan Chicago & 26.7 & 24.8 & 37.1 & 11.4 \\
Residential Salt Lake City & 38.6 & 23.9 & 31.6 & 6.0 \\
Residential Sacramento & 32.8 & 19.8 & 30.6 & 16.8 \\
Residential Chicago & 35.8 & 26.9 & 29.2 & 8.1 \\
\hline
\end{tabular}

Using digital, remotely sensed data at a $0.3-\mathrm{m}$ pixel size, it is possible to visually identify the materials and surfaces that make up the fabric of an area. The three bands of data (red, green, and blue) are in the visible spectrum and therefore do not capture the entire solar and thermal radiative ranges. In theory, correlating results from the urban fabric analysis with their spectral signatures as derived from satellite data could provide a basis for extrapolation both within a city and even in other cities with similar urban compositions (land-cover types). This would entail the analysis of study areas with satellite imagery, such as Landsat, covering the exact same extent under similar conditions. Combining these data types affords the opportunity of extrapolations to larger areas, since the coverage area of satellite data is virtually unlimited, and thereby determining study areas based on the site-specific fabric composition rather than on artificial boundaries of existing land-use, landcover data sets. Also, satellite imagery would allow for the selection of site-specific land-use, landcover categories at a higher resolution then generally available, thus yielding a better land-use, landcover map that would be as current as the satellite imagery provided. Other benefits of using both orthophotos and satellite imagery are that a larger range of wavelengths can be analyzed and multitemporal studies can be conducted. Multi-temporal studies would be particularly useful in identifying trends in fabric composition and land use development.

The Houston data was acquired with a sensor onboard a specially modified aircraft. The greater part of the imagery was acquired on January 24, 2002 under sunny, cloud-free conditions between approximately 10 am and $4 \mathrm{pm} \mathrm{CST}$. Originally, the data collection was scheduled for September 2001, but because of restrictions imposed by Federal Aviation Administration (FAA) the data could not be acquired until January 2002. Because of a relatively higher sun angle, a September flight 
would have yielded better results, but the January data were still quite adequate. The total area of the imagery acquired during these flights was $52 \mathrm{~km}^{2}\left(20 \mathrm{mi}^{2}\right)$. Of that, an area about $23 \mathrm{~km}^{2}$ was selected for detailed analysis. All data had a resolution of $0.3-\mathrm{m}$.

\section{Method of Analysis for Custom Color Digital Orthophotos}

The digital data obtained for Greater Houston covered a total of about $52 \mathrm{~km}^{2}\left(20 \mathrm{mi}^{2}\right)$, and at $0.3-\mathrm{m}$ resolution, they included approximately $5.8 \times 10^{8}$ pixels. Because of the large volume of data, reviewing all of them visually and in detail is very difficult and time-consuming. Hence, a semiautomated method was deemed necessary to classify the data. The method involved four steps:

1) visually inspecting aerial orthophotos and preparing a list of various surface-types identifiable in the photos;

2) grouping surface types and categories into major components;

3) randomly sampling a subset of data for each region via a Monte-Carlo sampling approach, and visually inspecting each sample and assigning a surface classification to it; and

4) extrapolating the results to Greater Houston, using USGS LULC as a basis.

\subsection{Identification of Surface-Types}

Each aerial orthophoto is visually inspected using ERDAS/Imagine software (ERDAS 1997). The purpose of this visual exercise is to identify qualitatively all surface-types and land-covers that can be seen at the resolution of the data (in this case, $0.30 \mathrm{~m}$ ). For Greater Houston, the surface-types that are shown in Table 3 were visually identified and used in the analysis .

Although more details can be seen in the photos, the categories identified in Table 3 covered most surfaces of interest for this study. In general, the "Other Features" category was a very small fraction (less than 1\%) of the selected samples. Also, a distinction was made between category 1, "Unidentified," and category 30, "Other Feature": those surfaces classified as "Unidentified" could not be accurately identified, whereas those in the "Other Feature" category could. This distinction was necessary to avoid assigning the known features incorrectly.

\subsection{Grouping the Surface-Types}

The grouping of surface-types is done differently for the categories corresponding to "above-thecanopy" and "under-the-canopy" views. The primary criterion for grouping above-the-canopy categories is the requirements for meteorological modeling. Thus, surface-types consisting of similar materials were grouped together since they have similar physical characteristics. However, the underthe-canopy categories were grouped based on requirements for implementation of heat-island reduction measures. For example, while meteorological models would categorize a part of a parking area covered by a tree as having the albedo of the tree, in order to determine the total surface area of a parking area for planning purposes the area should be identified as a parking area. Therefore, the under-the-canopy categories show the actual and functional land-cover categories according to their composition. Hence, there is a difference in the definition of the categories for the above-the-canopy and under-the-canopy views within the same category type.

The above- and under-the-canopy groupings are summarized in Table 4. As mentioned above, characterization of the surfaces under the canopy was based on the function or use of the surfacetype. For implementation purposes, one would like to "see" what lies beneath the canopy of trees. Hence, in order to calculate areas of various surfaces under the canopy, the areas beneath the trees 
are assigned to surface-types that trees shade. In these calculations it is assumed that the total area occupied by tree trunks is negligible. Also, a "Private-ownership Paved Surfaces" category was added to distinguish between those surfaces owned privately and those owned publicly. Obviously, this grouping can be rearranged depending on specific needs.

Table 3. Visually identifiable features of interest in the Houston region (based on aerial orthophotos).

\begin{tabular}{|ll||ll|}
\hline Category & Description & Category & Description \\
\hline 1 & Unidentified & 16 & Swimming Pool \\
2 & Tree Covering Roof & 17 & Auto Covering Road \\
3 & Tree Covering Road & 18 & Private-ownership Paved Surfaces \\
4 & Tree Covering Sidewalk & 19 & Parking Deck \\
5 & Tree Covering Parking & 20 & Alley \\
6 & Tree Covering Grass & 21 & Water \\
7 & Tree Covering Dry/Barren Land & 22 & Grass on Roof \\
8 & Tree Covering Other & 23 & Train Tracks \\
9 & Tree Covering Alley & 24 & Auto Covering Parking \\
10 & Roof & 25 & Recreational Surface \\
11 & Road & 26 & Residential Driveway \\
12 & Sidewalk & 27 & Awning \\
13 & Parking Area & 28 & N/A \\
14 & Grass & 29 & N/A \\
15 & Dry/Barren Land & 30 & Other Feature (not of interest) \\
\hline
\end{tabular}

\subsection{Identification of Random Samples}

Once the surface-types have been identified, as in Table 3, the next task is to determine the fractional areas covered by each type. We used a Monte-Carlo statistical technique for this purpose. The method is a simple process of randomly selecting pixels and visually identifying their surface-types and, subsequently, their land-cover fractions. The results are summarized as percentages for various surfaces. Initially, when the number of sample points is small, there is a large fluctuation in the computed percentage of various surface areas. As the number of sample points being examined increases, these fluctuations become smaller and approach asymptotic values. The process is stopped when the fluctuations in the percentages of each and all surface-types is acceptably small (here, less than $1 \%)$.

To locate the sample points randomly in a given region, ERDAS Imagine's capability to generate random numbers was used to create some 400-600 points for each scene (ERDAS 1997). This is the range of number of points at which the area percentages stabilize. A scene in Greater Houston averaged $1.5 \mathrm{~km}^{2}$ in area. Note that the scene area and number of sample points should be selected in a coordinated fashion so that a reasona ble distribution of random points is achieved. That is, the scene area should be selected so that a large number of surfaces are included and the randomly selected points are distributed at reasonable densities. 
Table 4. Major surface-types.

\begin{tabular}{|c|c|c|c|}
\hline Surface-Type & $\begin{array}{l}\text { Categories } \\
\text { Included* }\end{array}$ & Surface-Type & Categories Included \\
\hline \multicolumn{4}{|c|}{ Above-the-canopy view } \\
\hline Roof & 10,27 & Tree Cover & $2-9$ \\
\hline Road & 11 & Grass & 6,14 \\
\hline Parking Area & 13,19 & Barren Land & 15 \\
\hline Sidewalk \& Driveway & 12,26 & Miscellaneous & $16-18,20,21,23-25,30$ \\
\hline \multicolumn{4}{|c|}{ Under-the-canopy view } \\
\hline Roof & $2,10,19,22,27$ & $\begin{array}{l}\text { Private-ownership Paved } \\
\text { Surfaces }\end{array}$ & 18,26 \\
\hline Road & $3,9,11,17,20$ & Grass & 6,14 \\
\hline Parking Area & $5,13,24$ & Barren Land & 7,15 \\
\hline Sidewalk & 4,12 & Miscellaneous & $8,16,21,23,25,30$ \\
\hline
\end{tabular}

* Surface-type categories are defined in Table 1.

Once these points have been generated they are sequentially recalled by the software, and each is visually inspected and assigned to one of the surface-types listed in Table 3. Given the fine resolution of these images, the surface-type can almost always be identified. Even shaded surfaces can be relatively easily identified from continuity and context. Those surfaces that are impossible to identify are entered in the "Unidentified" category.

In the Monte-Carlo approach, as the sample size is increased the standard errors of the estimates of percentages for each land-cover area are expected to decrease. We performed a statistical exercise to evaluate the impact of sample size on standard error of estimate. In this exercise, we calculated the standard deviation of the observations progressively for all observations (samples 1-400), the last 300 observations (samples 101-400), the last 200 observations (samples 201-400), and the last 100 observations (samples 301-400). Table 5 shows the results of this analysis for both above and under the canopy for the Downtown Houston area. It can be clearly observed that the standard deviations become progressively smaller as the sample size is increased, indicating convergence toward the population mean. Based on this analysis, the estimated $95 \%$ confidence interval is less than $10 \%$ of the percentage for almost all surface-types.

\subsection{Extrapolation of Data for Climate Simulation}

For meteorological and air-quality modeling purposes, the region of interest needs to be characterized in terms of land cover and use, as well as physical properties. Aerial orthophotos can be used to derive LULC information on small scales. But because of the difficulty of characterizing the entire area (modeling domain), it is necessary to extrapolate the small-scale data to regional scale.

We used GLOBEIS model data from University of Texas and the land-use/land-cover (LULC) data from the United States Geological Survey (USGS) to extrapolate the limited data obtained from the analysis of aerial photos to the Greater Houston area. The USGS LULC data classify the surface at 200-meter resolution into many different urban and non-urban categories. LULC classifications for 
urban areas include residential, commercial and service, industrial, transportation and communications, industrial and commercial, mixed urban or built-up land, and other mixed urban and built-up land. The following steps were taken in order to extrapolate the data from aerial photographs to Greater Houston:

1. We first grouped data from aerial photographs into LULC categories (e.g., residential, commercial/services, industrial, etc).

2. We then calculated the average characteristics (fabric) for each category.

3. We assigned the properties of the observed land-use categories (OLUC) from the analysis of the aerial orthophotos to those of the USGS LULC data set.

4. Finally, the 200-meter resolution data were averaged to obtain data at 2,000 to 4,000 meter resolution for use in meteorological and air-quality modeling. Obviously, this averaging can introduce errors and can loose the detail obtained from aerial photography.

Table 5. The impact of sample size on estimates of area percentages of land-use categories for Downtown Houston. The entries show the "sample mean" in percentage of areas; the numbers in parenthesis are standard deviations of the means. Note that the above-the-canopy percentages show the "bird's-eye" view of the surfaces; under-the-canopy percentages are the actual land-use types.

\begin{tabular}{|c|c|c|c|c|c|c|c|c|}
\hline \multirow{2}{*}{$\begin{array}{l}\text { Sample Size } \\
\text { Surface-type }\end{array}$} & \multicolumn{4}{|c|}{ Above the Canopy } & \multicolumn{4}{|c|}{ Under the Canopy } \\
\hline & $1-400$ & $101-400$ & $201-400$ & $301-400$ & $1-400$ & $101-400$ & $201-400$ & $301-400$ \\
\hline Roof & $\begin{array}{c}26.1 \\
(3.4)\end{array}$ & $\begin{array}{c}26.8 \\
(0.8)\end{array}$ & $\begin{array}{c}26.5 \\
(0.6)\end{array}$ & $\begin{array}{c}26.9 \\
(0.3)\end{array}$ & $\begin{array}{l}32.0 \\
(3.5)\end{array}$ & $\begin{array}{l}32.7 \\
(0.6)\end{array}$ & $\begin{array}{l}32.8 \\
(0.5)\end{array}$ & $\begin{array}{c}33.1 \\
(0.3)\end{array}$ \\
\hline Road & $\begin{array}{c}27.9 \\
(4.1)\end{array}$ & $\begin{array}{c}27.6 \\
(1.0)\end{array}$ & $\begin{array}{c}28.0 \\
(0.6)\end{array}$ & $\begin{array}{l}27.7 \\
(0.6)\end{array}$ & $\begin{array}{c}29.3 \\
(4.1)\end{array}$ & $\begin{array}{c}29.3 \\
(1.0)\end{array}$ & $\begin{array}{c}29.4 \\
(0.8)\end{array}$ & $\begin{array}{c}28.9 \\
(0.6)\end{array}$ \\
\hline Parking Area & $\begin{array}{c}26.9 \\
(8.3)\end{array}$ & $\begin{array}{l}24.9 \\
(0.9)\end{array}$ & $\begin{array}{c}24.7 \\
(0.8)\end{array}$ & $\begin{array}{c}24.0 \\
(0.3)\end{array}$ & $\begin{array}{l}22.9 \\
(7.6)\end{array}$ & $\begin{array}{c}21.2 \\
(0.9)\end{array}$ & $\begin{array}{c}21.0 \\
(0.8)\end{array}$ & $\begin{array}{c}20.4 \\
(0.5)\end{array}$ \\
\hline Sidewalk & $\begin{array}{c}3.1 \\
(1.6)\end{array}$ & $\begin{array}{c}4.0 \\
(0.5)\end{array}$ & $\begin{array}{c}3.9 \\
(0.3)\end{array}$ & $\begin{array}{c}4.1 \\
(0.1)\end{array}$ & $\begin{array}{c}3.1 \\
(1.6)\end{array}$ & $\begin{array}{c}4.0 \\
(0.5)\end{array}$ & $\begin{array}{c}3.9 \\
(0.3)\end{array}$ & $\begin{array}{c}4.1 \\
(0.1)\end{array}$ \\
\hline Grass & $\begin{array}{c}4.1 \\
(2.1)\end{array}$ & $\begin{array}{c}3.3 \\
(0.2)\end{array}$ & $\begin{array}{c}3.2 \\
(0.2)\end{array}$ & $\begin{array}{c}3.2 \\
(0.1)\end{array}$ & $\begin{array}{c}4.8 \\
(1.9)\end{array}$ & $\begin{array}{c}4.1 \\
(0.4)\end{array}$ & $\begin{array}{c}3.9 \\
(0.2)\end{array}$ & $\begin{array}{c}3.8 \\
(0.1)\end{array}$ \\
\hline Barren Land & $\begin{array}{c}0.9 \\
(0.9)\end{array}$ & $\begin{array}{c}1.2 \\
(0.9)\end{array}$ & $\begin{array}{c}1.5 \\
(0.9)\end{array}$ & $\begin{array}{c}2.3 \\
(0.3)\end{array}$ & $\begin{array}{c}1.1 \\
(1.0)\end{array}$ & $\begin{array}{c}1.5 \\
(0.9)\end{array}$ & $\begin{array}{c}1.9 \\
(0.8)\end{array}$ & $\begin{array}{c}2.6 \\
(0.3)\end{array}$ \\
\hline Tree Cover & $\begin{array}{c}2.0 \\
(0.8)\end{array}$ & $\begin{array}{c}2.3 \\
(0.5)\end{array}$ & $\begin{array}{c}2.2 \\
(0.4)\end{array}$ & $\begin{array}{c}1.9 \\
(0.1)\end{array}$ & & & & \\
\hline Private Surfaces & & & & & $\begin{array}{c}2.0 \\
(0.9)\end{array}$ & $\begin{array}{c}1.9 \\
(0.3)\end{array}$ & $\begin{array}{c}1.7 \\
(0.1)\end{array}$ & $\begin{array}{c}1.7 \\
(0.1)\end{array}$ \\
\hline
\end{tabular}


The areas selected for these flights were chosen to be representative of the primary urbanized landuses in Greater Houston. A variety of resources were used to help in the selection process. We used a traditional map along with 1990 census data to identify the primary types of land-use in the city. Additionally, we sought assistance from the Houston Advanced Research Center (HARC) to acquire an understanding of the city's current state of development.

Researchers from HARC were able to identify trends in ongoing development and recommend what areas would be useful to characterize in their local planning and in determining the fabric of the city. Hence, a combination of commercial, industrial, educational, and residential areas was selected. Since the majority of Greater Houston is residential, an accurate assessment was necessary of the range and coverage of surfaces in residential neighborhoods. Therefore, six residential areas were analyzed, varying in age, housing density, and level of vegetation. All of the areas analyzed in this study are shown in Figure 1 in their exact geographic locations. They are relatively small and widely dispersed throughout the greater area. The following is a description and discussion of each area.

\subsection{Educational Area: University of Houston}

The area analyzed is the campus of the University of Houston. It is approximately $4 \mathrm{~km}$ from downtown and centered at UTM coordinate of $(273362.55,3290333.85)$. The total area is about 2 $\mathrm{km}^{2}$ and is shown in Figure 2. This area is a development unique to colleges, including offices, parking areas, residential areas, and recreational and educational facilities. In the USGS landuse/land-cover classification scheme it is identified as type 12, Commercial/Services.

As described above, 400 random points were generated throughout the selected study area. These points were then located in the acquired imagery and visually identified according to their surfacetype. Initially, the fractions of surface-types fluctuate widely, but as the sample size increases, the accuracy of the fraction of each surface-type increases and the fractions stabilize. The results of this analysis are detailed in Tables 6 and 7.

This type of area is unique in both its variety of uses and because its development is determined by a single entity, the University of Houston. From these results it appears that the surface-types with the greatest potential contribution to the heat-island effect at the University of Houston are paved surfaces, which cover about $40 \%$ of the entire area. The above-the-canopy categories "Road," "Sidewalk," and "Parking Area" are all paved surfaces. Thus, the greatest benefits for heat-island reduction could be attained in this area by targeting paved surfaces for increases in albedo.

\subsection{Typical Industrial Areas}

Several industrial areas were selected for analysis. Some of them were near downtown and intensively developed, others were much less developed. Their distance from the center of Houston was significant in their distribution of surface-types. In all, four industrial areas were studied.

\subsubsection{West of Jersey Village}

The selected industrial area is centered at UTM coordinates of $(249735.75,3309035.85)$. Its area is about $2 \mathrm{~km}^{2}$ and it is located about $26 \mathrm{~km}$ from downtown. As shown in Figure 3, the highway in the upper right corner of the area is US 290. Across that highway to the east is Jersey Village. This area is farther from downtown Houston than other industrial areas analyzed.

The industrial area, West of Jersey Village, is significantly less developed than the other areas analyzed. As shown in Figure 3, grassy plots are interspersed throughout the area leading to higher vegetation levels than in the more intensively developed industrial areas. Within this development 
there are even several small tracts of mobile homes. The presence of these small residential areas indicates that the area is not zoned for industrial development and perhaps explaining its unusual structure (the area lies outside the city limits). Although not apparent from the results, the orthophoto of this area clearly shows that large roofs and parking areas are typical of the industrial developments interspersed throughout the area. Thus, implementation of heat-island reduction in this area should target these large roofs and parking lots. Further analysis is required to determine the incidence of this type of development in the urban fringe. In the USGS classification system, the center cell $(200 \mathrm{~m} \times 200 \mathrm{~m})$ of the area acquired is identified as Residential.

\subsubsection{East of Downtown}

The East of Downtown industrial area is $2.5 \mathrm{~km}^{2}$. It is centered at UTM (coordinates 276435.75 , 3293684.25). It is located about $5 \mathrm{~km}$ from downtown. As shown in Figure 4, it is an intensively developed area. Some of the industries in this area include the Reed Tool Company and Electro Coatings of Texas.

The high percentages of roofs and parking areas, $21 \%$ and $25 \%$ respectively, are indicative of the intensity of development in this location. There are three modes of transport in this area: waterway, railroad, and roadway. Access to all these methods of transportation results in a slightly lower percentage of roads than might be expected for a development of this nature. In this area the most effective means of heat-island reduction would be tree planting and albedo increases on the roofs and parking areas. In the USGS LULC system, this area is identified as Industrial.

\subsubsection{Northwest of Downtown}

This industrial area shown in Figure 5 is also intensively developed. The Northwest of Downtown area is located at the UTM coordinate $(264217.75,3297607.05)$. It is $3.6 \mathrm{~km}^{2}$ in area and located about $8 \mathrm{~km}$ from the city center. Some of the industries in this area include General Electric (GE) and Smith Industries.

Similar to the previous area, the Northwest of Downtown area is near the city's central downtown. The roof and parking area fractions in this area are high at about $22 \%$ each. This area has good access to both rail and road transportation, with $10 \%$ of its area dedicated to roads. As in the East of Downtown area, the increase in albedo of roofs and roads can have significant effects on this area. In the USGS classification system this area is type 13, Industrial.

\subsubsection{Southeast of Downtown}

As shown in Figure 6, the Southeast of Downtown study area is centered at (281611.22, $3289844.25)$. Its area is approximately $1.1 \mathrm{~km}^{2}$ and it is located approximately $11 \mathrm{~km}$ southeast of downtown.

The distribution of surface-types in this area is similar to the West of Jersey Village area. These two areas are each more than $5 \mathrm{~km}$ from downtown and share significantly lower levels of roof coverage than the more urban areas. One striking difference in this area is the low fraction of tree cover, $0.8 \%$. This suggests that such an area could be a candidate for urban forestation efforts.

\subsection{Typical Commercial Areas}

A variety of commercial areas were analyzed. They ranged from intensively developed areas, similar to downtown, to shopping areas and office complexes on the urban fringe. Five commercial areas were selected for analysis. 


\subsubsection{Downtown}

The Downtown area includes the intensively developed core of the city, typified by tall buildings and virtually no undeveloped land. The UTM coordinate defining the center of the selected area is (271282.95, 3293791.05). The analyzed area (Figure 7) is $1.7 \mathrm{~km}^{2}$.

As expected, this area is dominated by impervious surfaces. Roads and roofs each cover about $28 \%$ of the total area. The total fraction of all impervious surfaces (roads, roofs, parking areas, and sidewalks) is a full $86 \%$. With a mere $1.8 \%$ tree coverage, the lowest of all commercial areas studied, tree-planting strategies would bring relief to this area. Tree planting strategies would be the simplest to implement since they can be added to sidewalks, roofs, or parking areas without resurfacing the entire area. In the USGS classification scheme this area is identified as type 12, Commercial and Services.

Note that in the downtown area, there are some tangible differences between the above- and under-the-canopy fabrics. Under-the-canopy roof area is about $6.3 \%$ higher than the above-the canopy roof area (34.3\% vs. $28.0 \%)$. This is primarily because in analysis of under-the-canopy data some of the parking areas (parking decks) and some of the miscellaneous areas are characterized as roofs.

\subsubsection{Garden Oaks Shopping Center}

The Garden Oaks Shopping Center area has the UTM coordinate $(267663.75,3301583.85)$ at its center point. As shown in Figure 8, the area analyzed totals $1.0 \mathrm{~km}^{2}$ and is located about $8.5 \mathrm{~km}$ from downtown.

This area is homogenous throughout and is bounded on all sides by residential development. It has the highest percentage of roof cover of any areas in the study at $39 \%$. Parking areas cover $28 \%$ of the area. Efforts to increase albedo in this area would be most successful if the large roofs were targeted. In the USGS classification system, the center of the area was identified as type 17, Other Urban or Built-Up Land, possibly because of the mix of residential and commercial land uses present.

\subsubsection{Greenspoint Mall}

The suburban Greenspoint Mall area is about $21.5 \mathrm{~km}$ outside of downtown Houston. The analyzed area is shown in Figure 9. It is centered on the UTM coordinate (267442.95, 3315230.25). The total area analyzed is $1.2 \mathrm{~km}^{2}$.

Similar to the previous area, Greenspoint Mall is another fairly typical suburban development. In an effort to isolate the commercial development without including more of a particular land-cover than should be assigned to this area, we drew the analysis boundary as shown in Figure 9. Around the selected area are several apartments that should not be included in this analysis. Thus, the centers of roadways dividing the homogenous commercial area from the residential developments were used to define the area. Unlike the Garden Oaks Shopping Center area, the predominant surface-type is parking at $45 \%$. Additionally, the percentage of road coverage is $18 \%$. This area has the highest percentage of pavements of all the study areas; these surfaces should be considered for large-scale albedo increases. Probably because of the age of the USGS data, this area was identified as type 21, Cropland and Pasture. 


\subsubsection{Bingle}

The Bingle area is composed of office complexes about $13 \mathrm{~km}$ from downtown. The center point of the selected study area is $(258634.35,3297717.45)$. It is a rectangular area of $281 \mathrm{~m}$ by $408 \mathrm{~m}$ in the center of Figure 10. The analyzed area is approximately $0.11 \mathrm{~km}^{2}$.

As shown in Figure 10, this area is homogenous in nature and contrasts starkly to the residential development surrounding it. To the east of the selected area is a barren area that may be developed for office complexes in the future. The dominant land-cover in this area is roof at $38 \%$. As seen in the picture these roofs are fairly dark in color and their albedos could be increased. This strategy may be the easiest to implement in this area as opposed to adding vegetation, since the area is fully developed.

In the USGS classification system, this area is identified as Residential. The possible classification error in the USGS system is either because of the age of the office development, or more likely because of a lack of information at the level of detail in the analyzed orthophotos. In lower resolution data, areas such as this would not be apparent since most of the larger-size pixels would be a mix of office and residential areas. While easily identified with high-resolution orthophotos, data of a lower resolution would simply incorporate this area into the surrounding residential area.

\subsubsection{Park Ten Place}

Park Ten Place is another office complex selected for analysis. It is located at (247567.35, 3298107.45 ), about $24 \mathrm{~km}$ from downtown. The analyzed area is shown in Figure 11. The total area analyzed is about $0.48 \mathrm{~km}^{2}$.

The selected area included the office development in the center of Figure 11 and the similar area to the right of it. In this analysis, the green space on the specific lot of the development was included and the large surrounding grassy spaces were excluded to keep the results specific to office developments. We based this decision on the assumption that these areas would be considered undeveloped at this time: In the future, when developed, they will likely consist of office developments similar in structure to the ones in the analysis area. The analysis area is bordered on the north by the edge of the lots. The east boundary of the area is the edge of Figure 11 . The southern edge of the area is the center of the curvy road below the developments and the western edge is the center of the road running north south in the area.

This area appears to have a substantial percentage of high-albedo surfaces and vegetation. The white parking covers are advantageous since they reflect significant amounts of radiation, cooling the vehicles and pavement underneath. The development has also maintained high percentages of vegetation, with $27 \%$ grass and $13 \%$ tree coverage.

\subsection{Typical Residential Areas}

Six areas were selected for analysis in order to accurately characterize the structure of residential areas in the Greater Houston area. They ranged from multi-family apartment complexes to new, single-family developments.

\subsubsection{Gulfton}

The Gulfton area is about $12 \mathrm{~km}$ outside of downtown Houston. This area includes several multifamily housing complexes. The analyzed area is shown in Figure 12. It is centered at (259840.95, $3289784.25)$. The total area analyzed includes about $2.4 \mathrm{~km}^{2}$. 
The area selected for analysis included all of that shown in Figure 12. Almost the entire acquired area was used for the urban fabric analysis since apartment buildings were scattered throughout. Only a small rectangular area of single-family housing was excluded from the analysis. Of the residential areas studied, this is one of the most intensively developed, with 72 percent of the area covered by roofs and pavements. Therefore, these man-made surfaces would be good targets for albedo increases. Also, with a tree cover of only $6.5 \%$, additional trees would be beneficial. In the USGS LULC classification system, the center coordinate of the acquired area was identified as type 17 , Other Urban or Built-Up Land, whereas the area is in fact predominantly residential in nature.

\subsubsection{Plum Creek}

The Plum Creek area is about $9 \mathrm{~km}$ from downtown. The analyzed area is shown in Figure 13. It is centered approximately at $(278768.55,3288099.45)$. The total area analyzed is $0.27 \mathrm{~km}^{2}$.

This area is similar to the Gulfton area. It is composed of multi-family housing and is extensively developed. This area has a slightly higher vegetation level at $21 \%$, but is still dominated by manmade surfaces. According to the USGS classification system this area is type 11, Residential.

\subsubsection{Adam School Area}

The Adam School area is shown in Figure 14. It is located about $32 \mathrm{~km}$ northwest of downtown Houston. This area is typical of suburban, single-family home developments and includes Adam School near the lower left corner inside the selected area. The selected area is $1094 \times 1025 \mathrm{~m}$, or about $1.1 \mathrm{~km}^{2}$. The center coordinate of the area is $(247957.35,3315081.45)$

The area selected for analysis was chosen to determine the urban fabric of the single-family home neighborhood in the vicinity of Adam School. Therefore, the lower boundary of the area is represented by the lot edges of the single-family homes south of the school. The right-hand boundary coincides with a change in lot size; larger lot sizes can be seen to the right of that boundary. The upper boundary consists of the lot edges of the homogenous area above Adam School.

Roofs cover $16 \%$ of the area; $66 \%$ of the area is vegetated. The pavement percentage is $14 \%$. In this type of neighborhood albedo increases would be desirable on roofs and pavements. In the USGS LULC system this area was identified as type 76, Transitional Areas. This is probably because of the age of the USGS data.

\subsubsection{Strawberry Mall Area}

The Strawberry Mall area, shown in Figure 15 is located about $18.5 \mathrm{~km}$ from downtown. The selected analysis area is centered on the coordinate $(287791.78,3284744.88)$. It is $1.7 \mathrm{~km}^{2}$ in area.

Compared to the Adam School area, this area has slightly less vegetation, 60\%, and slightly more roof and pavement coverage, $21 \%$ and $17 \%$, respectively. As in the previous area, man-made materials should be targeted for large-scale albedo modifications in this type of neighborhood. It is classified correctly as type 11, Residential, in the USGS LULC system.

\subsubsection{Cinco Ranch}

The Cinco Ranch development is about $38 \mathrm{~km}$ outside of downtown Houston. The area selected for analysis is shown in Figure 16. The center point of the selected area is the UTM coordinate $(233022.04,3297523.16)$ and it is about $1.4 \mathrm{~km}^{2}$ in area.

Cinco Ranch is another example of an area of homogenous single-family homes. The selected rectangle was defined by the commercial developments around the study area. These were excluded to obtain results specific to residential areas. Cinco Ranch is quite similar to the Strawberry Mall area 
in terms of its roof coverage, but it has higher pavement coverage than any of the single-family developments analyzed (26\%). In the USGS classification system the center of this acquired area is type 14, Transportation, Communications, and Utilities. Although a major highway runs horizontally on the north side of the photograph, the center portion is clearly residential.

\subsubsection{Sugarland}

The Sugarland area is shown in Figure 17. It is a single-family residential development typical of the commonly built "golf course" complexes. The center of the selected area is at $(247567.35$, 3298107.45 ) and the area is approximately $0.48 \mathrm{~km}^{2}$.

For this area, we analyzed the entire frame acquired. Interestingly, it appears that in the areas of clustered housing the surface-type distribution does not appear to be much different than that of the other single-family areas studied. When the interspaced grassy areas are included, the distribution of surface-types obviously changes significantly. The dominant surface-type in the area is vegetation. Also unlike the other single-family areas, the area covered by trees is much lower than that covered by grass. USGS data indicate that this area is type 21, Cropland and Pasture. This is probably a result of the age of the USGS data, but it could also be the result of the large green spaces utilized for the golf course having been erroneously identified for pasture.

\subsection{Summary}

The results of this analysis are summarized in Figure 18 (above-the-canopy view of the city) and Figure 19 (under-the-tree-canopy). In Figures 20 and 21, we show the fabric of Houston, grouped by land-use type. In Figures $\mathbf{2 2}$ and $\mathbf{2 3}$, we show the average results for residential, commercial and industrial areas. In the industrial areas, the percentage of grass tends to increase and the percentage of parking decrease in relation to the area's distance from the center of the city. Hence, the highest percentage of grass and lowest of parking is found in the West of Jersey Village area, followed by the Southeast of Downtown, the Northwest of Downtown, and finally the East of Downtown areas. In the commercial section of downtown Houston, the top view (above-the-canopy) shows that vegetation (trees, grass, and shrubs) covers $5 \%$ of the area, whereas roofs cover $28 \%$ and paved surface (roads, parking areas, and sidewalks) 58\%. (The under-the-canopy fabric consists of 58\% paved surfaces, $34 \%$ roofs, and $4 \%$ grass.) The surface-type percentages in the office park commercial area, consisting of the Bingle and Park Ten areas, were $27 \%$ trees and grass, $31 \%$ roofs, and $33 \%$ paved surfaces. The surface-type percentages in the shopping mall commercial area, made up of the Garden Oaks Shopping Center and Greenspoint Mall areas, were 16\% trees and grass, 27\% roofs, and 50\% paved surfaces. In the intensive industrial areas, Northwest of Downtown and East of Downtown, vegetation covers $22 \%$ of the area, whereas roofs cover $21 \%$, and paved surfaces $31 \%$. In the suburban industrial areas, West of Jersey Village and Southeast of Downtown, vegetation covers $43 \%$ of the area, whereas roofs cover $9 \%$ and paved surfaces $19 \%$. Residential areas exhibit a wide range of percentages among their surface-types. On the average, for single-family residential areas (Cinco Ranch, Adam School, Sugarland, and Strawberry Mall), vegetation covers about $61 \%$ of the area, roofs cover about $17 \%$, and paved surfaces about $18 \%$. The averages for multi-family residential areas are: $24 \%$ vegetation, $28 \%$ roofs, and $39 \%$, paved surfaces. 
Table 6. Above-the-canopy view of Greater Houston, TX. Entries are rounded to nearest $0.1 \%$. Numbers in parenthesis show the standard deviations of the last 100 samples.

\begin{tabular}{|c|c|c|c|c|c|c|c|c|}
\hline \multirow[b]{2}{*}{ Area } & \multicolumn{8}{|c|}{ Surface-Type (percent of total cover) } \\
\hline & Roof & Road & $\begin{array}{c}\text { Parking } \\
\text { Area }\end{array}$ & $\begin{array}{c}\text { Side- } \\
\text { walk/ } \\
\text { Drive- } \\
\text { way }\end{array}$ & $\begin{array}{l}\text { Tree } \\
\text { Cover }\end{array}$ & Grass & $\begin{array}{c}\text { Barren } \\
\text { Land }\end{array}$ & Misc. \\
\hline 1. University of Houston & $\begin{array}{l}11.9 \\
(0.3)\end{array}$ & $\begin{array}{c}7.1 \\
(0.1)\end{array}$ & $\begin{array}{l}29.4 \\
(0.8)\end{array}$ & $\begin{array}{c}2.5 \\
(0.2)\end{array}$ & $\begin{array}{l}10.6 \\
(0.4)\end{array}$ & $\begin{array}{l}30.1 \\
(0.3)\end{array}$ & $\begin{array}{c}4.1 \\
(0.2)\end{array}$ & $\begin{array}{r}4.3 \\
(0.4)\end{array}$ \\
\hline $\begin{array}{l}\text { 2. Industrial } \\
\text { 2.1 West of Jersey Village }\end{array}$ & $\begin{array}{l}11.3 \\
(0.4)\end{array}$ & $\begin{array}{c}5.1 \\
(0.3)\end{array}$ & $\begin{array}{r}7.2 \\
(0.2)\end{array}$ & $\begin{array}{l}0.5 \\
(0.0)\end{array}$ & $\begin{array}{l}17.5 \\
(0.2)\end{array}$ & $\begin{array}{l}40.4 \\
(0.4)\end{array}$ & $\begin{array}{l}15.4 \\
(0.3)\end{array}$ & $\begin{array}{r}2.6 \\
(0.2)\end{array}$ \\
\hline 2.2 East of Downtown & $\begin{array}{l}21.1 \\
(0.4)\end{array}$ & $\begin{array}{r}4.9 \\
(0.2)\end{array}$ & $\begin{array}{l}25.3 \\
(0.5)\end{array}$ & $\begin{array}{c}0.0 \\
(0.0)\end{array}$ & $\begin{array}{c}3.1 \\
(0.1)\end{array}$ & $\begin{array}{l}13.1 \\
(0.4)\end{array}$ & $\begin{array}{l}13.1 \\
(0.3)\end{array}$ & $\begin{array}{l}19.3 \\
(0.5)\end{array}$ \\
\hline 2.3 Northwest of Downtown & $\begin{array}{l}21.8 \\
(0.4)\end{array}$ & $\begin{array}{l}10.4 \\
(0.4)\end{array}$ & $\begin{array}{l}21.6 \\
(0.5)\end{array}$ & $\begin{array}{r}0.0 \\
(0.0)\end{array}$ & $\begin{array}{c}6.5 \\
(0.2)\end{array}$ & $\begin{array}{l}21.3 \\
(0.4)\end{array}$ & $\begin{array}{l}14.0 \\
(0.6)\end{array}$ & $\begin{array}{r}4.4 \\
(0.3)\end{array}$ \\
\hline 2.4 Southeast of Downtown & $\begin{array}{c}7.1 \\
(0.2)\end{array}$ & $\begin{array}{c}4.5 \\
(0.2)\end{array}$ & $\begin{array}{l}20.1 \\
(0.4)\end{array}$ & $\begin{array}{c}0.0 \\
(0.0)\end{array}$ & $\begin{array}{c}0.8 \\
(0.1)\end{array}$ & $\begin{array}{l}26.9 \\
(0.6)\end{array}$ & $\begin{array}{l}23.2 \\
(0.7)\end{array}$ & $\begin{array}{l}17.4 \\
(0.3)\end{array}$ \\
\hline $\begin{array}{l}\text { 3. Commercial } \\
\text { 3.1 Downtown }\end{array}$ & $\begin{array}{l}28.0 \\
(0.3)\end{array}$ & $\begin{array}{l}28.5 \\
(0.6)\end{array}$ & $\begin{array}{l}25.4 \\
(0.3)\end{array}$ & $\begin{array}{r}4.2 \\
(0.1)\end{array}$ & $\begin{array}{c}1.8 \\
(0.1)\end{array}$ & $\begin{array}{l}3.4 \\
(0.1)\end{array}$ & $\begin{array}{r}2.9 \\
(0.3)\end{array}$ & $\begin{array}{r}5.8 \\
(0.2)\end{array}$ \\
\hline 3.2 Garden Oaks Shopping Center & $\begin{array}{c}38.8 \\
(0.5)\end{array}$ & $\begin{array}{c}7.2 \\
(0.2)\end{array}$ & $\begin{array}{l}27.9 \\
(0.3)\end{array}$ & $\begin{array}{c}1.0 \\
(0.1)\end{array}$ & $\begin{array}{c}7.0 \\
(0.3)\end{array}$ & $\begin{array}{c}9.0 \\
(0.6)\end{array}$ & $\begin{array}{c}3.6 \\
(0.1)\end{array}$ & $\begin{array}{c}5.4 \\
(0.5)\end{array}$ \\
\hline 3.3 Greenspoint Mall & $\begin{array}{l}16.1 \\
(0.2)\end{array}$ & $\begin{array}{l}18.4 \\
(0.5)\end{array}$ & $\begin{array}{l}44.5 \\
(0.4)\end{array}$ & $\begin{array}{c}0.5 \\
(0.1)\end{array}$ & $\begin{array}{c}5.6 \\
(0.3)\end{array}$ & $\begin{array}{r}9.5 \\
(0.1)\end{array}$ & $\begin{array}{c}3.3 \\
(0.2)\end{array}$ & $\begin{array}{r}2.0 \\
(0.2)\end{array}$ \\
\hline 3.4 Bingle & $\begin{array}{c}38.4 \\
(0.6)\end{array}$ & $\begin{array}{c}5.4 \\
(0.1)\end{array}$ & $\begin{array}{l}36.3 \\
(0.3)\end{array}$ & $\begin{array}{c}0.8 \\
(0.1)\end{array}$ & $\begin{array}{c}7.7 \\
(0.6)\end{array}$ & $\begin{array}{r}5.9 \\
(0.1)\end{array}$ & $\begin{array}{c}0.3 \\
(0.0)\end{array}$ & $\begin{array}{c}5.4 \\
(0.2)\end{array}$ \\
\hline 3.5 Park Ten Place & $\begin{array}{l}24.5 \\
(0.9)\end{array}$ & $\begin{array}{c}4.3 \\
(0.2)\end{array}$ & $\begin{array}{l}18.1 \\
(0.5)\end{array}$ & $\begin{array}{c}0.3 \\
(0.0)\end{array}$ & $\begin{array}{l}12.5 \\
(0.3)\end{array}$ & $\begin{array}{l}27.3 \\
(0.4)\end{array}$ & $\begin{array}{c}3.8 \\
(0.2)\end{array}$ & $\begin{array}{r}9.2 \\
(0.4)\end{array}$ \\
\hline $\begin{array}{l}\text { 4. Residential } \\
\text { 4.1 Gulfton }\end{array}$ & $\begin{array}{l}29.1 \\
(0.5)\end{array}$ & $\begin{array}{l}10.1 \\
(0.5)\end{array}$ & $\begin{array}{l}27.5 \\
(0.3)\end{array}$ & $\begin{array}{c}3.1 \\
(0.2)\end{array}$ & $\begin{array}{c}6.5 \\
(0.2)\end{array}$ & $\begin{array}{l}16.6 \\
(0.9)\end{array}$ & $\begin{array}{c}2.3 \\
(0.2)\end{array}$ & $\begin{array}{r}4.7 \\
(0.2)\end{array}$ \\
\hline 4.2 Plum Creek & $\begin{array}{l}27.8 \\
(0.3)\end{array}$ & $\begin{array}{c}5.7 \\
(0.4)\end{array}$ & $\begin{array}{l}27.5 \\
(0.4)\end{array}$ & $\begin{array}{c}3.6 \\
(0.1)\end{array}$ & $\begin{array}{r}8.2 \\
(0.3)\end{array}$ & $\begin{array}{l}17.2 \\
(0.3)\end{array}$ & $\begin{array}{c}4.1 \\
(0.2)\end{array}$ & $\begin{array}{r}5.9 \\
(0.5)\end{array}$ \\
\hline 4.3 Adam School & $\begin{array}{l}16.2 \\
(0.4)\end{array}$ & $\begin{array}{c}8.1 \\
(0.3)\end{array}$ & $\begin{array}{c}0.5 \\
(0.1)\end{array}$ & $\begin{array}{c}5.5 \\
(0.2)\end{array}$ & $\begin{array}{l}28.5 \\
(0.3)\end{array}$ & $\begin{array}{l}37.9 \\
(0.5)\end{array}$ & $\begin{array}{c}1.0 \\
(0.1)\end{array}$ & $\begin{array}{r}2.3 \\
(0.2)\end{array}$ \\
\hline 4.4 Strawberry Mall & $\begin{array}{l}20.7 \\
(0.3)\end{array}$ & $\begin{array}{c}8.8 \\
(0.3)\end{array}$ & $\begin{array}{r}2.6 \\
(0.3)\end{array}$ & $\begin{array}{c}5.2 \\
(0.3)\end{array}$ & $\begin{array}{l}24.1 \\
(0.5)\end{array}$ & $\begin{array}{l}35.5 \\
(0.3)\end{array}$ & $\begin{array}{c}1.0 \\
(0.1)\end{array}$ & $\begin{array}{c}2.1 \\
(0.2)\end{array}$ \\
\hline 4.5 Cinco Ranch & $\begin{array}{l}21.9 \\
(0.4)\end{array}$ & $\begin{array}{l}16.9 \\
(0.2)\end{array}$ & $\begin{array}{c}1.1 \\
(0.1)\end{array}$ & $\begin{array}{c}7.7 \\
(0.3)\end{array}$ & $\begin{array}{l}19.5 \\
(0.5)\end{array}$ & $\begin{array}{l}29.8 \\
(0.8)\end{array}$ & $\begin{array}{c}0.8 \\
(0.2)\end{array}$ & $\begin{array}{r}2.4 \\
(0.1)\end{array}$ \\
\hline 4.6 Sugarland & $\begin{array}{c}7.5 \\
(0.4)\end{array}$ & $\begin{array}{c}9.4 \\
(0.3)\end{array}$ & $\begin{array}{c}0.0 \\
(0.0)\end{array}$ & $\begin{array}{c}4.7 \\
(0.4)\end{array}$ & $\begin{array}{l}14.3 \\
(0.6)\end{array}$ & $\begin{array}{l}55.1 \\
(0.7)\end{array}$ & $\begin{array}{c}0.8 \\
(0.1)\end{array}$ & $\begin{array}{r}8.3 \\
(0.3)\end{array}$ \\
\hline
\end{tabular}


Table 7. Under-the-canopy view of Greater Houston, TX. Entries are rounded to nearest $0.1 \%$. Numbers in parenthesis show the standard deviations of the last 100 samples.

\begin{tabular}{|c|c|c|c|c|c|c|c|c|}
\hline \multirow[b]{2}{*}{ Area } & \multicolumn{8}{|c|}{ Surface-Type (percent of total cover) } \\
\hline & Roof & Road & $\begin{array}{c}\text { Parking } \\
\text { Area }\end{array}$ & $\begin{array}{l}\text { Side- } \\
\text { walk }\end{array}$ & $\begin{array}{l}\text { Private } \\
\text { Srfaces }\end{array}$ & Grass & $\begin{array}{c}\text { Barren } \\
\text { Land }\end{array}$ & Misc. \\
\hline 1. University of Houston & $\begin{array}{l}11.9 \\
(0.3)\end{array}$ & $\begin{array}{c}7.1 \\
(0.1)\end{array}$ & $\begin{array}{l}29.9 \\
(0.7)\end{array}$ & $\begin{array}{c}3.3 \\
(0.2)\end{array}$ & $\begin{array}{c}0.3 \\
(0.1)\end{array}$ & $\begin{array}{l}37.5 \\
(0.4)\end{array}$ & $\begin{array}{c}4.1 \\
(0.2)\end{array}$ & $\begin{array}{c}6.1 \\
(0.2)\end{array}$ \\
\hline $\begin{array}{l}\text { 2. Industrial } \\
\text { 2.1 West of Jersey Village }\end{array}$ & $\begin{array}{l}11.3 \\
(0.4)\end{array}$ & $\begin{array}{c}5.1 \\
(0.3)\end{array}$ & $\begin{array}{c}8.0 \\
(0.3)\end{array}$ & $\begin{array}{c}0.3 \\
(0.0)\end{array}$ & $\begin{array}{c}0.3 \\
(0.0)\end{array}$ & $\begin{array}{l}56.6 \\
(0.3)\end{array}$ & $\begin{array}{l}15.7 \\
(0.3)\end{array}$ & $\begin{array}{c}2.8 \\
(0.2)\end{array}$ \\
\hline 2.2 East of Downtown & $\begin{array}{l}21.1 \\
(0.4)\end{array}$ & $\begin{array}{r}4.9 \\
(0.2)\end{array}$ & $\begin{array}{l}25.8 \\
(0.4)\end{array}$ & $\begin{array}{c}0.0 \\
(0.0)\end{array}$ & $\begin{array}{c}0.0 \\
(0.0)\end{array}$ & $\begin{array}{l}13.4 \\
(0.4)\end{array}$ & $\begin{array}{l}13.4 \\
(0.3)\end{array}$ & $\begin{array}{l}21.4 \\
(0.5)\end{array}$ \\
\hline 2.3 Northwest of Downtown & $\begin{array}{l}22.3 \\
(0.3)\end{array}$ & $\begin{array}{l}10.4 \\
(0.4)\end{array}$ & $\begin{array}{l}22.1 \\
(0.6)\end{array}$ & $\begin{array}{c}0.3 \\
(0.0)\end{array}$ & $\begin{array}{c}0.0 \\
(0.0)\end{array}$ & $\begin{array}{l}24.9 \\
(0.4)\end{array}$ & $\begin{array}{l}14.0 \\
(0.6)\end{array}$ & $\begin{array}{c}6.0 \\
(0.3)\end{array}$ \\
\hline 2.4 Southeast of Downtown & $\begin{array}{c}7.1 \\
(0.2)\end{array}$ & $\begin{array}{c}4.5 \\
(0.2)\end{array}$ & $\begin{array}{l}20.1 \\
(0.4)\end{array}$ & $\begin{array}{c}0.0 \\
(0.0)\end{array}$ & $\begin{array}{c}0.0 \\
(0.0)\end{array}$ & $\begin{array}{l}27.4 \\
(0.7)\end{array}$ & $\begin{array}{l}23.2 \\
(0.7)\end{array}$ & $\begin{array}{l}17.7 \\
(0.4)\end{array}$ \\
\hline $\begin{array}{l}\text { 3. Commercial } \\
\text { 3.1 Downtown }\end{array}$ & $\begin{array}{l}34.3 \\
(0.3)\end{array}$ & $\begin{array}{l}29.6 \\
(0.6)\end{array}$ & $\begin{array}{l}22.0 \\
(0.5)\end{array}$ & $\begin{array}{c}4.2 \\
(0.1)\end{array}$ & $\begin{array}{c}1.8 \\
(0.1)\end{array}$ & $\begin{array}{c}3.9 \\
(0.1)\end{array}$ & $\begin{array}{c}3.1 \\
(0.3)\end{array}$ & $\begin{array}{c}1.0 \\
(0.1)\end{array}$ \\
\hline 3.2 Garden Oaks Shopping Center & $\begin{array}{l}39.0 \\
(0.5)\end{array}$ & $\begin{array}{r}7.2 \\
(0.2)\end{array}$ & $\begin{array}{l}29.2 \\
(0.3)\end{array}$ & $\begin{array}{c}1.3 \\
(0.2)\end{array}$ & $\begin{array}{c}0.5 \\
(0.2)\end{array}$ & $\begin{array}{l}13.2 \\
(0.8)\end{array}$ & $\begin{array}{c}3.6 \\
(0.1)\end{array}$ & $\begin{array}{r}5.9 \\
(0.2)\end{array}$ \\
\hline 3.3 Greenspoint Mall & $\begin{array}{l}19.9 \\
(0.3)\end{array}$ & $\begin{array}{l}18.9 \\
(0.5)\end{array}$ & $\begin{array}{l}41.4 \\
(0.6)\end{array}$ & $\begin{array}{c}0.5 \\
(0.1)\end{array}$ & $\begin{array}{c}1.5 \\
(0.1)\end{array}$ & $\begin{array}{l}11.8 \\
(0.3)\end{array}$ & $\begin{array}{c}3.3 \\
(0.2)\end{array}$ & $\begin{array}{c}2.6 \\
(0.1)\end{array}$ \\
\hline 3.4 Bingle & $\begin{array}{c}38.6 \\
(0.6)\end{array}$ & $\begin{array}{c}5.6 \\
(0.2)\end{array}$ & $\begin{array}{l}42.7 \\
(0.2)\end{array}$ & $\begin{array}{c}0.8 \\
(0.1)\end{array}$ & $\begin{array}{c}0.5 \\
(0.1)\end{array}$ & $\begin{array}{r}8.7 \\
(0.2)\end{array}$ & $\begin{array}{c}0.5 \\
(0.1)\end{array}$ & $\begin{array}{c}2.6 \\
(0.4)\end{array}$ \\
\hline 3.5 Park Ten Place & $\begin{array}{l}24.5 \\
(0.9)\end{array}$ & $\begin{array}{c}4.3 \\
(0.2)\end{array}$ & $\begin{array}{l}19.1 \\
(0.4)\end{array}$ & $\begin{array}{c}0.5 \\
(0.0)\end{array}$ & $\begin{array}{c}0.3 \\
(0.0)\end{array}$ & $\begin{array}{l}34.9 \\
(0.5)\end{array}$ & $\begin{array}{c}3.8 \\
(0.2)\end{array}$ & $\begin{array}{l}12.5 \\
(0.4)\end{array}$ \\
\hline $\begin{array}{l}\text { 4. Residential } \\
\text { 4.1 Gulfton }\end{array}$ & $\begin{array}{l}29.4 \\
(0.5)\end{array}$ & $\begin{array}{l}10.4 \\
(0.6)\end{array}$ & $\begin{array}{l}28.8 \\
(0.3)\end{array}$ & $\begin{array}{c}3.1 \\
(0.2)\end{array}$ & $\begin{array}{r}0.8 \\
(0.2)\end{array}$ & $\begin{array}{l}18.4 \\
(1.0)\end{array}$ & $\begin{array}{c}2.3 \\
(0.2)\end{array}$ & $\begin{array}{r}6.8 \\
(0.4)\end{array}$ \\
\hline 4.2 Plum Creek & $\begin{array}{l}28.5 \\
(0.3)\end{array}$ & $\begin{array}{c}6.4 \\
(0.4)\end{array}$ & $\begin{array}{l}33.2 \\
(0.2)\end{array}$ & $\begin{array}{c}3.6 \\
(0.1)\end{array}$ & $\begin{array}{c}0.3 \\
(0.0)\end{array}$ & $\begin{array}{l}21.3 \\
(0.5)\end{array}$ & $\begin{array}{c}4.4 \\
(0.2)\end{array}$ & $\begin{array}{c}2.3 \\
(0.1)\end{array}$ \\
\hline 4.3 Adam School & $\begin{array}{r}17.2 \\
(0.4)\end{array}$ & $\begin{array}{c}8.1 \\
(0.3)\end{array}$ & $\begin{array}{c}0.5 \\
(0.1)\end{array}$ & $\begin{array}{c}1.0 \\
(0.1)\end{array}$ & $\begin{array}{r}6.3 \\
(0.2)\end{array}$ & $\begin{array}{l}58.5 \\
(0.8)\end{array}$ & $\begin{array}{c}1.0 \\
(0.1)\end{array}$ & $\begin{array}{r}7.3 \\
(0.6)\end{array}$ \\
\hline 4.4 Strawberry Mall & $\begin{array}{l}21.2 \\
(0.3)\end{array}$ & $\begin{array}{l}10.1 \\
(0.3)\end{array}$ & $\begin{array}{c}2.8 \\
(0.3)\end{array}$ & $\begin{array}{r}0.8 \\
(0.1)\end{array}$ & $\begin{array}{c}5.7 \\
(0.3)\end{array}$ & $\begin{array}{l}52.8 \\
(0.3)\end{array}$ & $\begin{array}{c}1.0 \\
(0.1)\end{array}$ & $\begin{array}{c}5.4 \\
(0.1)\end{array}$ \\
\hline 4.5 Cinco Ranch & $\begin{array}{l}22.4 \\
(0.4)\end{array}$ & $\begin{array}{l}17.2 \\
(0.2)\end{array}$ & $\begin{array}{c}1.3 \\
(0.1)\end{array}$ & $\begin{array}{c}2.9 \\
(0.1)\end{array}$ & $\begin{array}{c}6.1 \\
(0.3)\end{array}$ & $\begin{array}{l}43.5 \\
(0.7)\end{array}$ & $\begin{array}{c}0.8 \\
(0.2)\end{array}$ & $\begin{array}{c}5.8 \\
(0.4)\end{array}$ \\
\hline 4.6 Sugarland & $\begin{array}{c}7.8 \\
(0.3)\end{array}$ & $\begin{array}{l}11.4 \\
(0.4)\end{array}$ & $\begin{array}{c}0.0 \\
(0.0)\end{array}$ & $\begin{array}{c}1.6 \\
(0.2)\end{array}$ & $\begin{array}{c}5.5 \\
(0.3)\end{array}$ & $\begin{array}{l}65.2 \\
(0.4)\end{array}$ & $\begin{array}{c}0.8 \\
(0.1)\end{array}$ & $\begin{array}{c}7.8 \\
(0.3)\end{array}$ \\
\hline
\end{tabular}




\section{$5 \quad$ Extrapolation to Regional Scale}

We extrapolated the results from this small-scale analysis to the Greater Houston-Galveston (HG) region, roughly corresponding to the 8 counties area, including and surrounding Harris County, using existing LULC databases. For this purpose, the GLOBEIS model LULC was used as a template to map the results from the orthophoto analysis to the greater HG region. Table 8 shows the distribution of urban LULC in the HG region, according to the GLOBEIS model database. The table shows only urban categories and the total area $(100 \%)$ is $3433 \mathrm{~km}^{2}$.

Table 8. GLOBEIS LULC in the Houston-Galveston area.

\begin{tabular}{|l|l|c|}
\hline $\begin{array}{l}\text { GLOBEIS } \\
\text { LULC ID } \\
\text { (Urban) }\end{array}$ & LULC & \% Area \\
\hline 11 & Residential & 51.9 \\
\hline 12 & Commercial/Services & 6.8 \\
\hline 13 & Industry & 12.3 \\
\hline 14 & University/Institutional & 1.5 \\
\hline 15 & Transportation/Communication & 2.9 \\
\hline 16 & Vegetation/forest & 8.2 \\
\hline 17 & Water & 0 \\
\hline 18 & Vacant/undeveloped & 16.4 \\
\hline 19 & Mixed & 0 \\
\hline
\end{tabular}

However, in order to keep the LULC classification consistent with that we used in other regions, e.g., Sacramento, Chicago, and Salt Lake City, the GLOBEIS model LULC in Table 8 were recast to match the urban USGS LULC classification, which was the basis we used in these other regions. These are shown in Table 9.

Table 9. Recast of Houston-Galveston GLOBEIS LULC into USGS LULC classification.

\begin{tabular}{|l|l|c|}
\hline $\begin{array}{l}\text { USGS } \\
\text { LULC ID } \\
\text { (Urban) }\end{array}$ & LULC & $\begin{array}{l}\% \\
\text { Area }\end{array}$ \\
\hline 11 & Residential & 56.1 \\
\hline 12 & Commercial/Services & 5.1 \\
\hline 13 & Industrial & 9.3 \\
\hline 14 & Transportation/Communication & 2.9 \\
\hline 15 & Industrial and commercial & 4.8 \\
\hline 16 & Mixed urban/built up & 3.5 \\
\hline 17 & Other mixed urban or built up & 18.3 \\
\hline
\end{tabular}

In this case, GLOBEIS LULC 14 was mapped into USGS LULC 16, whereas GLOBEIS LULC 16 was mapped into USGS LULC 11, 16, and 17 (additional 4.2\%, 2\%, and 2\% respectively). Finally, GLOBEIS LULC 18 was mapped into USGS LULC 17 and one fourth of each of GLOBEIS 12 and 13 was mapped into USGS LULC 15. 
Table 10 summarizes the assignments of the observed land-use categories (OLUC) in the Houston-Galveston area to the USGS Land-Use/Land-Cover (LULC) categories. Since our aerial orthophotos were mostly concentrated in urban areas, we have several samples of residential and commercial categories and only limited samples for industrial, industrial/commercial, and mixed urban or built-up land. For "transportation/communication" we used the fabric estimates for Chicago metropolitan area (Akbari and Rose 2001b). For "mixed urban or built-up land" and "other mixed urban or built-up land," we assigned the areas based on our best judgments.

The average characteristics (percent of areas) of various LULC categories are listed in Table 11. The USGS LULC categories presented in Table 11 are summarized in Figure 24a. The data indicate that about $56 \%$ of the $3430 \mathrm{~km}^{2}$ analyzed in this study is residential. Commercial service and industrial areas taken together constitute another $19 \%$ of the total area.

As shown in Table 11, tree cover in Houston is highest in the Residential land-use category (11), at $17 \%$. It is followed by the Other Mixed Urban or Built-Up Land (17) and Mixed Urban or BuiltUp Land (16) categories at 8\%. This is in contrast, for example, with Sacramento where category 11 has tree cover of $15 \%$ and categories 16 and 17 have a tree cover of $27 \%$. The percentage of roof cover differs less than 10\% for all of the land-use categories except for categories 13 and 14. In the Residential (11) category, roads covered $10 \%$ on average and grass covers $32 \%$ of the area. Also notable is the high percentage of parking area in almost all categories but residential areas of Houston. Interestingly, in Houston the percentage of grassy areas is higher for all land-use categories.

The area for each LULC category for the entire Houston region simulation domain was then calculated (See Table 12). Of about $3430 \mathrm{~km}^{2}$ categorized as urban area, approximately $56 \%$ is residential. The total roof area as seen above the canopy comprises about $21 \%$ of the urban area (about $736 \mathrm{~km}^{2}$ ), total paved surfaces (roads, parking areas, sidewalks) comprise 29\% (about 997 $\mathrm{km}^{2}$ ), and total vegetated area about $39 \%\left(1325 \mathrm{~km}^{2}\right.$ ) (see Figure $24 \mathbf{b}$ ). The actual total roof area as seen under the canopy comprises about $21 \%$ of the urban area (about $732 \mathrm{~km}^{2}$ ), total paved surfaces (roads, parking areas, sidewalks, and private surfaces) comprise 29\% (about $1002 \mathrm{~km}^{2}$ ), and total vegetated area (only grass and bushes) about 37\% (1274 $\mathrm{km}^{2}$ ) (see Figure 24c). Tables 13 and 14 expand the data presented in Tables 1 and 2 to include Greater Houston.

To provide a rough estimate of the potential for planting additional trees in Houston, we guess that trees can potentially shade $20 \%$ of the roof area, $20 \%$ of roads, $50 \%$ of sidewalks, and $30 \%$ of parking areas; the potential exists for a $12 \%$ increase in tree cover for the entire city. An additional tree cover of $12 \%$ is about $410 \mathrm{~km}^{2}$ of the urban area. Assuming that the horizontal cross-section of an average mature tree can reach about $50 \mathrm{~m}^{2}$, these calculations suggest a potential for an additional 8 million trees in Houston. As climate and air-quality simulations have indicated, 8 million additional trees can have a significant impact on cooling Houston and improving ozone air quality. Houston Advanced Research Center (HARC) and other local organization in Houston have suggested that a more realistic figure would be around 4 million additional trees in the region.

The potential is also large for increasing the albedo of Houston. Impermeable surfaces (roofs and pavements) comprise about $50 \%$ of the total area of Houston. For illustration purposes, we calculate potentials for changing the albedo of Houston assuming two different scenarios. One scenario assumes a modest change in the albedo of impermeable surfaces; the other assumes an aggressive increase in albedo of all surfaces. These scenarios are summarized in Table 15. The resulting change in the albedo of the city is summarized in Table 16. Under the low-albedo scenario, the overall residential and commercial albedos change by 0.055 and 0.095 , respectively; the average albedo of the city increases by 0.076 . For the high-albedo scenario, the overall albedo of residential and commercial areas changes by 0.121 and 0.198 , and the average albedo of the city is increased by 
0.135. Like urban vegetation, increasing albedo would reduce the ambient temperature and in turn can reduce ozone concentration in the city.

These examples are used for illustration purposes only. For climate and air-quality simulations where both albedo and the vegetation fraction are increased, the overall changes in albedo and vegetation differ from these calculations. Certainly though, combinations of changes in both albedo and vegetation would have benefits in lowering the ambient air temperature and thus potentially decreasing ozone levels. In the latest meteorological and air-quality modeling for Houston (Taha, 2002), the assumed average increases in albedo were 0.02 and 0.04 (corresponding to the low- and high-albedo scenarios mentioned above). For vegetation, only 4 million trees were "added" in the simulations.

\section{Discussion}

This report described the characterization of the Houston urban area in terms of surface-type makeup. The data obtained from the Houston, Salt Lake City, and Sacramento flyovers suggest that it is possible to characterize the fabric of a region of interest accurately and cost-effectively. However, depending on the purpose of the application and the availability of funds, a separate decision must be made for each UHIPP city or region as to the most appropriate combination of data sources, i.e., a combination of aerial photographs, USGS LULC, and satellite/aircraft data such as DAIS, ATLAS, Landsat, or AVHRR.

Based on the studies performed for Houston, Salt Lake City, and Sacramento, it is estimated that in cities the size of Houston, Salt Lake City, and Sacramento, between 10 and $50 \mathrm{~km}^{2}$ of aerial photography would suffice for reasonably good characterization of the fabric. At a rate of \$140-200 per $\mathrm{km}^{2}$, the total cost of the flight and data would amount to about $\$ 7,000-10,000$ per region. Usually a minimum order is required (by the flight company) of over $\$ 10,000$; so for small data selections the per- $\mathrm{km}^{2}$ price given here is therefore not applicable because of fixed costs associated with overflights.

The companies that perform this type of data collection are flexible in dealing with and designing flight paths and selecting flight times that suit the needs of projects such as this study. This permits better planning of the flight track and its timing thereby minimizing shadows and focusing on areas of interest, e.g., specific land-uses or land-covers. This process is recommended for any city interested in implementing heat-island reduction strategies or in modeling their meteorological and air-quality aspects.

Apart from possible human error in analyzing the data (minimized to the extent possible by repeating the analysis and developing standard analytical processes and protocols), there exist two other possible sources of error in determining the fabric of a city. First, the error introduced by use of the Monte-Carlo approach is typically less than 1\% (for a 95\% confidence interval). This error can be controlled by studying the relationship between the sample size and standard error of estimate for each aerial frame studied. Second, errors may be introduced when mapping the fabric data obtained from aerial orthophotos into USGS LULC categories. We performed an analysis of this source of error using imagery from one of the areas acquired in the Salt Lake City flight and found it to be insignificant (Akbari and Rose 2001b). Potential errors related to the accuracy of USGS LULC data are not addressed in this report. Finally, USGS data are typically older than the recent aerial orthophotos, thereby introducing discrepancies between USGS data and aerial orthophotos. Another issue associated with USGS data, is the error introduced by the limited range of categories in the dataset. If the data set included the differing types of residential (multi-family and single-family), commercial (office parks and shopping), and industrial (intensive and light) categories, the 
extrapolation would yield more accurate results. The 200-m x 200-m cell size of the USGS LULC data is another limitation, since it does not capture all variations in the urban landscape.

Table 10. USGS LULC description for urban area and related observed land-use categories (OLUC).

\begin{tabular}{|c|l|l|}
\hline USGS LULC & Description & OLUC Included \\
\hline 11 & Residential & $4.1-4.6$ \\
12 & Commercial/Service & $3.1-3.5$ \\
13 & Industrial & $2.1-2.4$ \\
14 & Transportation/Communications & Used Chicago Data \\
15 & Industrial and Commercial & $2.2-2.3,3.4-3.5$ \\
16 & Mixed Urban or Built-Up Land & $1,2.2-2.3,3.4-3.5,4.1-4.2$ \\
17 & Other Mixed Urban or Built-Up Land & $1,2.2-2.3,3.4-3.5,4.1-4.2$ \\
\hline
\end{tabular}

Table 11. Calculated surface area percentages by USGS LULC categories.

\begin{tabular}{|c|c|c|c|c|c|c|c|c|}
\hline USGS LULC & ن & $\stackrel{4}{\mathscr{8}}$ & 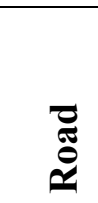 & 瓷 & 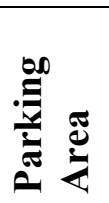 & ֻ & 就 & 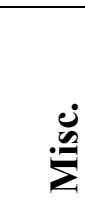 \\
\hline 11. Residential & 16.9 & 20.5 & 9.8 & 5.0 & 9.9 & 1.7 & 32.0 & 4.3 \\
\hline 12. Commercial/Service & 6.9 & 29.2 & 12.8 & 1.4 & 30.4 & 2.8 & 11.0 & 5.6 \\
\hline 13. Industrial & 7.0 & 15.3 & 6.2 & 0.1 & 18.6 & 16.4 & 25.4 & 10.9 \\
\hline 14. Transportation/Communications & 0.8 & 10.4 & 32.5 & 0.0 & 19.1 & 4.9 & 9.0 & 23.2 \\
\hline 15. Industrial and Commercial & 7.5 & 26.5 & 6.3 & 0.3 & 25.3 & 7.8 & 16.9 & 9.6 \\
\hline 16. Mixed Urban or Built-Up Land & 7.9 & 24.9 & 6.8 & 1.5 & 26.5 & 6.0 & 18.8 & 7.6 \\
\hline 17. Other Mixed Urban or Built-Up Land & 7.9 & 24.9 & 6.8 & 1.5 & 26.5 & 6.0 & 18.8 & 7.6 \\
\hline
\end{tabular}


Table 12. Total surface areas $\left(\mathrm{km}^{2}\right)$ in Greater Houston (by Category).

\begin{tabular}{|c|c|c|c|c|c|c|c|c|c|}
\hline USGS LULC & 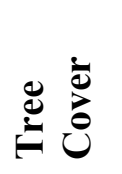 & 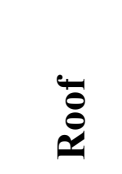 & 气ूँ & 莀 & 苞 & 氞 & שै & $\stackrel{\dot{0}}{\ddot{z}}$ & $\stackrel{\bar{\sigma}}{\stackrel{\pi}{\theta}}$ \\
\hline 11. Residential & 324.5 & 395.5 & 189.4 & 95.7 & 190.0 & 32.1 & 616.6 & 82.5 & 1926 \\
\hline $\begin{array}{l}\text { 12. Commercial/ } \\
\text { Service }\end{array}$ & 12.1 & 51.1 & 22.3 & 2.4 & 53.3 & 4.9 & 19.3 & 9.7 & 175 \\
\hline 13. Industrial & 22.3 & 48.9 & 19.9 & 0.4 & 59.2 & 52.4 & 81.2 & 34.9 & 319 \\
\hline $\begin{array}{l}\text { 14. Transportation/ } \\
\text { Communications }\end{array}$ & 0.8 & 10.4 & 32.4 & 0.0 & 19.0 & 4.9 & 9.0 & 23.1 & 100 \\
\hline $\begin{array}{l}\text { 15. Industrial and } \\
\text { Commercial }\end{array}$ & 12.3 & 43.6 & 10.3 & 0.5 & 41.7 & 12.9 & 27.8 & 15.8 & 165 \\
\hline $\begin{array}{l}\text { 16. Mixed Urban or } \\
\text { Built-Up Land } \\
\text { 17. Other Mixed }\end{array}$ & 9.5 & 30.0 & 8.2 & 1.8 & 31.9 & 7.2 & 22.6 & 9.1 & 120 \\
\hline $\begin{array}{l}\text { Urban or Built-Up } \\
\text { Land }\end{array}$ & 49.5 & 156.7 & 43.0 & 9.2 & 166.7 & 37.4 & 118.0 & 47.7 & 628 \\
\hline \multirow[t]{2}{*}{ Total Urban Area } & & & & & & & & & \\
\hline & 430.9 & 736.0 & 325.5 & 109.9 & 561.8 & 151.7 & 894.5 & 222.9 & 3433 \\
\hline
\end{tabular}

Table 13. USGS land use/land cover (LULC) percentages for three cities: Sacramento, CA, Salt Lake City, UT, Chicago, IL, and Houston, TX.

\begin{tabular}{|lcccc|}
\hline & Sacramento & Salt Lake City & Chicago & Houston \\
\hline Total Metropolitan Area $\left.\mathbf{( k m}^{2}\right)$ & 809 & 624 & 2521 & 3433 \\
LULC (\%) & & & & \\
Residential & 49.3 & 59.1 & 53.5 & 56.1 \\
Commercial/Service & 17.1 & 15.0 & 19.2 & 5.1 \\
Industrial & 7.2 & 4.9 & 11.5 & 9.3 \\
Transportation/Communication & 11.4 & 9.8 & 7.7 & 2.9 \\
Industrial and Commercial & 0.3 & 0.0 & 0.1 & 4.8 \\
Mixed Urban or Built-up Land & 5.2 & 1.9 & 0.4 & 3.5 \\
Other Mixed Urban or Built-up Land & 9.5 & 9.4 & 7.6 & 18.3 \\
\hline
\end{tabular}


Table 14. Comparison of the fabric of Salt Lake City, UT, Sacramento, CA, Chicago, IL, and Houston, TX.

\begin{tabular}{|lcccr|}
\hline City & Vegetation & Roofs & Pavements & Other \\
\hline Above-the-canopy & & & & \\
Metropolitan Salt Lake City & 40.9 & 19.0 & 30.3 & 9.7 \\
Metropolitan Sacramento & 28.6 & 18.7 & 38.5 & 14.3 \\
Metropolitan Chicago & 30.5 & 24.8 & 33.7 & 11.0 \\
Greater Houston & 38.6 & 21.4 & 29.0 & 10.9 \\
Residential Salt Lake City & 46.6 & 19.7 & 25.3 & 8.5 \\
Residential Sacramento & 39.2 & 19.4 & 25.6 & 15.8 \\
Residential Chicago & 44.3 & 25.9 & 25.7 & 4.1 \\
Residential Houston & 48.9 & 20.5 & 24.7 & 6.0 \\
Under-the-canopy & & & & \\
Metropolitan Salt Lake City & 33.3 & 21.9 & 36.4 & 8.5 \\
Metropolitan Sacramento & 20.3 & 19.7 & 44.5 & 15.4 \\
Metropolitan Chicago & 26.7 & 24.8 & 37.1 & 11.4 \\
Greater Houston & 37.1 & 21.3 & 29.2 & 12.4 \\
Residential Salt Lake City & 38.6 & 23.9 & 31.6 & 6.0 \\
Residential Sacramento & 32.8 & 19.8 & 30.6 & 16.8 \\
Residential Chicago & 35.8 & 26.9 & 29.2 & 8.1 \\
Residential Houston & 47.4 & 21.1 & 23.9 & 7.6 \\
\hline
\end{tabular}

Table 15. Two albedo modification scenarios.

\begin{tabular}{|l|c|c|}
\hline Surface-Type & High-Albedo Change & Low-Albedo Change \\
\hline Residential Roofs & 0.3 & 0.1 \\
Commercial Roofs & 0.4 & 0.2 \\
Roads & 0.25 & 0.15 \\
Parking Areas & 0.25 & 0.15 \\
Sidewalks & 0.2 & 0.1 \\
\hline
\end{tabular}


Table 16. Net change in the albedo of Houston for high- and low-albedo scenarios.

\begin{tabular}{|l|c|c|}
\hline Area & High-Albedo Scenario & Low-Albedo Scenario \\
\hline Residential & 0.121 & 0.055 \\
Commercial/Service & 0.198 & 0.095 \\
Industrial & 0.108 & 0.053 \\
Transportation/Communications & 0.160 & 0.088 \\
Industrial and Commercial & 0.159 & 0.074 \\
Mixed Urban or Built-Up Land & 0.161 & 0.076 \\
Other Mixed Urban or Built-Up Land & 0.161 & 0.076 \\
\hline Average over the Entire Area & 0.135 & 0.063 \\
\hline
\end{tabular}

\section{$7 \quad$ Summary and Conclusions}

To estimate the impact of light-colored surfaces (roofs and pavements) and urban reforestation (trees, grass, shrubs) on the meteorology and air quality of a city, it is essential to characterize accurately the surface components of an urban area. This consists of the characterization of the area fraction of various surface-types and the vegetative cover. In this report, a method was discussed for developing data on surface-type distribution and city-fabric makeup (percentage of various surface-types) using aerial color orthophotography. We devised a semi-automatic Monte-Carlo method to sample the data and visually identify the surface-type for each pixel. We then applied this method to the HoustonGalveston, TX region. The color aerial orthophotos for Houston covered a total of about $52 \mathrm{~km}^{2}$ (20 $\mathrm{mi}^{2}$ ). At $0.30-\mathrm{m}$ resolution, approximately $5.8 \times 10^{8}$ pixels of data were available for analysis.

Results from this analysis suggest several possible land-use and surface-type classifications for the Houston area. We examined four major land-use types: 1) commercial, 2) industrial, 3) educational, and 4) residential. For each of these major land-uses, up to 30 different surface-types were identified and their fractional areas computed. In addition, a method was devised to extrapolate these results from neighborhood to metropolitan scales. The method relies on using GLOBEIS and USGS land-use/land-cover data to map the area distributions from one classification system to another.

In the commercial area of downtown Houston, a top-down view (above the canopy) shows that vegetation covers $13 \%$ of the area, whereas roofs cover $23 \%$ and paved surfaces (roads, parking areas, and sidewalks) $55 \%$. The under-the-canopy fabric consists of $65 \%$ paved surfaces, $24 \%$ roofs, and $3 \%$ grass. In the industrial areas, vegetation covers $25 \%$ of the area, whereas roofs cover $19 \%$, and paved surfaces $46 \%$. The surface-type percentages in new commercial areas were $19 \%$ trees, $23 \%$ roofs, and $55 \%$ paved surfaces. Residential areas exhibit a wide range of percentages among their various surface-types. On the average, vegetation covers about $46 \%$ of the area (ranging from 44 to $52 \%$ ), roofs about 20\% (15-24\%), and paved surfaces about 25\% (21-27\%). For the most part, trees shade streets, parking lots, grass, and sidewalks. Under the canopy, the percentage of paved surfaces is significantly higher. In most non-residential areas, paved surfaces cover $25-37 \%$ of the area. In residential areas, paved surfaces cover an average of about $32 \%$.

Land-use/land-cover (LULC) data from GLOBEIS (University of Texas) and the USGS were used to extrapolate these results from neighborhood scales to regional Houston. For an area of roughly $3430 \mathrm{~km}^{2}$, including most of Greater Houston, about $56 \%$ is residential. The total roof area as seen above the canopy comprises about $21 \%$ of the urban area (about $736 \mathrm{~km}^{2}$ ), total paved 
surfaces (roads, parking areas, sidewalks) comprise 29\% (about $997 \mathrm{~km}^{2}$ ), and total vegetated area about $39 \%\left(1325 \mathrm{~km}^{2}\right)$. The actual total roof area as seen under the canopy comprises about $21 \%$ of the urban area (about $732 \mathrm{~km}^{2}$ ), total paved surfaces (roads, parking areas, sidewalks, and privatelyowned surfaces) comprise $29 \%$ (about $1002 \mathrm{~km}^{2}$ ), and total vegetated area (only grass and bushes) about $37 \%\left(1274 \mathrm{~km}^{2}\right)$.

The potential appears to be large for additional urban vegetation in Houston. If we assume that trees can potentially shade $20 \%$ of the roof area, $20 \%$ of roads, $50 \%$ of sidewalks, and $30 \%$ of parking areas, the possibility exists to increase tree cover for the entire area about $12 \%$. Additional tree cover of $12 \%$ amounts to about $410 \mathrm{~km}^{2}$ of urban forest. Assuming that the horizontal crosssection of an average mature tree can reach about $50 \mathrm{~m}^{2}$, these calculations suggest a potential for 8 million additional trees in Houston. As climate and air-quality simulations have indicated, 8 million additional trees can have a significant impact on cooling Houston and potentially improving ozone air quality.

The potential is also relatively large for increasing Houston's albedo. According to this study, impermeable surfaces (roofs and pavements) comprise about $50 \%$ of the total area in Houston. For illustration proposes, if we assume that the albedo of residential roofs can increase by 0.10 , commercial roofs by 0.20 , roads and parking areas by 0.15 , and sidewalks by 0.10 , the albedo of Houston can then be increased by about 0.07 . Like urban vegetation, increasing albedo would reduce ambient temperatures and in turn reduce ozone concentrations in the city.

In Greater Houston, a significant variation exists in the fabric of the selected for this analysis. Although an attempt was made to select areas that represent the widely divergent types of neighborhoods overall, these results should not be extrapolated to other cities or regions. Many cities are unique in their land-use patterns and construction (e.g., most urban homes on the West Coast are single-story, as opposed to two-story houses in the East). It is recommended that a similar full analysis be performed for several other cities in different regions of the country to expand our understanding of the fabric of various regions.

Additionally, results from this study and previous studies of Sacramento, California, Chicago, Illinois and Salt Lake City, Utah can be examined to see if general conclusions can be drawn about the urban fabric in these types of cities or identified land-uses. It is recommended that satellite data from the previously analyzed cities be acquired for this purpose. An examination of the similarities between the urban fabric of these cities based on combining existing satellite data and the detailed analysis of the urban fabric studies would yield more accurate land-use/land-cover maps and hence better metropolitan-area extrapolations. The use of satellite data for extrapolation would be more accurate since it can be acquired for the specific time of interest, and therefore would be more current than outdated land-use/land-cover data sets. Furthermore, time-series analysis using satellite imagery would yield information on the trends in land cover/land use that are affecting a city. Also, the use of satellite imagery would allow for the detection of variation in urban fabric for areas outlying the sample study areas collected previously. This ability of satellite data to provide information about land-cover for the entire metropolitan area instead of selected small areas would significantly improve the results of city-fabric analysis. The acquisition of satellite imagery for each of the study sites yields an additional major benefit: it could potentially allow for highly accurate urban fabric information to be derived for other cities without the need to collect of more high-resolution data. 


\section{References}

Akbari, H., L. S. Rose, and H. Taha. 1999. "Characterizing the Fabric of the Urban Environment: A Case Study of Sacramento, California," LBNL-44688, Lawrence Berkeley National Laboratory, Berkeley, California (December).

Akbari, H. and L. S. Rose. 2001a. "Characterizing the Fabric of the Urban Environment: A Case Study of Salt Lake City, Utah,” LBNL-47851, Lawrence Berkeley National Laboratory, Berkeley, California (February).

Akbari, H. and L. S. Rose. 2001b. "Characterizing the Fabric of the Urban Environment: A Case Study of Chicago, Illinois" LBNL-49275, Lawrence Berkeley National Laboratory, Berkeley, California (October).

Bureau of the Census. 1990. 1990 Census of Population and Housing. Washington, D.C.

ERDAS. 1997. ERDAS Field Guide, 4th Edition, Atlanta, Georgia, ERDAS, Inc.

Myrup, L. O. and D. L. Morgan, 1972. "Numerical Model of the Urban Atmosphere, Volume I: The City-Surface Interface," Department of Agricultural Engineering, Department of Water Science and Engineering, University of California, Davis, California 95616 (October).

Taha, H. 2002. "Potential meteorological and air-quality implications of heat-island reduction strategies (HIRS) in the Houston-Galveston TX region". LBNL / Heat Island Group Technical Note No. HIG-12-2002-1 (December). 


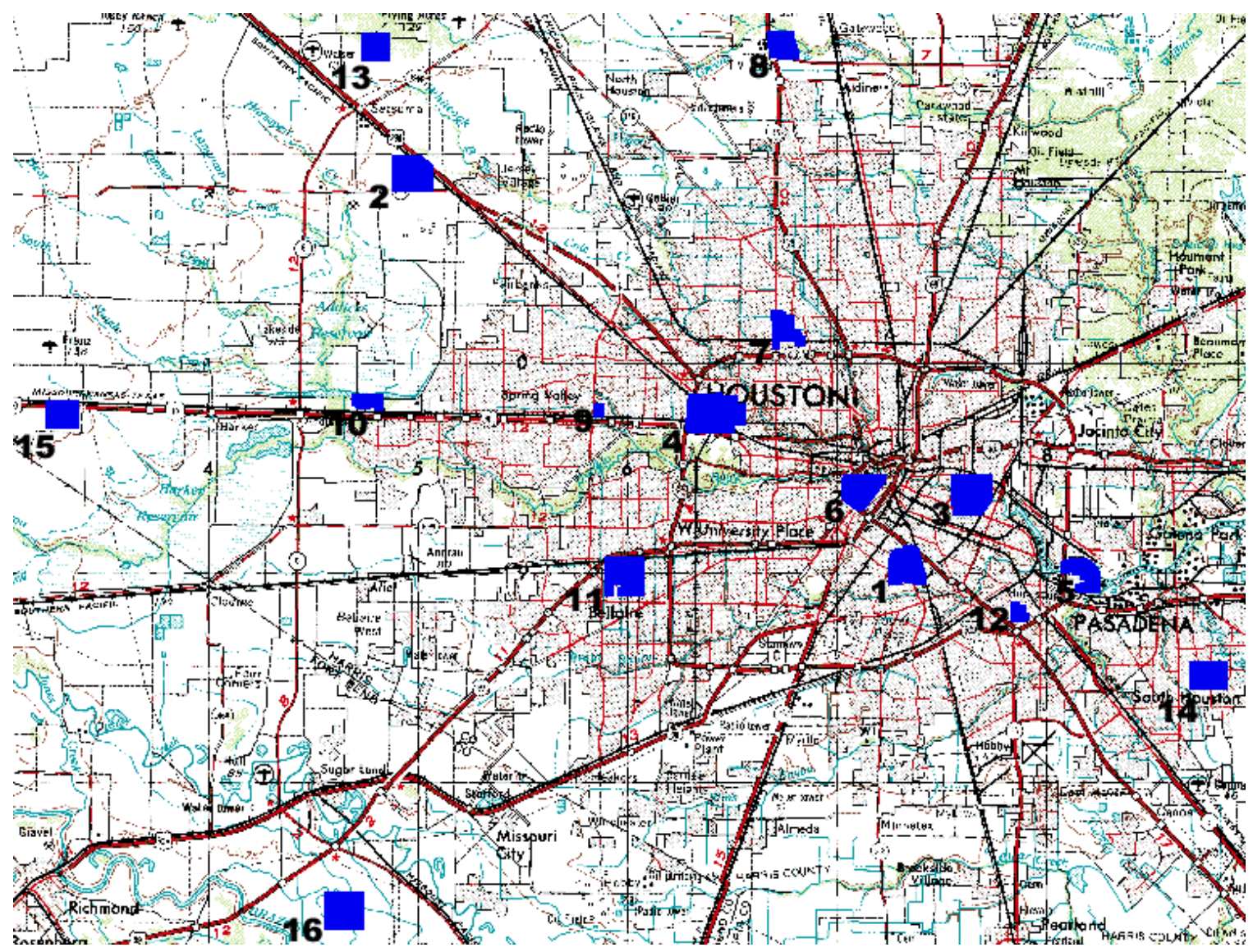

\section{Area Name}

1. University of Houston

2. West of Jersey Village

3. East of Downtown

4. Northwest of Downtown

5. Southeast of Downtown

6. Downtown

7. Garden Oaks Shopping Center

8. Greenspoint Mall

9. Bingle

10. Park Ten Place

11. Gulfton

12. Plum Creek

13. Adam School

14. Strawberry Mall

15. Cinco Ranch

16. Sugarland

Type
Educational
Industrial
Industrial
Industrial
Industrial
Commercial
Commercial
Commercial
Commercial
Commercial
Residential
Residential
Residential
Residential
Residential
Residential

Figure 1. Geographical locations of the digital aerial orthophotos taken for analysis in the Greater Houston area. 


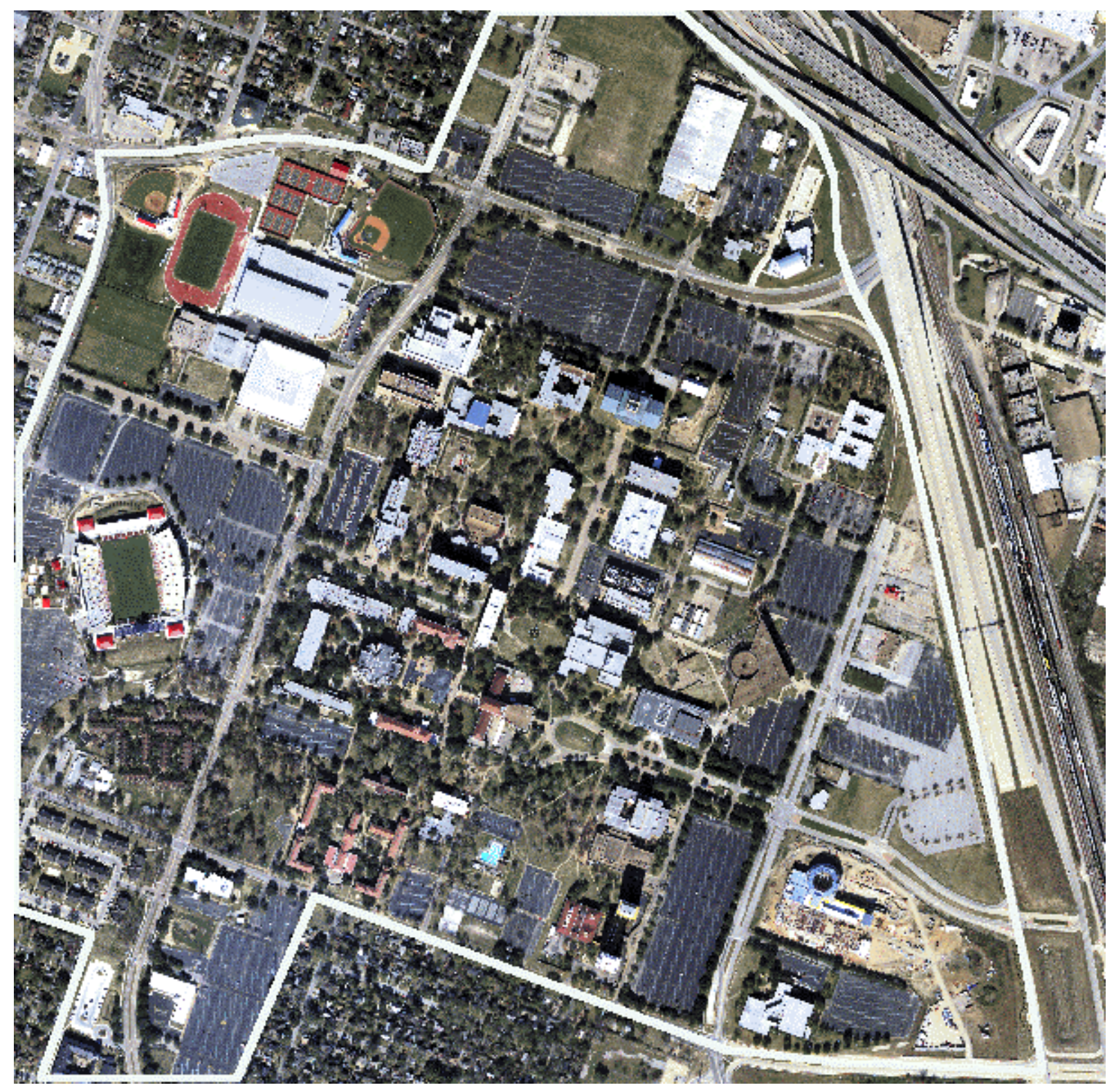

Figure 2. Aerial orthophoto of University of Houston area. 


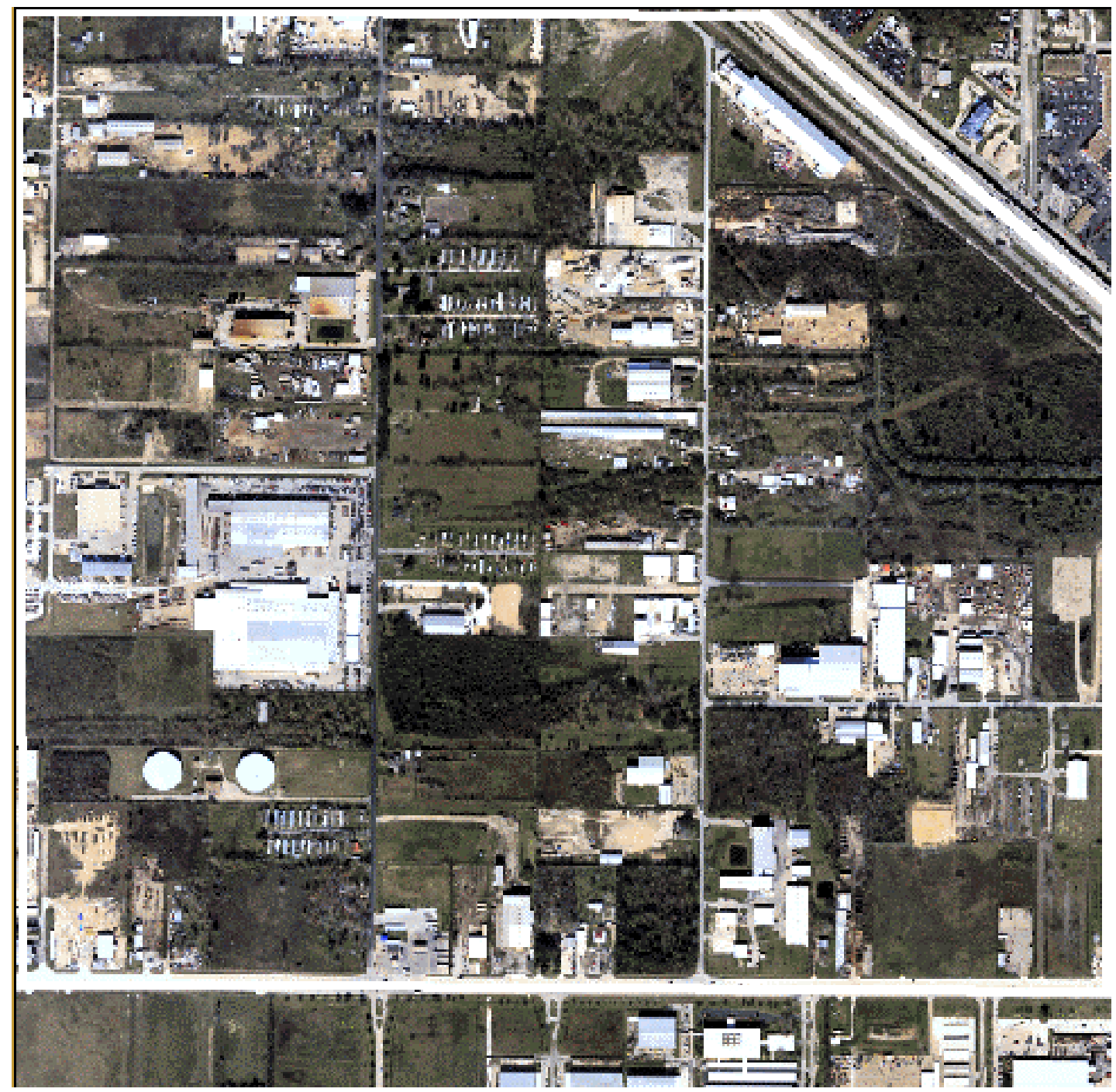

Figure 3. Aerial orthophoto of the West of Jersey Village area. 


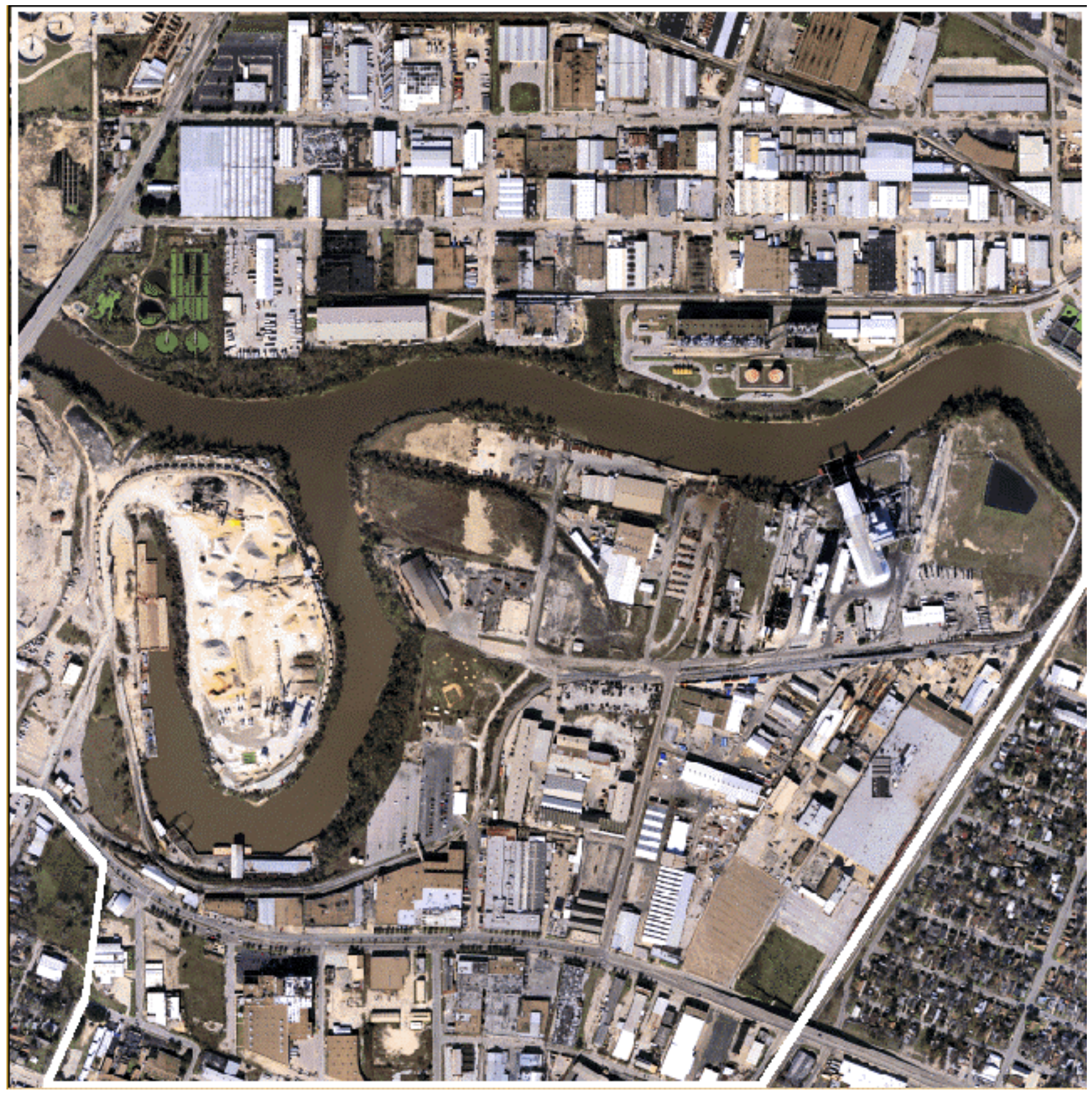

Figure 4. Aerial orthophoto of the East of Downtown Houston area. 


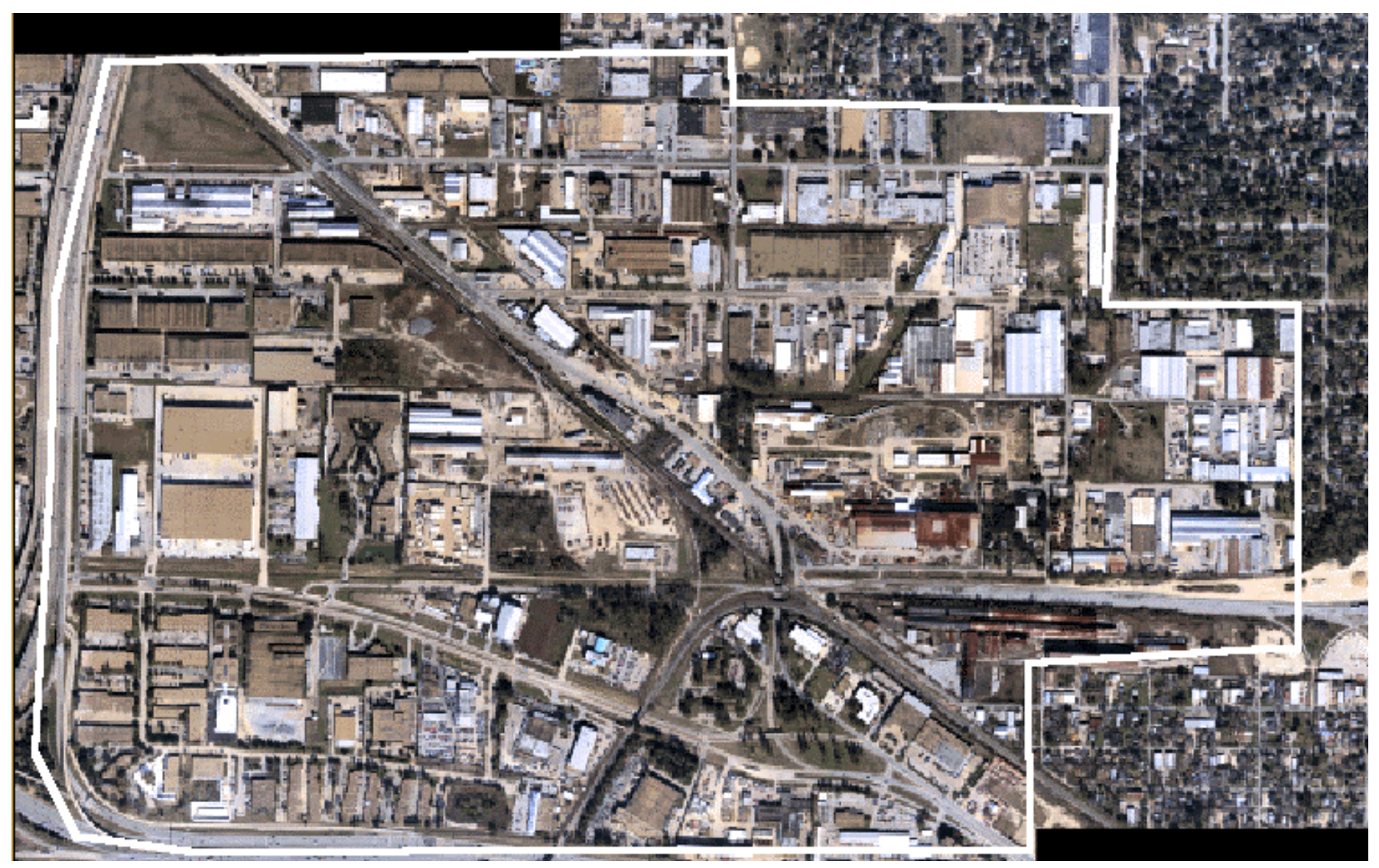

Figure 5. Aerial orthophoto of the Northwest of Downtown Houston area. 


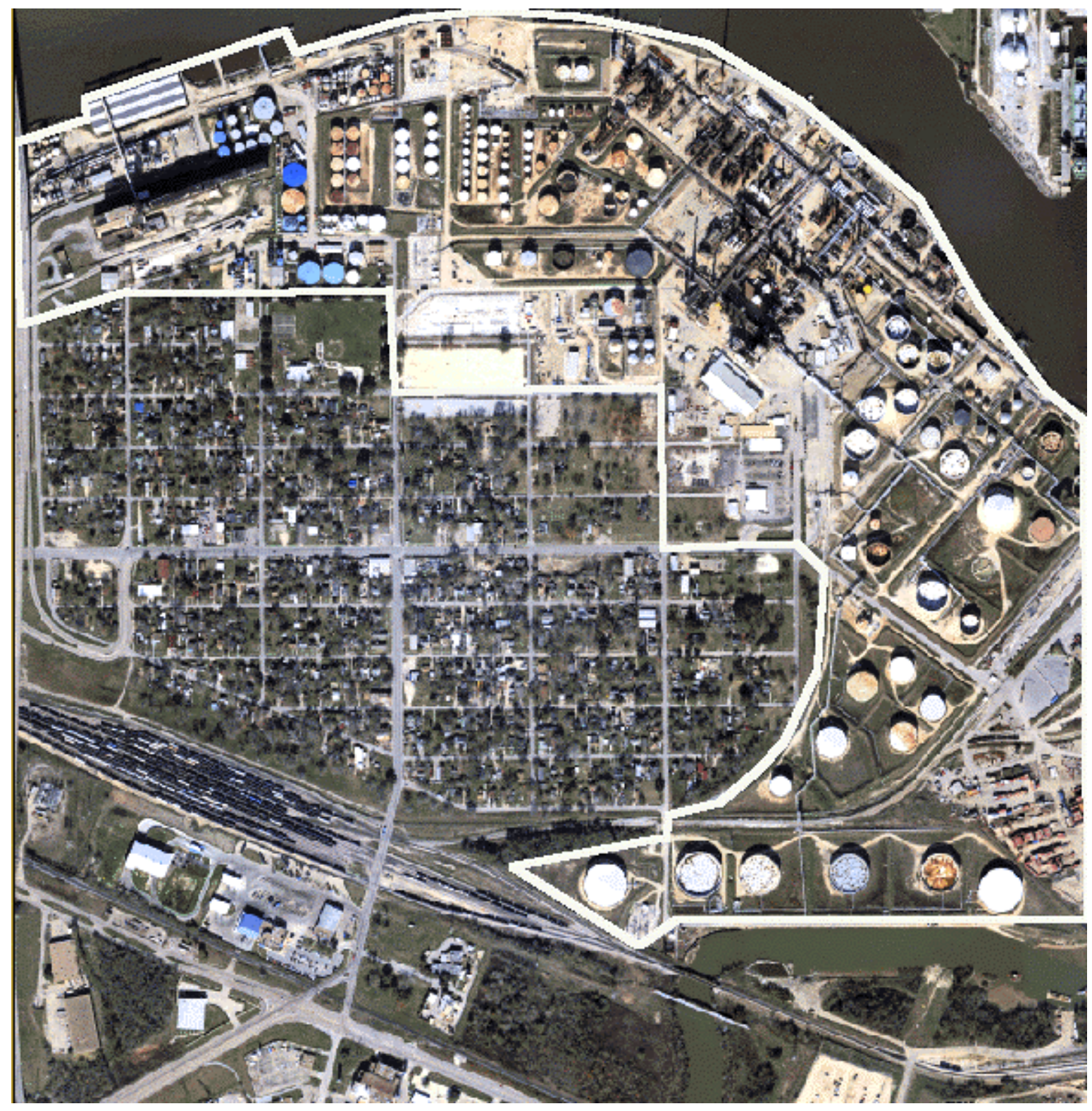

Figure 6. Aerial orthophoto of the Southeast of Downtown Houston area. 


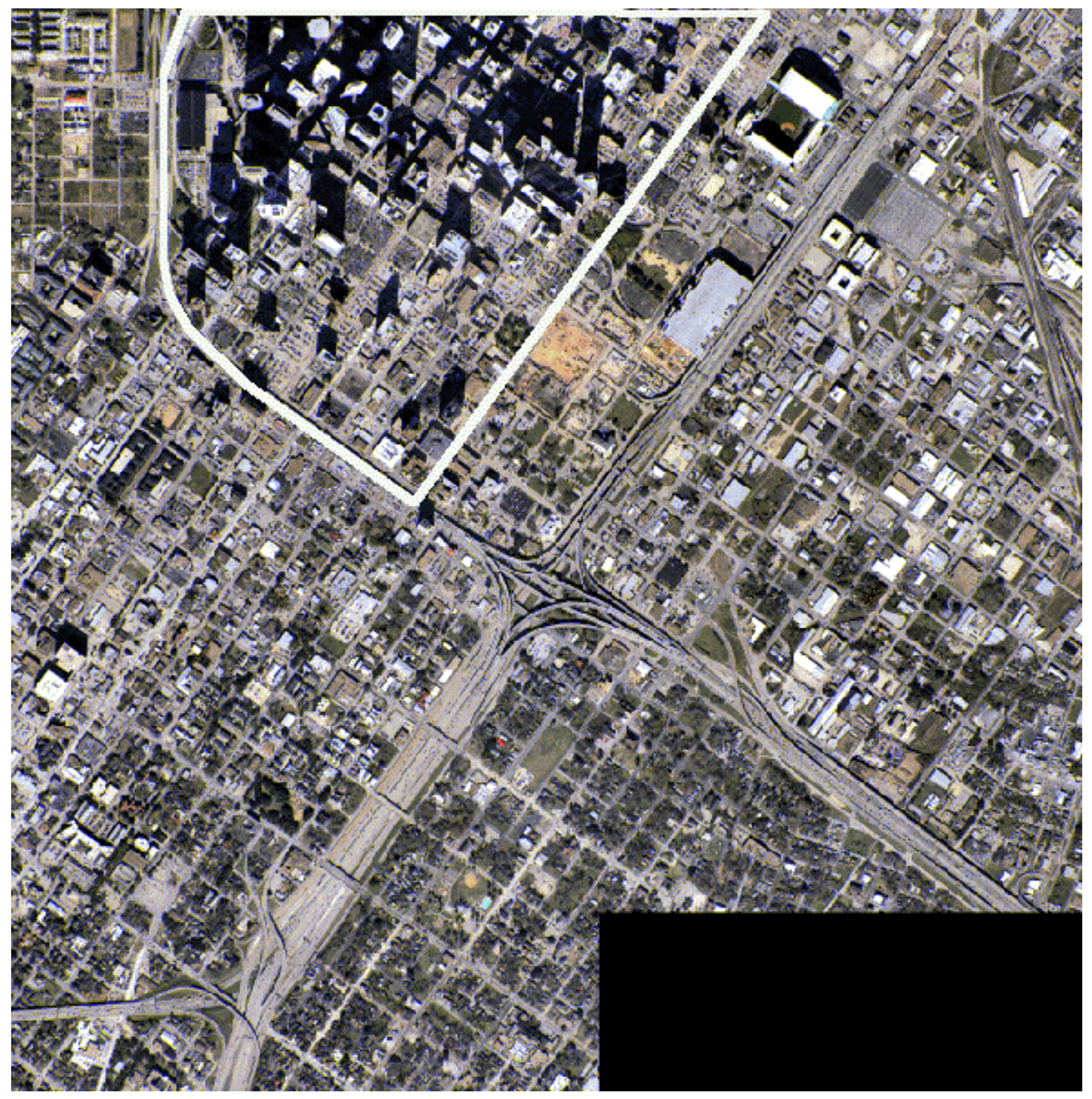

Figure 7. Aerial orthophoto of the Downtown area in Houston. 


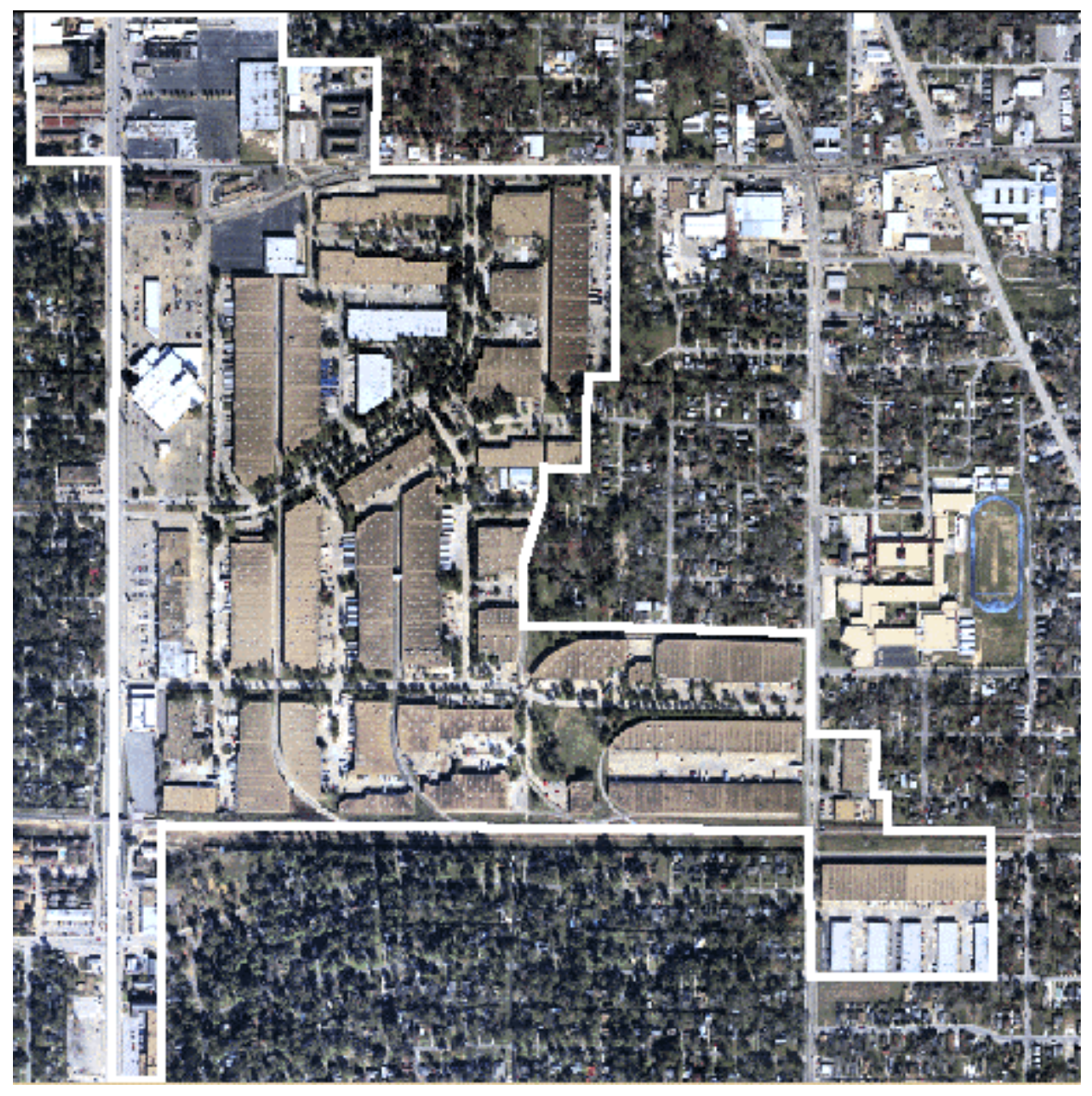

Figure 8. Aerial orthophoto of the Garden Oaks Shopping Center area. 


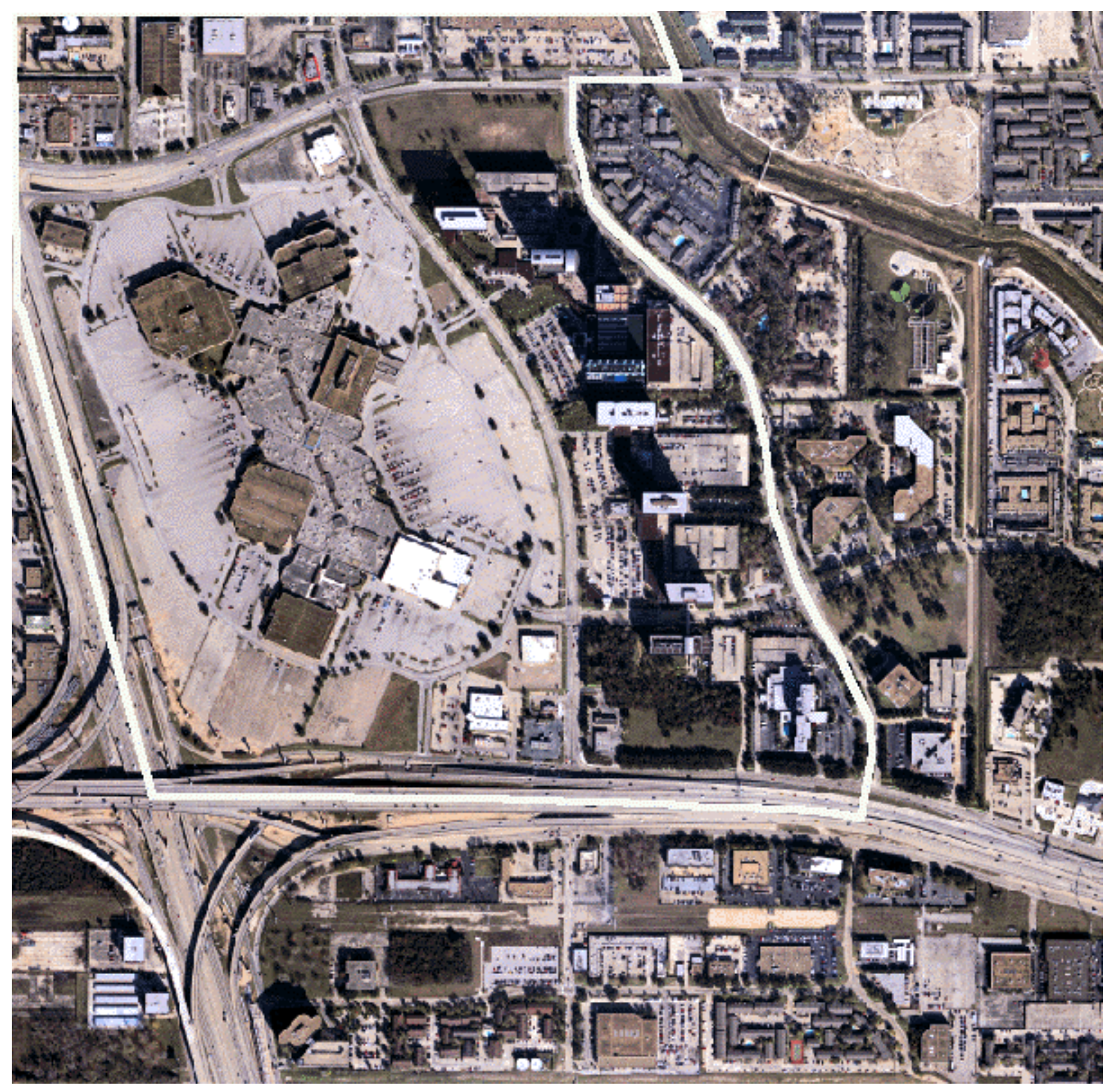

Figure 9. Aerial orthophoto of the Greenspoint Mall area. 


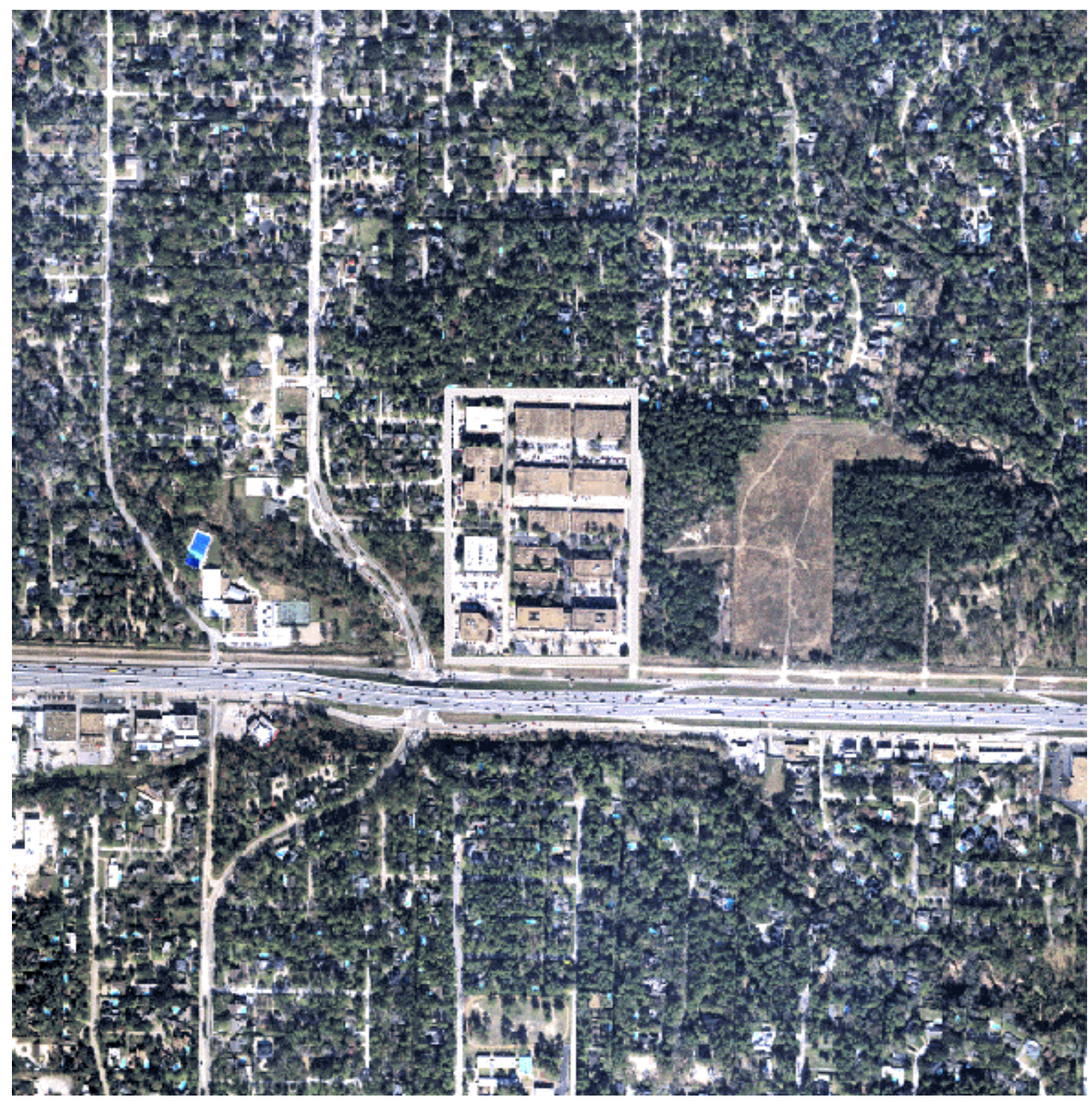

Figure 10. Aerial orthophoto of the Bingle area. 


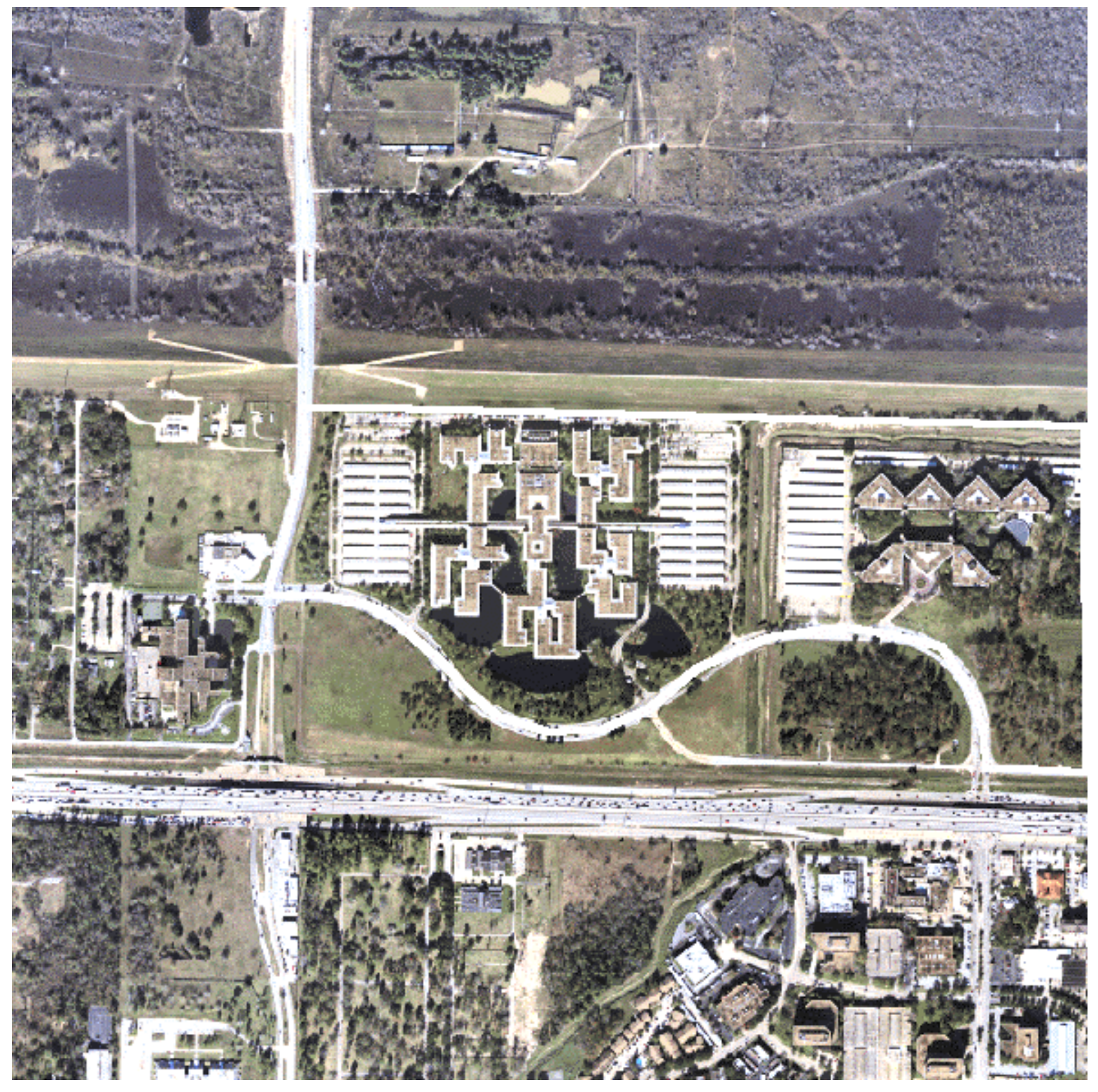

Figure 11. Aerial orthophoto of the Park Ten Place area. 


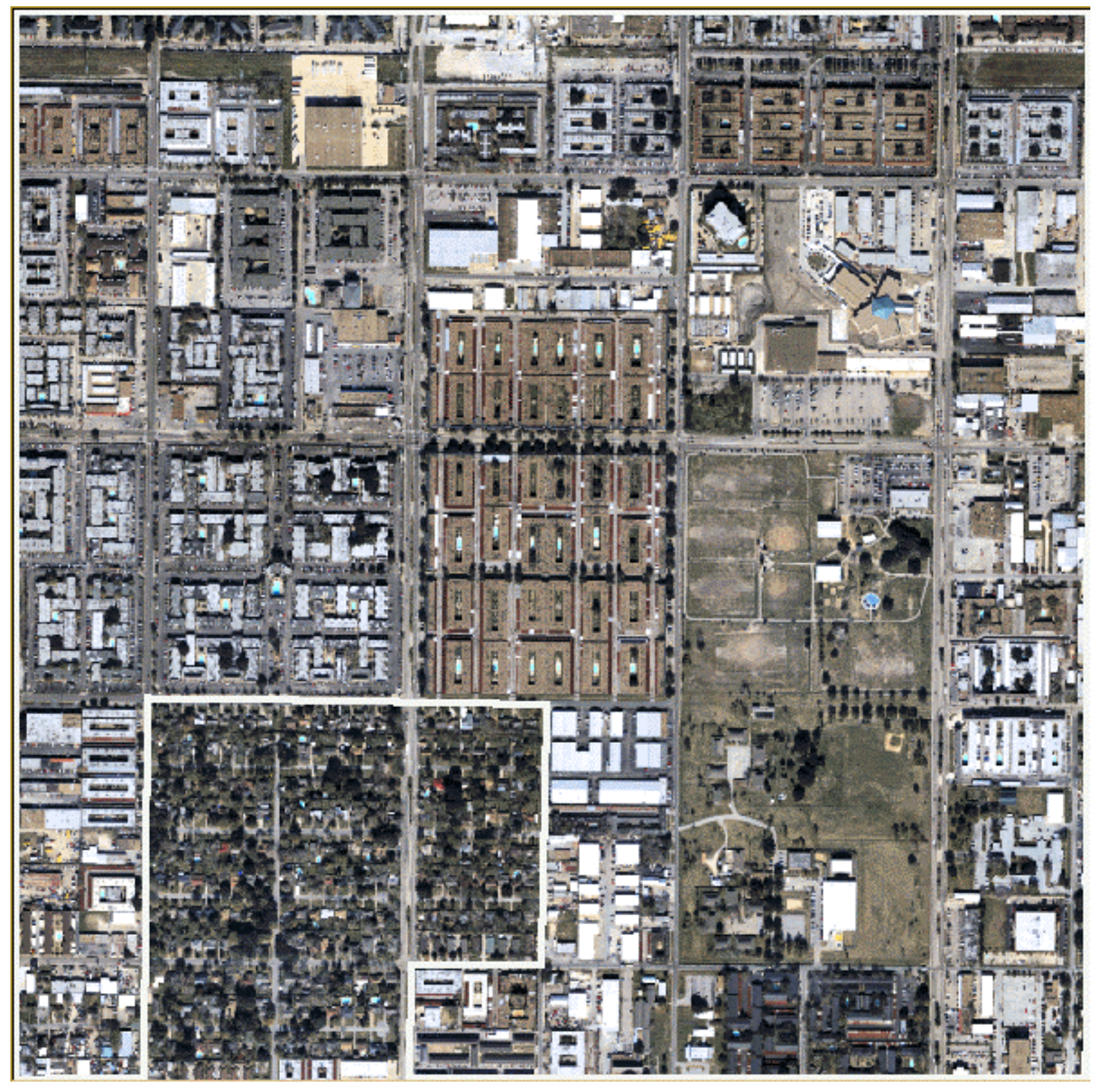

Figure 12. Aerial orthophoto of the Gulfton area. 


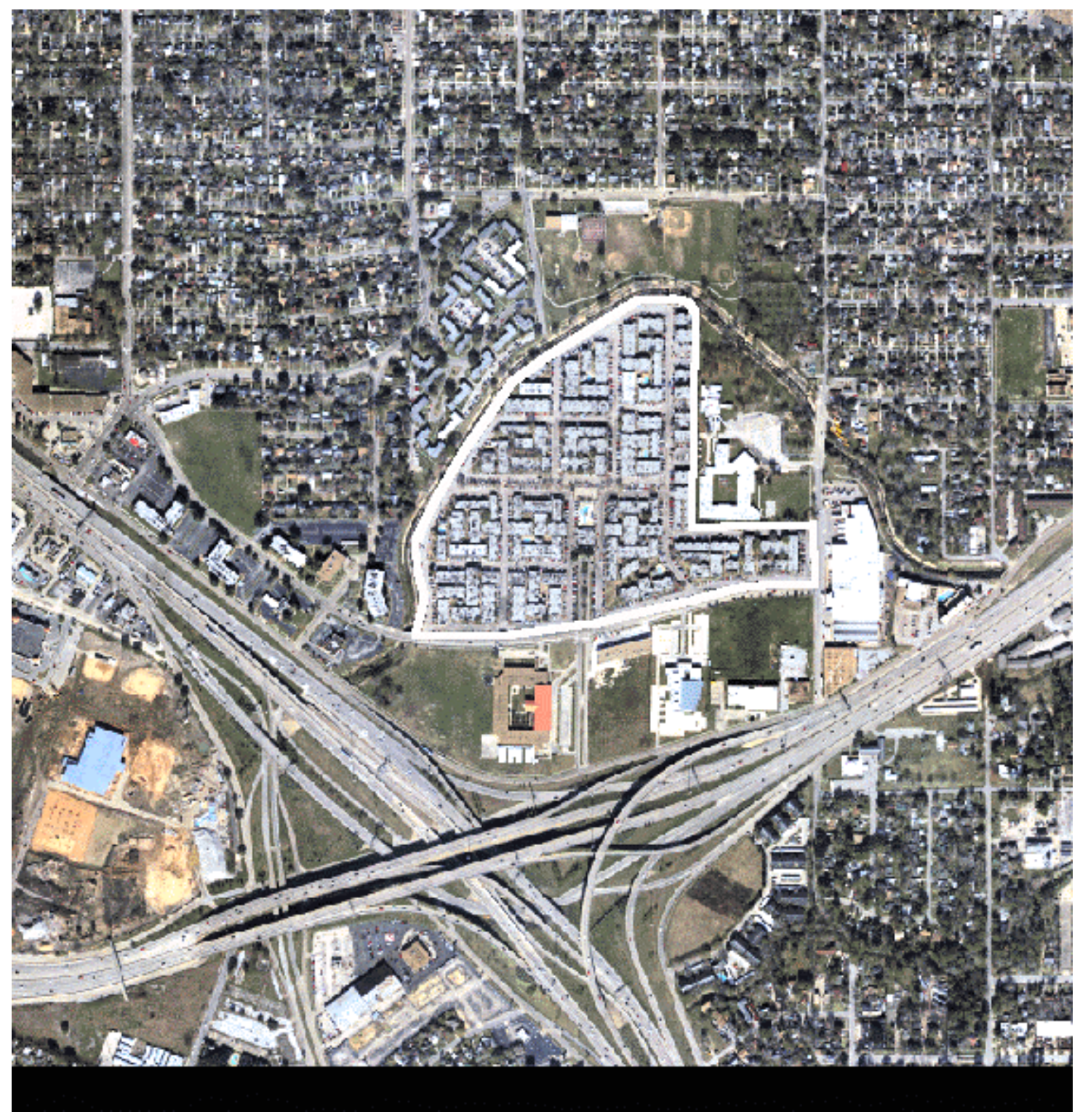

Figure 13. Aerial orthophoto of the Plum Creek area. 


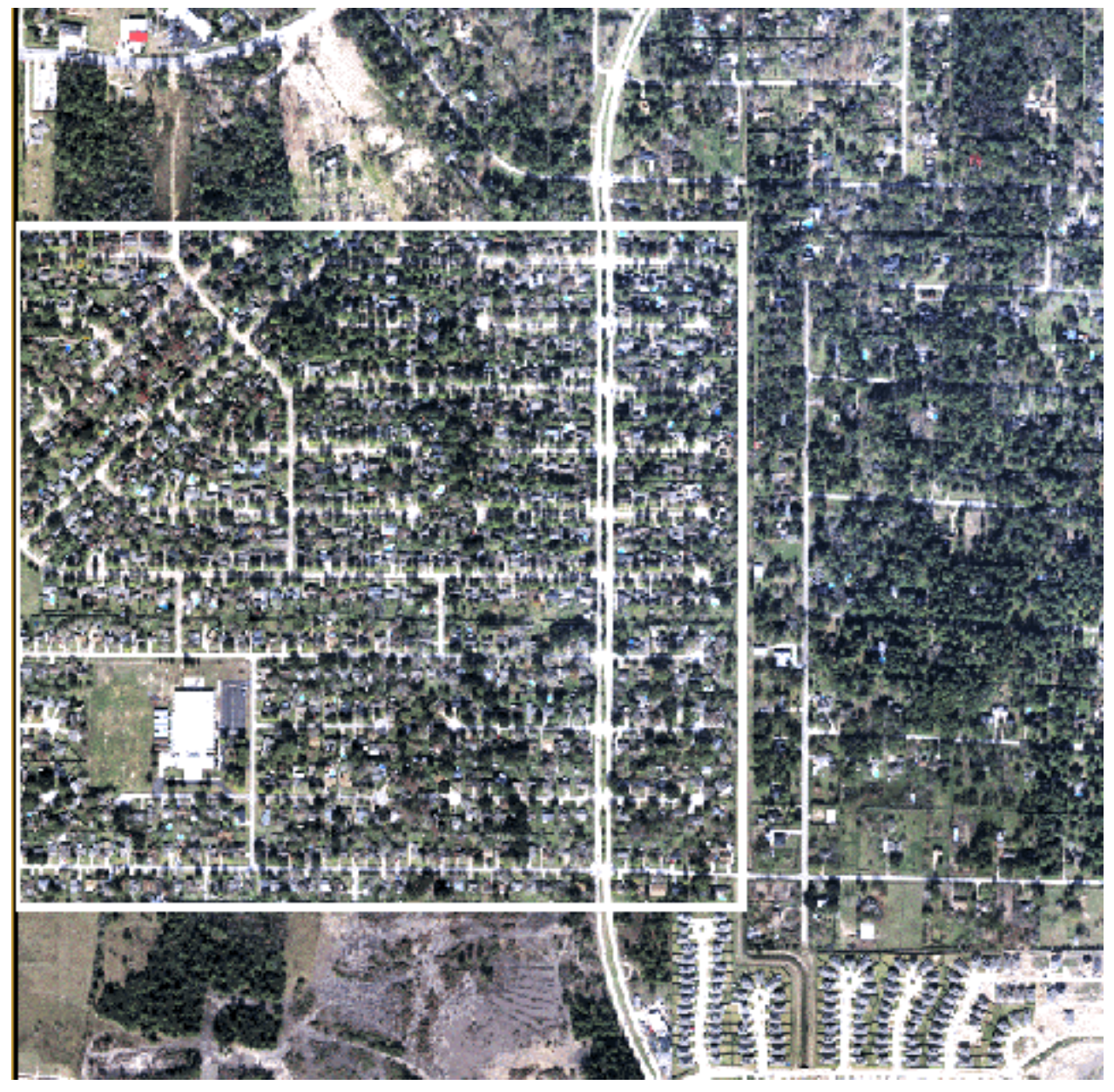

Figure 14. Aerial orthophoto of the Adam School area. 


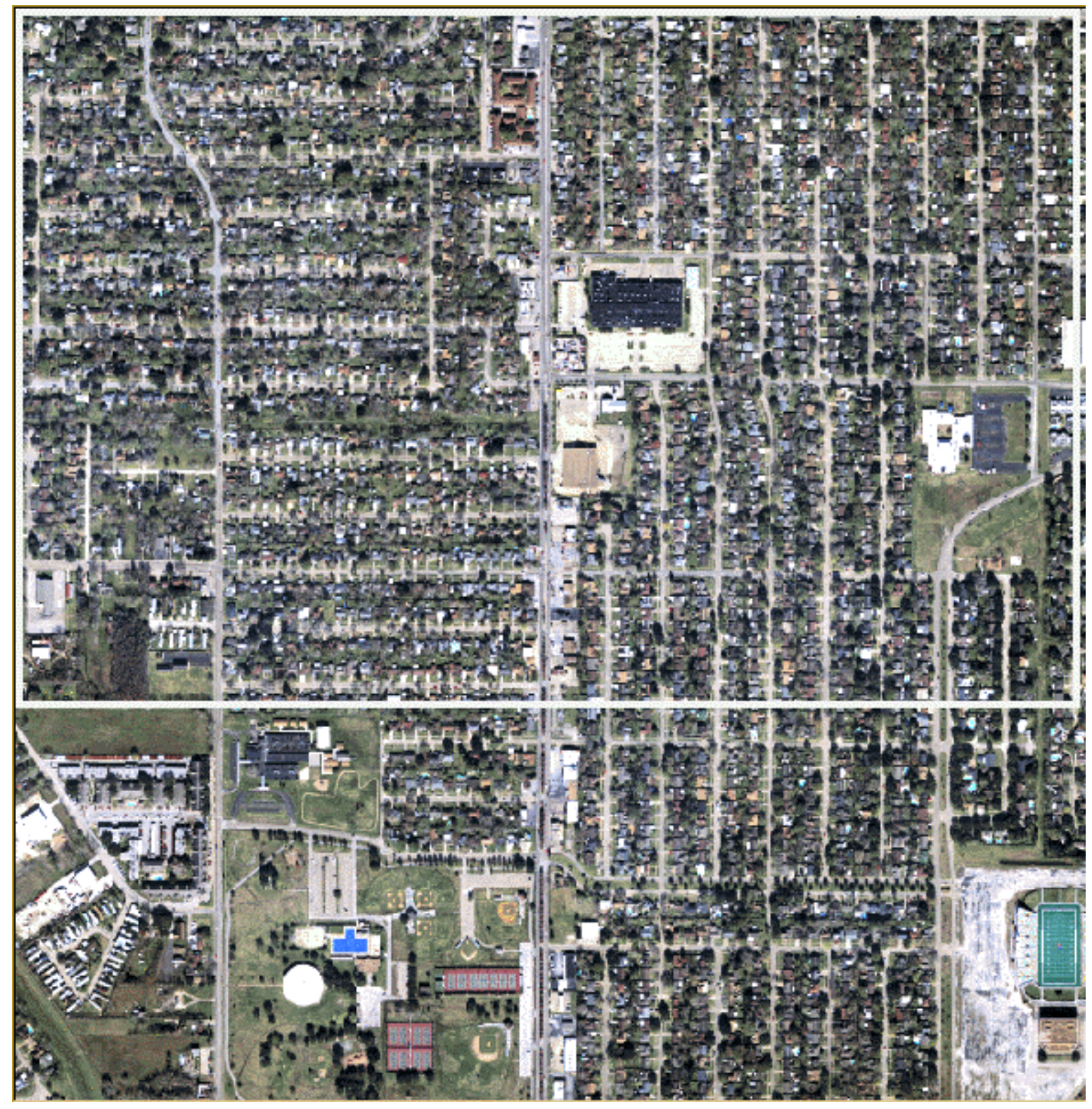

Figure 15. Aerial orthophoto of the Strawberry Mall area. 


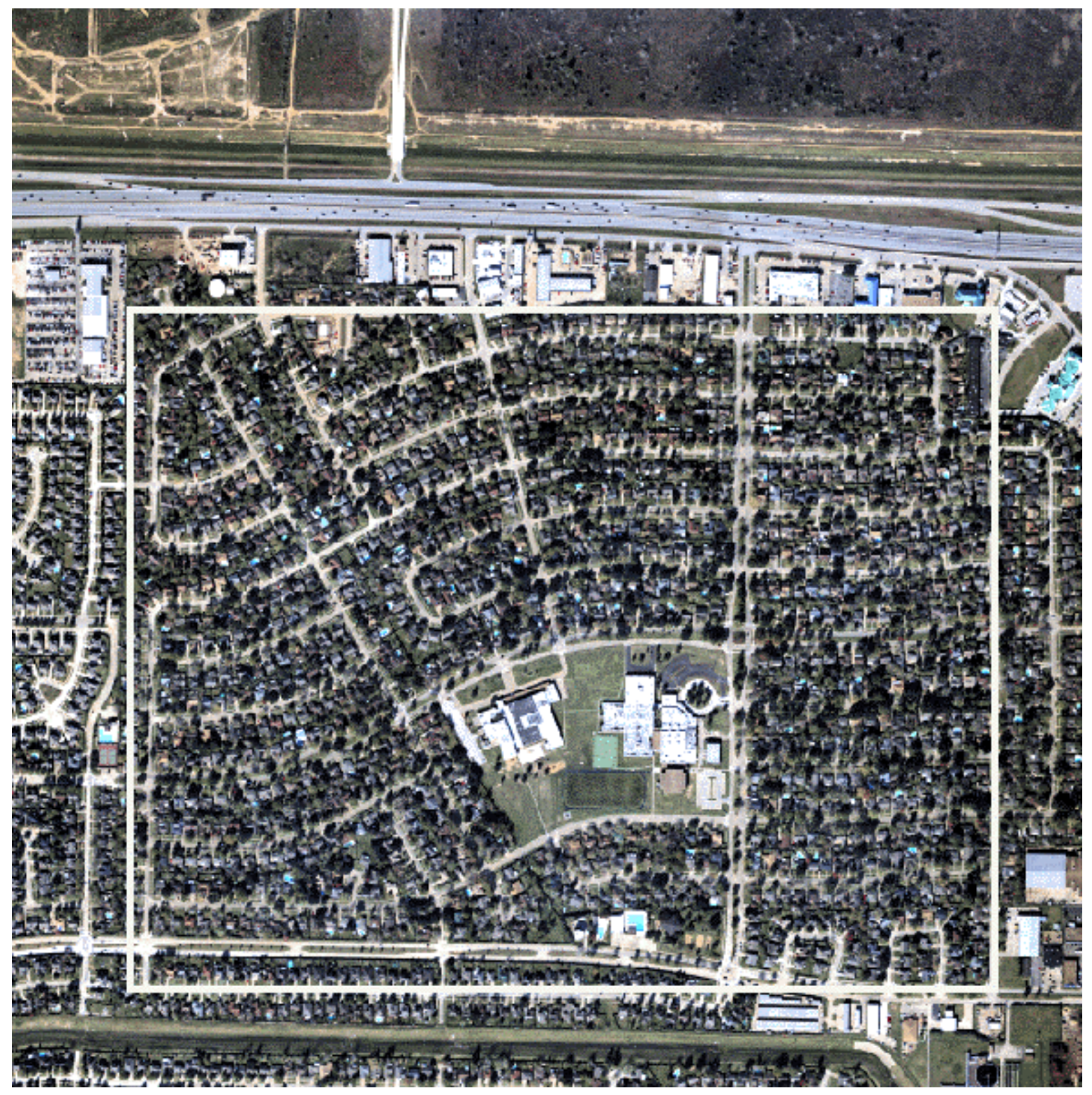

Figure 16. Aerial orthophoto of the Cinco Ranch area. 


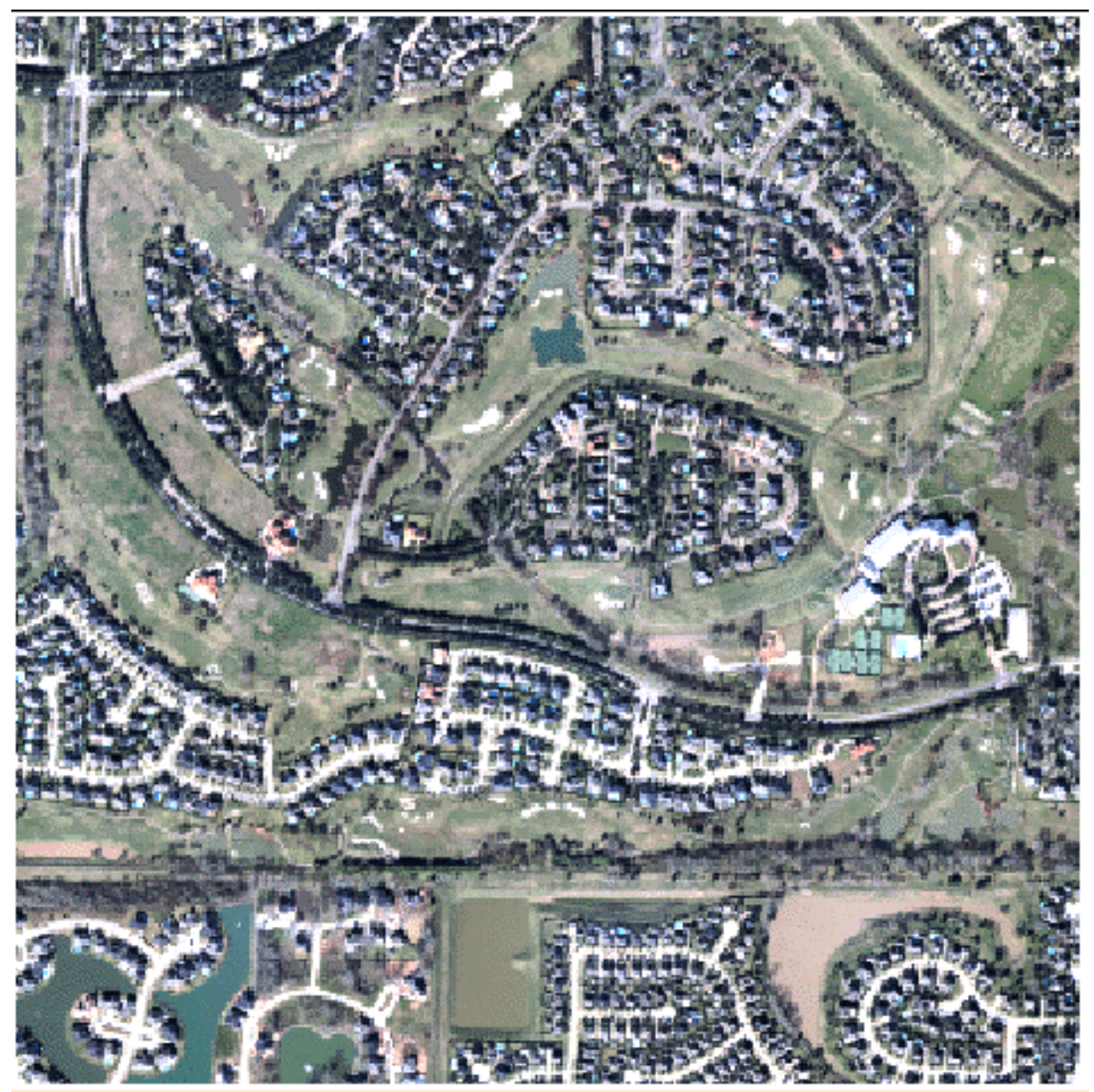

Figure 17. Aerial orthophoto of the Sugarland area. 


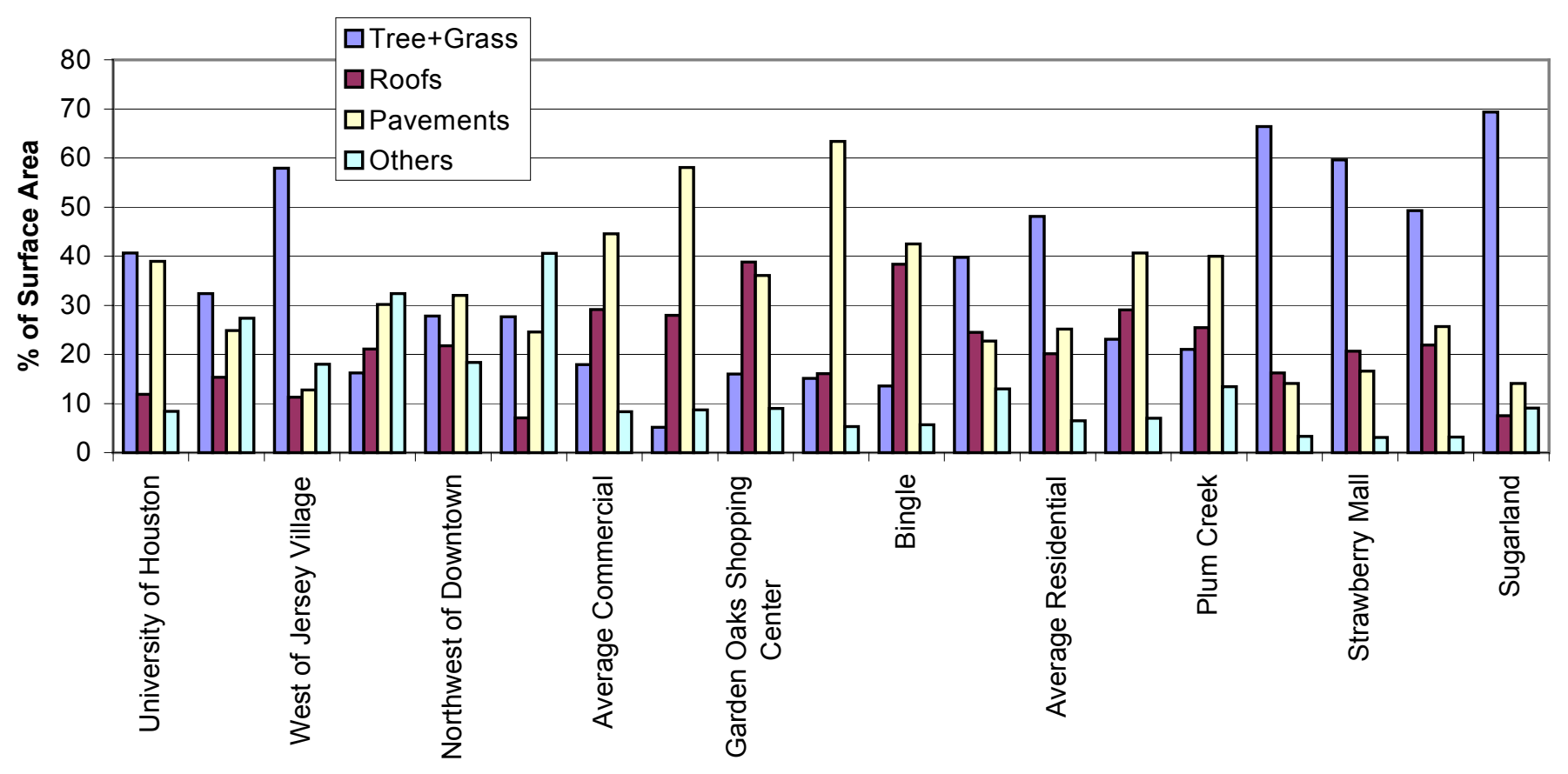

Figure 18. Above-the-canopy fabric of Greater Houston, TX.

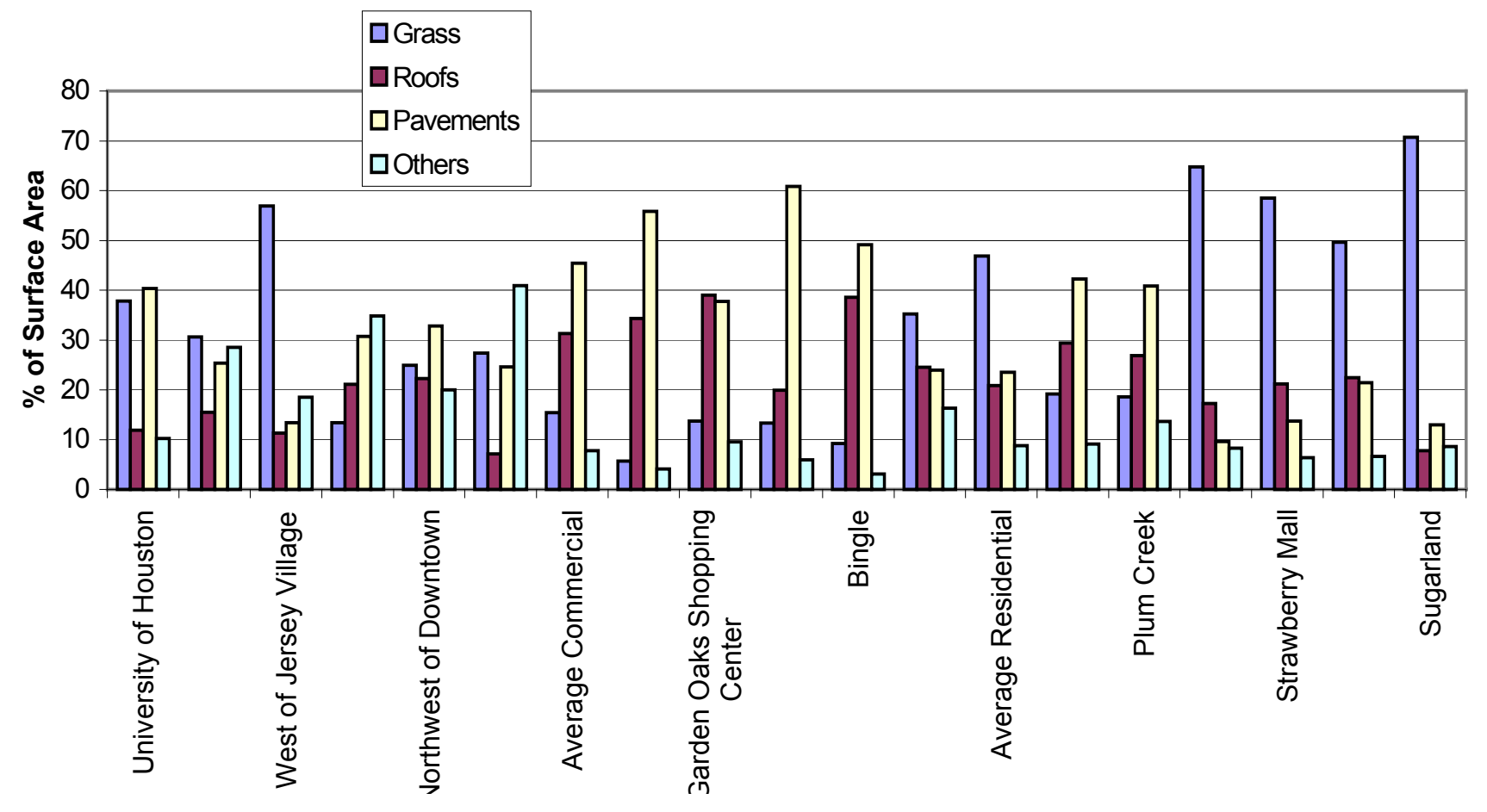

Figure 19. Under-the-canopy fabric of Greater Houston, TX. 


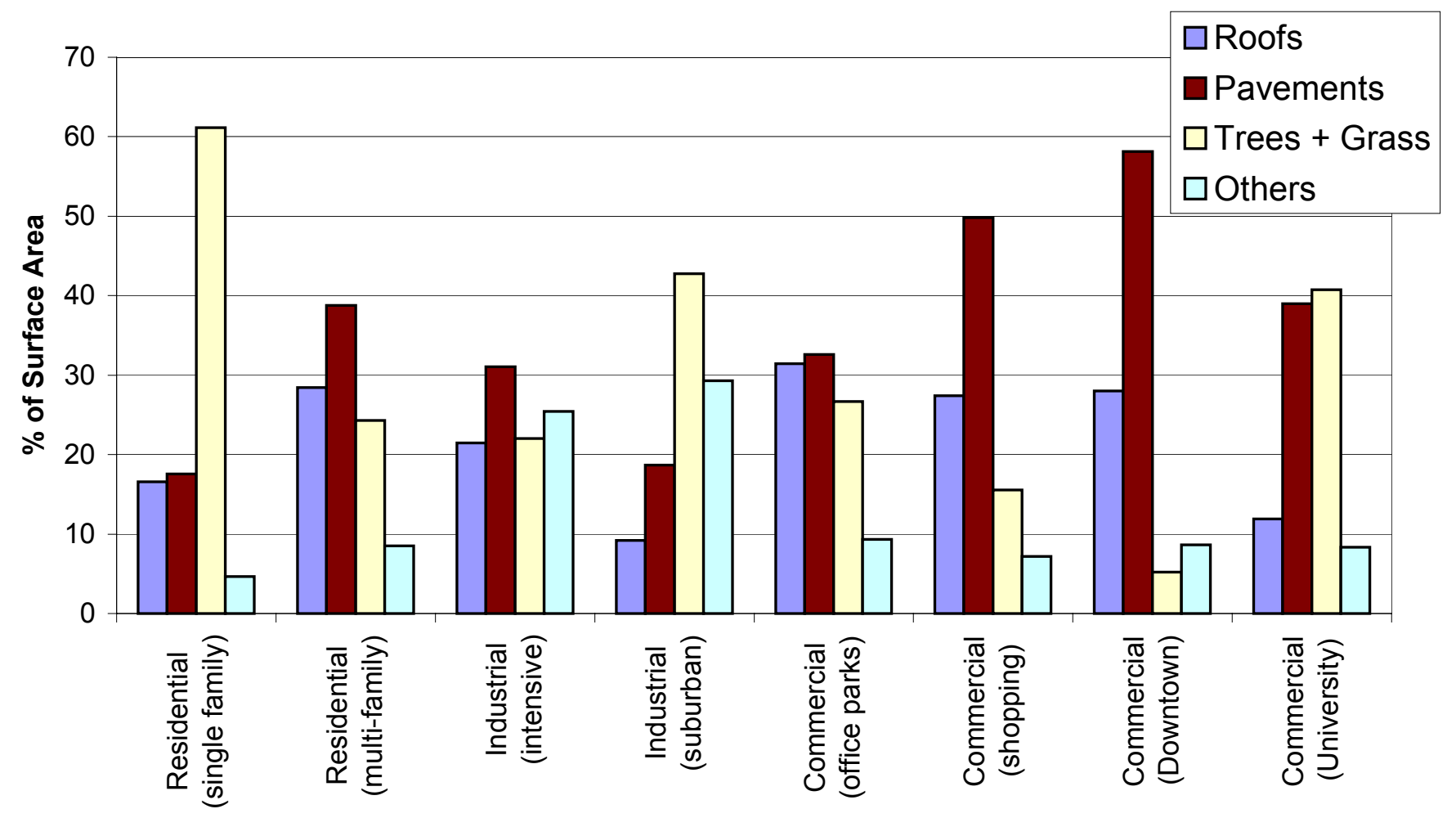

Figure 20. Above-the-canopy fabric of Greater Houston, TX grouped by land-use type.

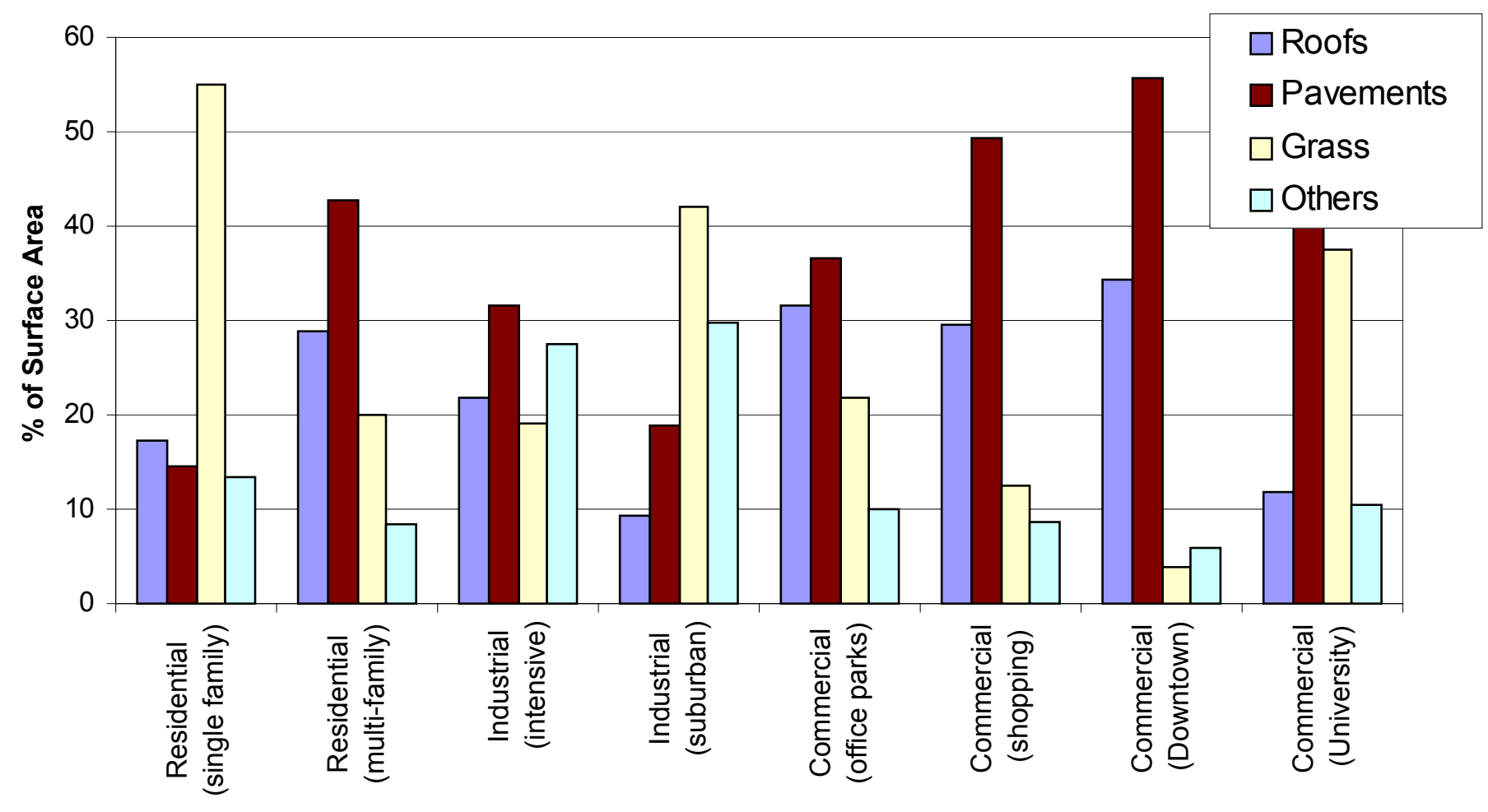

Figure 21. Under-the-canopy fabric of Greater Houston, TX, grouped by land-use type. 


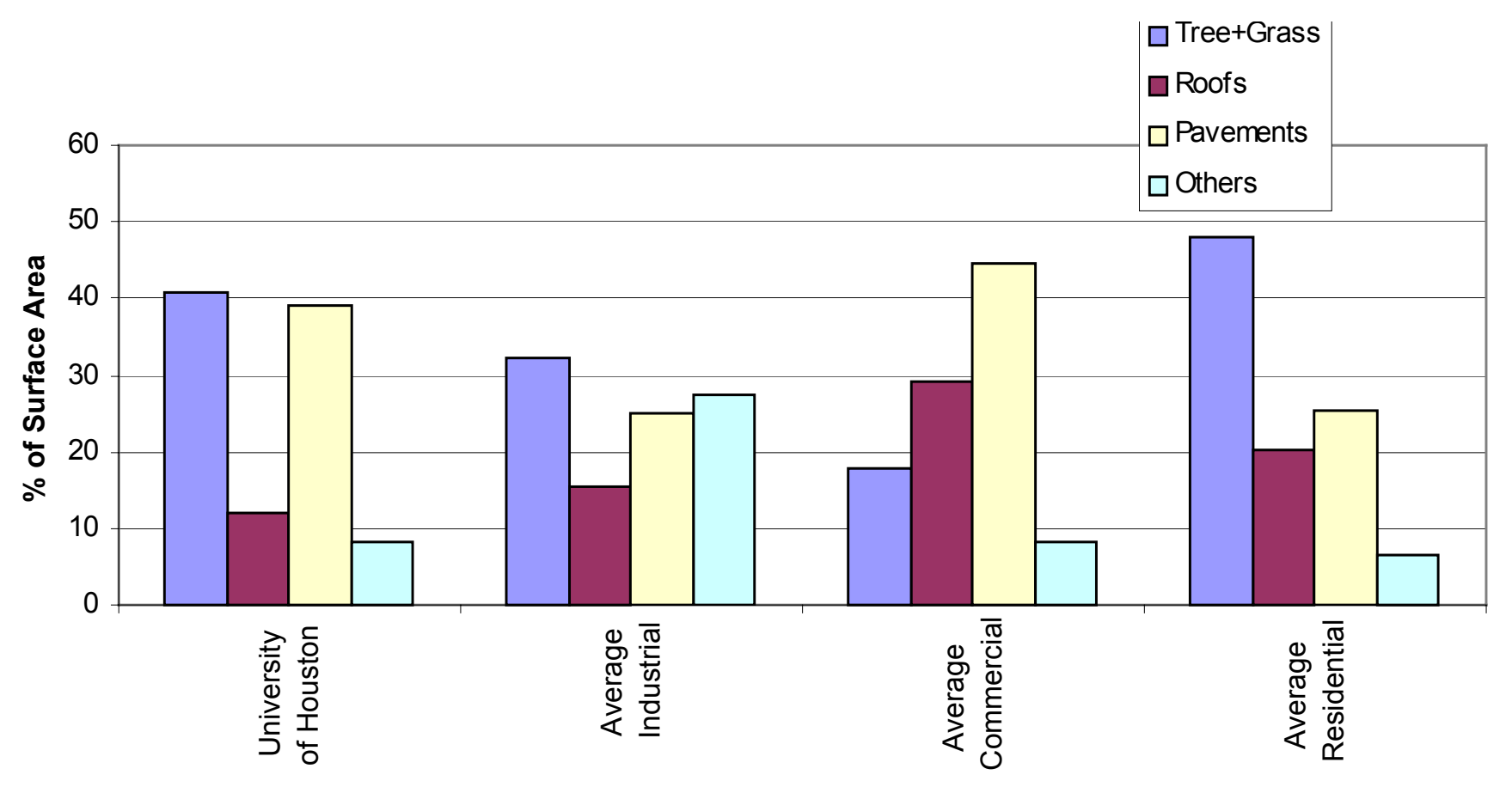

Figure 22. Average characteristics of above-the-canopy fabric of Greater Houston, TX.

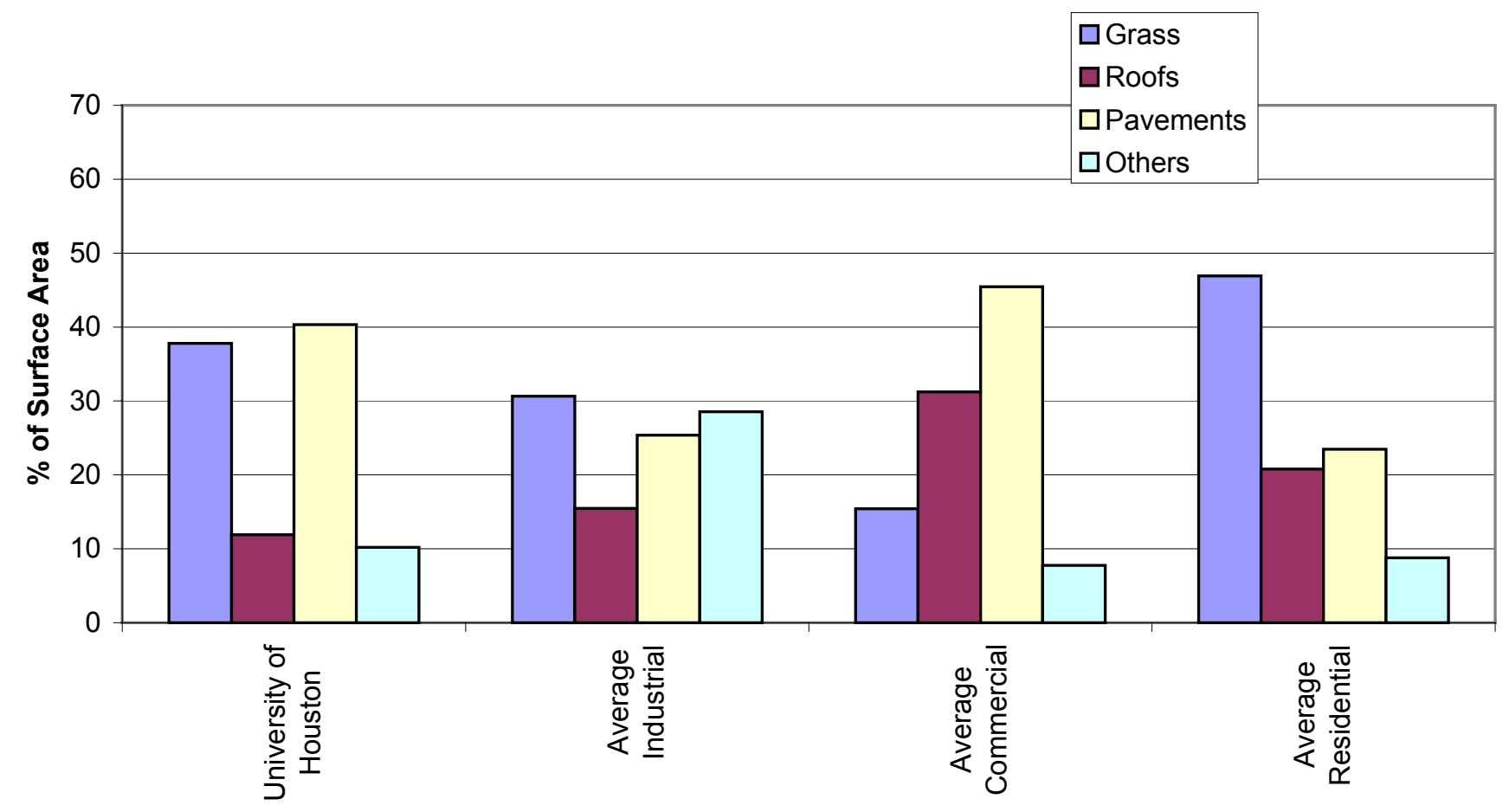

Figure 23. Average characteristics of under-the-canopy fabric of Greater Houston, TX. 


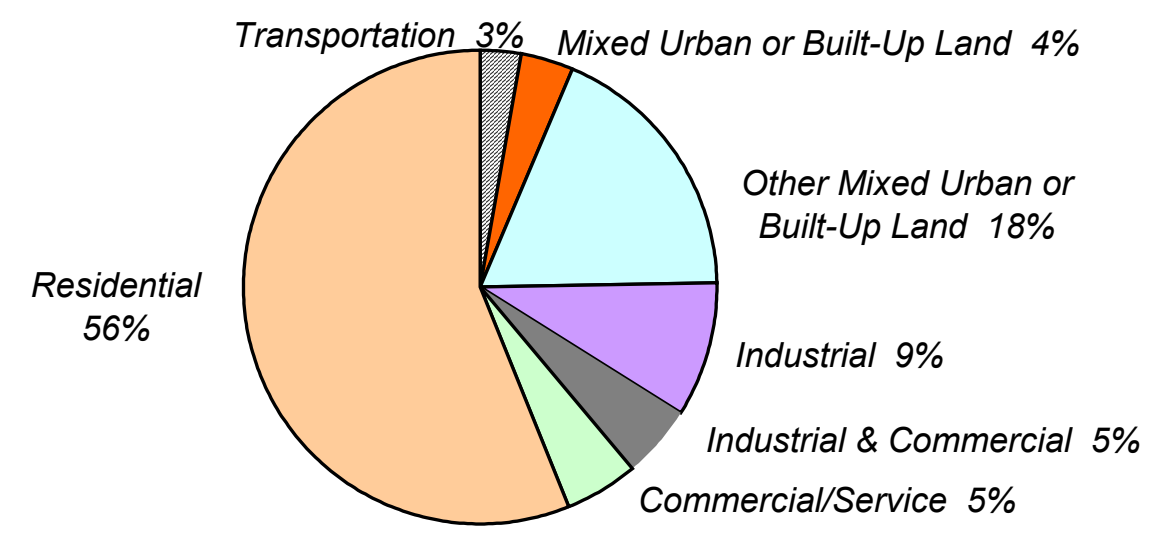

a) Area by USGS LULC Categories

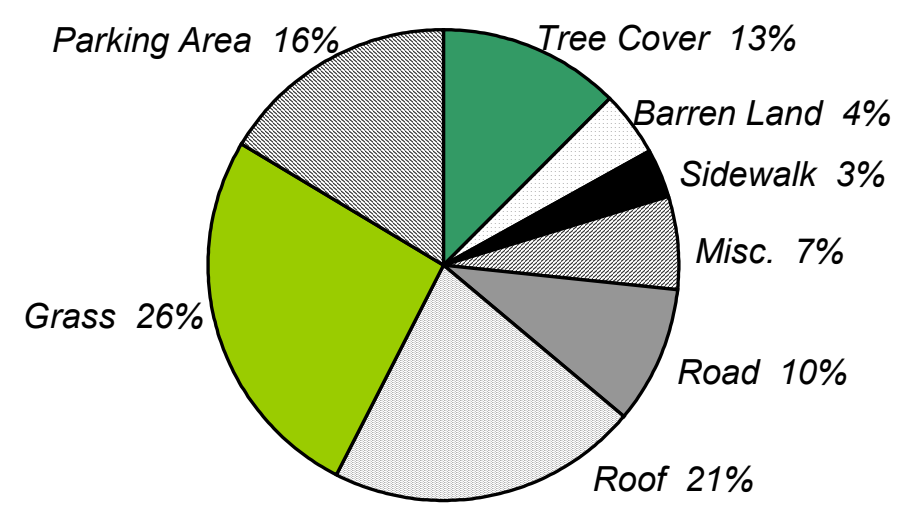

b) Area by Land-Cover Category Above the Canopy

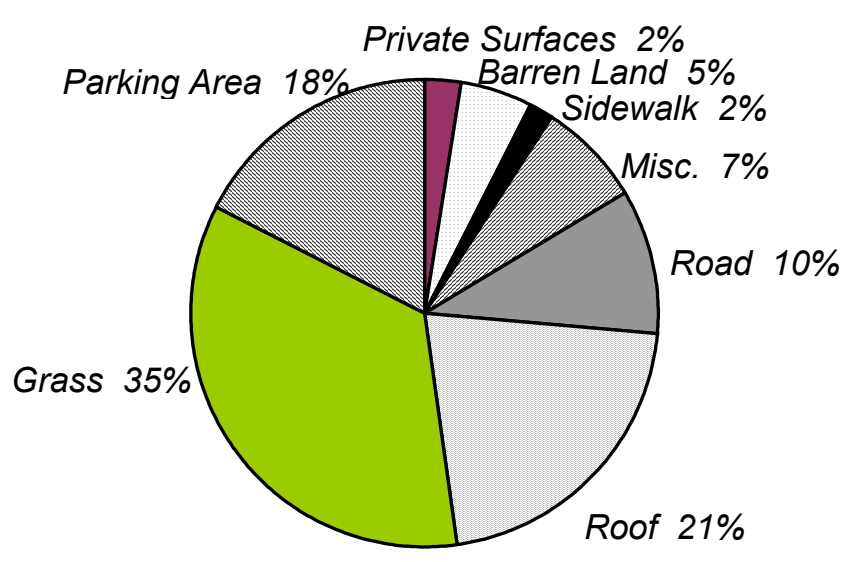

c) Area by Land-Cover Category Under the Canopy

Figure 24. Land use/land cover of the entire developed area of Greater Houston, TX. 